\title{
Manufacture and rehabilitation of guard-rail posts using composites for superior performance
}

\author{
Swetha Anegunta \\ West Virginia University
}

Follow this and additional works at: https://researchrepository.wvu.edu/etd

\section{Recommended Citation}

Anegunta, Swetha, "Manufacture and rehabilitation of guard-rail posts using composites for superior performance" (2000). Graduate Theses, Dissertations, and Problem Reports. 1031.

https://researchrepository.wvu.edu/etd/1031

This Thesis is protected by copyright and/or related rights. It has been brought to you by the The Research Repository @ WVU with permission from the rights-holder(s). You are free to use this Thesis in any way that is permitted by the copyright and related rights legislation that applies to your use. For other uses you must obtain permission from the rights-holder(s) directly, unless additional rights are indicated by a Creative Commons license in the record and/ or on the work itself. This Thesis has been accepted for inclusion in WVU Graduate Theses, Dissertations, and Problem Reports collection by an authorized administrator of The Research Repository @ WVU. For more information, please contact researchrepository@mail.wvu.edu. 


\author{
Swetha Anegunta \\ Thesis submitted to the \\ College of Engineering and Mineral Resources \\ at West Virginia University \\ in partial fulfillment of the requirements
}

for the degree of

Master of Science
in
Chemical Engineering

Rakesh K. Gupta, Ph.D., Chair Ganga Rao Hota, Ph.D.

John W. Zondlo, Ph.D.

Department of Chemical Engineering

Morgantown, West Virginia 2000

Keywords: composite, reinforcement, FRP, aging, durability, guard-rail Copyright 2000 Swetha Anegunta 


\title{
ABSTRACT \\ MANUFACTURE AND REHABILITATION OF GUARD-RAIL POSTS USING COMPOSITES FOR SUPERIOR PERFORMANCE
}

\author{
Swetha Anegunta
}

The objective of this research was to study the effectiveness of an external composite reinforcement in increasing the strength and durability of a conventional CCA treated wood post. Glass fibers (with excellent mechanical properties and low cost) in a polymer matrix were used for wrapping CCA treated wood posts. Six chemically different resins were screened, and a combination of HMR (Hydroxy Methylated Resorcinol) as primer and epoxy as adhesive was found to provide the best possible adhesion of the wrap to CCA treated wood. Wooden posts of $0.5^{\prime \prime}$ OD and wrapped posts of $0.6^{\prime \prime} \mathrm{OD}$, representing a scaled down version of the proposed posts were subjected to a 6-cycle aging procedure that involved application of vacuum and pressure under water. The wrapped posts were also subjected to freeze-thaw cycling in four different liquid media: (1) water (2) $3 \%$ salt water (3) acidic solution of $\mathrm{pH} 3$ (4) alkaline solution of $\mathrm{pH}$ 13. The retention of flexural strength and stiffness of the wrapped posts after chemical aging was measured. Samples of dimensions $50 \mathrm{~mm}$ X $9 \mathrm{~mm}$ X $2 \mathrm{~mm}$ wrapped with $1 \mathrm{~mm}$ thick wrap were also subjected to aging. The retention in strength and stiffness was measured and the service life was estimated.

Results of flexure tests show that the strength of the wrapped post reduces due to aging. Results of DMTA (Dynamic Mechanical Thermal Analysis) show that freeze-thaw cycling and 6-cycle aging increase the Tg (glass transition temperature) and widen the glass transition region. After a service life of about 20 years, the stiffness of a wrapped post is predicted to be about 1.8 times that of an unwrapped wood post of the same age. Heating and freezing in liquid media causes more damage than heating and freezing in the absence of a liquid medium. Among the liquid media, it was found that the alkaline medium damages the epoxy matrix, the epoxy/glass interface and also the wood/HMR/epoxy bond. Acid medium primarily damages the epoxy/glass interface. Water diffuses easily through the epoxy matrix and primarily damages the epoxy/glass interface. Salt water damages the wood/HMR/epoxy bond. The performance in terms of flexural strength, modulus and rigidity was reduced the most by acidic medium, and the least by saltwater medium. There was no delamination at the wood/FRP interface under any of the aging conditions. It was concluded that under unaged conditions, the flexural rigidity of wood is improved by $162 \%$ due to composite wrapping. The technique of composite wrapping also shows a promise of improving the properties of guard-rail posts under actual field conditions. 


\section{ACKNOWLEDGEMENTS}

I'm greatly indebted to my research advisors, Dr. Rakesh Gupta and Dr. GangaRao Hota for their invaluable guidance throughout this research. The advice and insight provided by Dr. Gupta in all matters pertaining to this research have been extremely invaluable. I was fortunate to have him as a teacher in the classroom. Dr. Hota was extremely kind in explaining the important aspects of the research. His guidance and encouragement have made a difference. I would like to express special thanks to both of them for their generous time and kind co-operation.

I'm grateful to Dr. John Zondlo for his valuable comments and suggestions that improved the quality of the report. His suggestions during the initial stages of the research were also valuable. His kindness is very much appreciated.

I'm thankful to Sharon Santos, Sharon Chadderton and Eleanor Nevera for processing my paper work and for their extremely kind and encouraging nature. I greatly appreciate the assistance of Dave Turner, Jim Hall and Dana Humberson in machining a lot of samples and also in operating heavy equipment. The creativity of Jim Hall in building experimental accessories was of great help to me.

I sincerely thank Dr. Hemanth Thippeswamy and Dr. P. V. Vijay for clearing my doubts and for their constant support and encouragement. The support and assistance of Barry Dickson are also appreciated.

My heartfelt thanks to Rajesh Kalluri, Sanjay Palakamshetty, Uday Chamarthy, Bryan King and Krit Laosiriphong for helping me conduct the accelerated aging. I'm also thankful to Shahab Ghasemzadeh and Vimala Shekar for helping me with sample 
preparation and for clearing my doubts. All of their help was very much required to complete things in the required time.

Financial support for this research was provided by the West Virginia Department of Transportation. Their support is very much appreciated.

My sincere regards and appreciation to my husband, Aravind, for supporting me through tough times and for his understanding. The love and blessings of my family were essential for the successful completion of this work. I thank them for being my loving family. 
TITLE PAGE

ABSTRACT

ii

ACKNOWLEDGEMENTS

iii

TABLE OF CONTENTS

V

LIST OF TABLES

xi

LIST OF FIGURES

xiv

\section{Chapter I}

INTRODUCTION

1.1 Introduction

1.2 Proposed Work

2

1.3 Scope of Research

\section{Chapter II}

MATERIAL SELECTION

2.1 Fibers

2.1.1 Glass Fibers

2.1.2 Carbon Fibers

2.1.3 Aramid Fibers 
2.2.6 Urethanes

\section{Chapter III}

\section{ADHESION FUNDAMENTALS}

3.1 Adhesion 


\section{Chapter IV}

DURABILITY OF BONDED ASSEMBLIES

4.1 Introduction 36

4.2 Accelerated Aging 38

4.3 Chemical Aging 40

4.4 Summary of Test Methods Used 41

\section{Chapter V}

\section{ADHESIVE SCREENING}

5.1 Overview 42

5.2 Materials Used 42

5.2.1 Wood 42

5.2.2 Glass Fibers 43

5.2.3 Adhesives and Primers 43

5.3 Sample Preparation 44

5.4 Description of Test Procedure 46

5.5 Sample Conditioning 48

5.6 Summary of Test Results 49

5.6.1 Strength of Adhesives at Different Pressures 49

5.6.2 Strength of Adhesives at Optimum Curing Pressure 52

5.6.3 Strength of Adhesives in Combination with Different Primers 53

5.6.4 Accelerated Aged Strength of Different Combinations 56

5.6.5 Strength of Sandwich Samples 62 
5.6.7 Performance of Chosen Combination under Accelerated Aging $\quad 66$

5.6.8 Performance of Chosen Combination under Chemical Aging $\quad 68$

5.7 Summary

\section{Chapter VI}

\section{STRENGTH AND STIFFNESS EVALUATION OF WRAPPED POSTS}

$\begin{array}{ll}6.1 \text { Overview } & 73\end{array}$

$\begin{array}{ll}\text { 6.2 Materials Used } & 73\end{array}$

$\begin{array}{ll}\text { 6.3 Sample Preparation } & 73\end{array}$

6.4 Description of Test Procedure $\quad 75$

$\begin{array}{ll}\text { 6.5 Sample Conditioning } & 77\end{array}$

$\begin{array}{ll}\text { 6.6 Summary of Test Results } & 78\end{array}$

$\begin{array}{ll}\text { 6.6.1 Accelerated Aging } & 78\end{array}$

6.6.2 Prediction of Flexural Rigidity using Rule of Mixtures 84

$\begin{array}{ll}\text { 6.6.2 Chemical Aging } & 89\end{array}$

6.6.3 Effect of Primer 95

$\begin{array}{ll}\text { 6.7 Cost Analysis } & 96\end{array}$

$\begin{array}{lr}6.8 \text { Summary } & 98\end{array}$ 


\section{Chapter VII}

DYNAMIC MECHANICAL THERMAL ANALYSIS OF WRAPPED COMPOSITES

$\begin{array}{ll}7.1 \text { Overview } & 99\end{array}$

$\begin{array}{ll}\text { 7.2 Materials Used } & 99\end{array}$

$\begin{array}{ll}\text { 7.3 Sample Preparation } & 100\end{array}$

$\begin{array}{ll}\text { 7.4 Description of Test Procedure } & 100\end{array}$

$\begin{array}{ll}\text { 7.5 Sample Conditioning } & 102\end{array}$

7.6 Summary of Test Results 103

7.6.1 Accelerated Aging of Wood and Wood/HMR/Epoxy/Glass

$\begin{array}{ll}\text { Hybrid Specimens } & 103\end{array}$

7.6.2 Chemical Aging of Wood/HMR/Epoxy/Glass Hybrid Specimens 106

$\begin{array}{ll}\text { 7.6.3 Time-Temperature Superposition } & 111\end{array}$

$\begin{array}{ll}\text { 7.7 Summary } & 114\end{array}$

\section{Chapter VIII}

CONCLUSIONS AND RECOMMENDATIONS

8.1 Conclusions

8.1.1 Testing of Wood/Adhesive and Wood/FRP Interface by Shear Tests117

8.1.2 Testing of Wood/HMR/Epoxy/Glass Hybrids by Flexure Tests 118

8.1.3 Testing of Wood/HMR/Epoxy/Glass Hybrids by DMTA 118

$\begin{array}{ll}\text { 8.1.4 Effect of Aging Media } & 118\end{array}$

$\begin{array}{ll}\text { 8.2 Recommendations } & 119\end{array}$ 
$\begin{array}{ll}\text { APPENDIX A } & 124\end{array}$

A.1 Calculation of Fiber Volume Fraction of Flexure Test Samples 125

A.2 Calculation of Fiber Volume Fraction of DMTA Samples 126

$\begin{array}{ll}\text { APPENDIX B } & 127\end{array}$

B.1 Sample Calculation of Shear Strength from Shear Test Data 128

B.2 Sample Calculations of Mechanical Properties from Flexure Test Data $\quad 130$

B.3 Sample Calculations for the Generation of a Master Curve from Mechanical

$\begin{array}{ll}\text { Spectroscopy Data } & 142\end{array}$

$\begin{array}{ll}\text { APPENDIX C } & 150\end{array}$

Dynamic Spectra of Wood and Wood/HMR/Epoxy/Glass Hybrid Samples 151 


\section{LIST OF TABLES}

Table

Page

2.1 Properties of commercial reinforcing fibers 8

2.2 Properties of thermosetting resins 21

3.1 Mechanical properties of thermosetting adhesives 34

5.1 Resins used in adhesive screening $\quad 43$

5.2 Unaged shear strength of epoxy adhesive at varying pressure $\quad 50$

5.3 Unaged shear strength of phenolic adhesive at varying pressure 50

5.4 Unaged shear strength of polyester adhesive at varying pressure 51

5.5 Unaged shear strength of RF adhesive at varying pressure 51

5.6 Optimum curing pressure of adhesives 51

5.7 Unaged shear strength of unprimed resins 52

5.8 Unaged shear strength of adhesives using HMR primer 54

5.9 Unaged shear strength of adhesives using RF primer 55

5.10 Unaged shear strength of adhesives using G-1260 primer 55

5.11 Unaged and aged shear strength of different primer/resin combinations 57

5.12 Strength of different primer/resin combinations exposed to freeze-thaw cycling in water and $3 \%$ saltwater

5.13 Wood failure of different primer/resin combinations exposed to freeze-thaw cycling in water and $3 \%$ saltwater

5.14 Shear strength of sandwiches prepared with chosen combination(s)

5.15 Performance of wood/HMR/epoxy/glass/epoxy/HMR/wood sandwich 
samples exposed to 6-cycle aging

5.16 Shear strength of wood/HMR/epoxy/glass/epoxy/HMR/wood sandwiches exposed to different conditions

5.17 Shear strength of wood/HMR/epoxy/HMR/wood samples exposed to different conditions

6.1 Comparison of strength and modulus of wood, wood/epoxy/glass hybrid and wood/HMR/epoxy/glass hybrid specimens exposed to 6-cycle accelerated aging

6.2 Comparison of flexural rigidity of unaged and aged wood/epoxy/glass hybrid obtained using rule of mixtures and from experiments at different values of $\mathrm{E}_{\text {wood }}$

6.3 Comparison of flexural rigidity of unaged and aged wood/HMR/epoxy/glass hybrid obtained using rule of mixtures and from experiments at different values of $\mathrm{E}_{\mathrm{wood}}$

6.4 Flexural strength of wood/HMR/epoxy/glass hybrid exposed to freeze-thaw cycling in different solutions

6.5 Flexural modulus of wood/HMR/epoxy/glass hybrid exposed to freeze-thaw cycling in different solutions

6.6 Flexural rigidity of wood/HMR/epoxy/glass hybrid exposed to freeze-thaw cycling in different solutions

7.1 Variation of $\mathrm{T}_{\mathrm{g}}$ and storage modulus of wood/HMR/epoxy/glass hybrid under different aging conditions 
7.2 Storage modulus $\left(\mathrm{G}^{\prime}\right)$ of wood and wood/HMR/epoxy/glass hybrid at a service life of 20 years 


\section{LIST OF FIGURES}

Figure $\quad$ Page

2.1 Raw materials for the preparation of epoxy resin (a) a molecule of DGEBA epoxy resin; (b) a molecule of DETA curing agent

2.2 Schematic representation of a cross-linked epoxy resin

(a) reaction of epoxide group with DETA molecule; (b) formation of

(b) cross-links; (c) three-dimensional structure of solid epoxy resin

2.3 Raw materials for the preparation of a polyester resin (a) unsaturated polyester molecule; (b) styrene molecule; (c) t-butyl perbenzoate molecule (tBPB)

2.4 Schematic representation of a cross-linked polyester resin

2.5 Addition of formaldehyde to phenol

2.6 Formation of novolac resin

2.7 Formation of resole resin

2.8 Formation of novolac from resorcinol and formaldehyde

2.9 Chemistry of a vinyl ester resin

2.10 Schematic representation of a cross-linked vinyl ester resin

2.11 Partial structure of a lignin molecule

2.12 Structure of a cellulose molecule

3.1 An idealized chain link concept of adhesive bond anatomy

3.2 A diagrammatic sketch of flow, transfer and penetration functions in wood adhesive bond development 
3.3 Test specimen for different types of tests 32

$3.4 \quad$ Test specimen for flexural test (three point bending) 32

4.1 Temperature and humidity variations in cyclic freeze-thaw conditioning 41

5.1 (a) rectangular billet with adhesive film in between (b) shear coupon 46

5.2 Measurement of shear strength by compressive shear loading $\quad 48$

5.3 Covalent and hydrogen bonding of HMR with epoxy resin and cellulosics

of wood $\quad 65$

6.1 Glass fiber wrapping of a wood post using banding machine $\quad 74$

6.2 Schematic of the cross-section of a wrapped sample 75

6.3 Three-point flexural loading of a wrapped specimen 77

6.4 Comparison of elastic modulus of wood, hybrid specimen after each cycle

$\begin{array}{lr}\text { of 6-cycle aging } & 80\end{array}$

6.5 Comparison of flexural strength of wood, hybrid specimen after each cycle

$\begin{array}{lr}\text { of 6-cycle aging } & 80\end{array}$

6.6 Comparison of flexural rigidity of wood, hybrid specimen after each cycle

of 6-cycle aging

6.7 Variation of flexural rigidity of wood/HMR/epoxy/glass hybrid exposed to freeze-thaw cycling in different media for 25 days

6.8 Variation of flexural rigidity of wood/HMR/epoxy/glass hybrid with time in different media

6.9 Comparison of flexural rigidity of wood/epoxy/glass hybrid and wood/HMR/epoxy/glass hybrid exposed to different conditions 
$\begin{array}{lll}7.1 & \text { Loaded sample in the DMTA set up } & 101\end{array}$

7.2 Dynamic properties of wood under unaged and 6-cycle aged conditions 103

7.3 Dynamic properties of wood/HMR/epoxy/glass hybrid under unaged and 6-cycle aged conditions

7.4 Dynamic properties of wood/HMR/epoxy/glass hybrid under unaged and acidic conditions

7.5 Dynamic properties of wood/HMR/epoxy/glass hybrid under unaged and alkaline conditions

7.6 Dynamic properties of wood/HMR/epoxy/glass hybrid under unaged and neutral conditions

7.7 Dynamic properties of wood/HMR/epoxy/glass hybrid under unaged and salt water conditions

7.8 Comparison of master curves of wood/HMR/epoxy/glass hybrid aged in different media

7.9 Comparison of master curves of CCA treated wood aged in different media

B1 Load versus deflection data of wood/HMR/epoxy/glass hybrid with zeroed intercept

B2 Master curve of wood/HMR/epoxy/glass hybrid subjected to freeze-thaw cycling in water for 25 days

C1 Dynamic properties of wood under unaged and 6-cycle aged conditions

C2 Dynamic properties of wood/HMR/epoxy/glass hybrid under unaged and 6-cycle aged conditions 
C3 Dynamic properties of wood/HMR/epoxy/glass hybrid under unaged and acidic conditions

C4 Dynamic properties of wood/HMR/epoxy/glass hybrid under unaged and alkaline conditions

C5 Dynamic properties of wood/HMR/epoxy/glass hybrid under unaged and neutral conditions

C6 Dynamic properties of wood/HMR/epoxy/glass hybrid under unaged and salt water conditions 


\section{Chapter I \\ INTRODUCTION}

\subsection{Introduction}

Guardrail posts are particularly important for highway traffic safety and are constructed of steel or wood. Steel posts are more expensive than wood posts and less forgiving in terms of damping. However, wooden posts have a larger cross-sectional area and require larger and more expensive equipment for driving them into the ground. Approximately 50,000 wood guardrail posts are sold annually to the West Virginia Department of Transportation. In comparison, approximately 200,000 steel posts are used in the same time period because of ease of field installation. Also the wooden posts that are installed are subject to deterioration by environmental attack. The higher cost of steel posts, the greater difficulty in installing wood posts plus the potential for degradation, motivate the development of a more practical and economic alternative.

Fiber reinforced composite materials technology promises superior structural performance of wood posts that are wrapped with a composite fabric. Wrapping of wooden posts with glass fabric in a polymeric resin matrix can improve the mechanical properties of a conventional wood post. This technique can be used to manufacture new posts and can be extended to rehabilitate old posts as well. Enhanced service life lowers consumption of wood and reduces the use of expensive steel. 


\subsection{Proposed Work}

Steel posts have good mechanical properties and are easy to drive into the soil. However they are expensive. Wood is highly forgiving with excellent damping capability and is easy to find in rural areas. Wood posts also have reasonable mechanical properties and low cost but are subject to environmental decay. Treatment of wood with a variety of materials is performed but treated wood can damage the soil and plant life. It can also result in end checking and splitting of wood.

The objective of the proposed work was to develop GFW (glass fabric wrapped)-wood posts using the technique of composite wrapping. In this method, a composite consisting of glass fibers embedded in a polymeric matrix is externally wrapped around a wood post. The polymeric matrix serves as an adhesive between the fibers and the wood. It protects wood from environmental attack and also forms a moisture-resistant barrier around the post that reduces decay. Expected superior mechanical properties of a wrapped post compared to an unwrapped wood post can make it possible to achieve better structural performance with a wood post, smaller in diameter than the currently used wood posts. Such a smaller diameter post wrapped with composite requires lesser driving force than a larger diameter post. The smaller wood post is also less expensive than a regular-sized wood post being used in highway applications.

The proposed GFW wood posts are being developed as a cost-effective alternative to steel posts. Wrapping of posts could also prevent direct exposure of soil to preservative treated wood. These wrapped posts are expected to render mechanical performance that is at least equal to steel posts and preservative treated posts. To achieve this objective, appropriate experiments have been suggested (in section 1.3) on samples made using CCA treated wood, E-glass fibers and a polymeric adhesive system. Details of the choice of materials and types of samples 
prepared are listed in later chapters (Chapters II through VII).

\subsection{Scope of the Research}

To achieve the objective of developing a GFW-wood post, a research program that has both fundamental and applied aspects was proposed. The scope of this research was divided into the following tasks:

\section{$\checkmark$ Adhesive screening}

Six different resins were tested for adhesion with CCA treated southern pine wood. Priming of wood surface before adhesion was also done. The primer/resin combination that adheres the best to wood was determined.

\section{- Laboratory manufacturing of test samples (coupons)}

Shear coupons of wood with adhesive, primer/adhesive were prepared. Shear coupons of wood with sandwiched glass fabric were also prepared. Wood samples of circular and rectangular cross-section were wrapped with glass fibers wetted in the chosen adhesive.

\section{- Testing and evaluation of the performance of shear coupons and wrapped specimens}

All shear coupons were tested for shear strength using an Instron machine. Wrapped rectangular specimens were tested for dynamic behavior using a Rheometrics Mechanical Spectrometer, model RMS 800. Wrapped dowels were tested for stiffness and flexural modulus using the Instron machine.

\section{- Monitoring of stiffness/strength degradation of wrapped posts as a function of time}

Shear coupons and wrapped specimens were exposed to moisture and chemical solutions. Variation in shear strength, flexural properties and dynamic behavior of samples was measured after exposure for different lengths of time. 
- Understanding the possible reaction mechanism behind the adhesive bonding between the wrap and wood, and the reasons for changes occurring with time

Effect of factors such as moisture, length of exposure time, curing pressure, etc. on the quality of the adhesive bond was studied. The experimental results and theoretical predictions were compared and conclusions were drawn.

Each of these tasks, their experimental procedure and the explanation of results are presented in later chapters. 


\section{Chapter II}

\section{MATERIAL SELECTION}

The mechanical properties and behavior of a fiber-reinforced composite are influenced by the choice of its components. Typically a fiber-reinforced composite material consists of fibers embedded in a continuous matrix. In hybrid materials, one combines FRPs with structural materials like steel, concrete and wood. In the current investigation, the principal materials of interest are fibers, resin and wood. Different types of these raw materials were examined, and the details of their properties are presented in this section.

\subsection{Fibers}

Fibers are the principal constituent in a fiber-reinforced composite material. They bear the major part of the load acting on a composite structure. The properties of a composite laminate such as compressive strength and modulus, tensile strength and modulus, flexural strength and modulus, fatigue strength, electrical and thermal conductivities and cost are influenced by the nature, amount and orientation of the fibers. The most commonly used fibers in composites are glass, carbon and aramid fibers.

\subsubsection{Glass Fibers}

Glass fibers are the most common of all reinforcing fibers for polymer matrix composites. They have high tensile strength, chemical resistance and insulating properties and are the least expensive class of reinforcing fibers. Their disadvantages are low tensile 
modulus, relatively high specific gravity, low fatigue resistance, sensitivity to abrasion with handling and high hardness. The two commonly used types of glass fibers in FRP industry are E-glass (electric grade) and S-glass (high strength). E-glass has Silicon, Aluminum, Boron, Calcium, Magnesium and Sodium oxides present in it. S-glass has only Silicon, Aluminum and Magnesium oxides present in it. E-glass has the lowest cost of all commercially available reinforcing fibers and so is most widely used in the FRP industry. S-glass originally developed for aircraft components and missile casings, has the highest tensile strength among all the fibers in use.

The internal structure of glass fibers is a three dimensional network of silicon, oxygen and other atoms like boron and aluminum arranged in a random fashion. This gives glass fibers an amorphous and isotropic nature.

\subsubsection{Carbon (graphite) Fibers}

Carbon fibers have an exceptionally high tensile strength to weight ratio as well as tensile modulus to weight ratio, very low linear thermal expansion and high fatigue strength. They are commercially available with a variety of tensile moduli ranging from 30 Mpsi to $150 \mathrm{Mpsi}$. In general, the low modulus fibers have lower specific gravities, lower cost, and higher tensile and compressive strengths than the high modulus fibers. The disadvantages of carbon fibers are low impact resistance and high electrical conductivity and high cost. They are used mostly in the aerospace industry where weight savings is considered more important than cost.

Carbon fibers contain a blend of amorphous carbon and graphitic carbon. The arrangement of carbon atoms in the planes, the forces between the planes and the bonds 
between the atoms in a plane, all result in highly anisotropic physical and mechanical properties of the fiber.

\subsubsection{Kevlar 49 (Aramid) Fibers}

Kevlar 49 fibers are highly crystalline aramid or aromatic polyamide fibers that have the lowest specific gravity and the highest tensile strength-to-weight ratio among the current reinforcing fibers. They have low linear thermal expansion, which is utilized in designing low thermal expansion composite printed circuit boards. The major disadvantages of aramid fiber-reinforced composites are their low compressive strengths and difficulty in cutting or machining. They are used in marine and aerospace applications where light weight, high tensile strength and resistance to impact are important.

The repeat unit in Kevlar fiber molecules contains an amide $(-\mathrm{N}-$ ) group and an aromatic ring. The repeat unit provides a higher chain stiffness, or consequently higher modulus and also better chemical and thermal stability over other commercial organic fibers, such as nylons.

Typical mechanical properties of various fibers are presented in Table 2.1. 
Table 2.1: Properties of commercial reinforcing fibers [1]

\begin{tabular}{lcccc}
\hline Property & E-glass & S-glass & $\begin{array}{c}\text { Aramid } \\
\text { (Kevlar 49) }\end{array}$ & $\begin{array}{c}\text { Graphite } \\
\text { (PAN) }\end{array}$ \\
\hline $\begin{array}{l}\text { Specific gravity } \\
(---)\end{array}$ & 2.54 & 2.49 & 1.48 & 1.78 \\
$\begin{array}{l}\text { Diameter } \\
(\mu \mathrm{m})\end{array}$ & 10 & 10 & 11.9 & 7 \\
$\begin{array}{l}\text { Young's } \\
\text { Modulus } \\
(\mathrm{GPa})\end{array}$ & 72.4 & 85.5 & 131.0 & 241.3 \\
$\begin{array}{l}\text { Ultimate } \\
\text { Tensile } \\
\begin{array}{l}\text { Strength } \\
(\mathrm{MPa})\end{array}\end{array}$ & 3447 & 4585 & 3620 & \\
$\begin{array}{l}\text { Axial co- } \\
\text { efficient of } \\
\text { thermal } \\
\text { expansion } \\
\left(\mu \mathrm{m} / \mathrm{m} /{ }^{\circ} \mathrm{C}\right)\end{array}$ & 5.04 & & & \\
\hline
\end{tabular}

\subsection{Adhesives}

Though the adhesive matrix carries a minor part of the tensile-load acting on a composite structure, it has a major influence on inter-laminar shear and in-plane shear properties of the composite material. These properties are important design considerations for structures under bending and torsional loads. The matrix also influences the compressive strength of the composite material by preventing the fibers from buckling under compressive load. Further, physical and thermal characteristics of 
the matrix like viscosity, melting point and cure temperature influence the processability and the presence of any defects in a composite. The use of a specific resin determines which properties are strongest and the range of conditions over which the composite structure can be used. In general, the best adhesive for a particular application depends on the materials to be bonded, the service assembly conditions and the economics of the bonding operation.

For high performance composites in structural applications, thermoset polymers such as epoxies, phenolics, polyesters and vinylesters are most widely used. In the formation of thermosetting polymers, the reactants undergo chemical cross-linking and produce a three dimensional solid network. The properties of the solid depend on the nature of the reactants and the cross-linking process. The following discussion presents a description of each of the more common resins.

\subsubsection{Epoxies}

Epoxy resins have epoxide groups $\left(-{\stackrel{\mathrm{C}}{\mathrm{C}_{-}}}_{\mathrm{C}_{\mathrm{l}}}^{\mathbf{O}} \mathrm{C}_{-}\right)$which are three membered rings containing one oxygen atom and two carbon atoms. The starting materials for the preparation of an epoxy resin are low molecular weight organic liquids. Diglycidyl ether of bisphenol A (DGEBA), shown in figure 2.1 (a) which contains an epoxide group at each end of the molecule is a common starting material for the manufacture of epoxy resins. The resins are cross-linked with catalysts or hardeners such as diethylene triamine (DETA), shown in figure 2.1(b). Starting materials may be mixed with other ingredients such as diluents (dibutyl phthalate, for example) to reduce viscosity, and flexibilizers to give impact strength of cured epoxy matrix. 


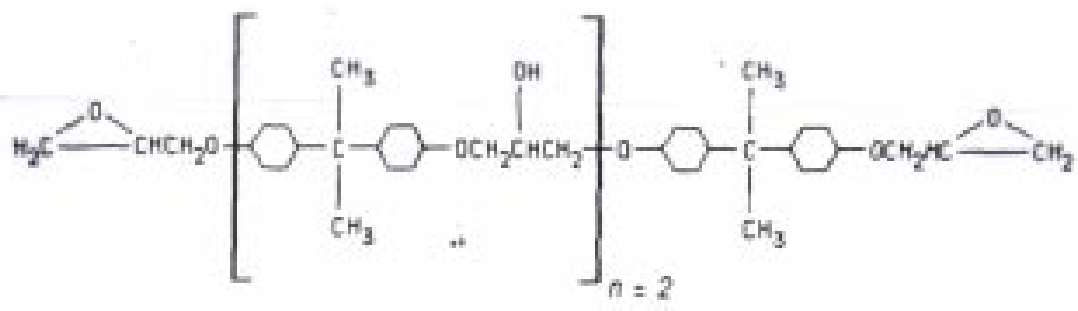

(a)

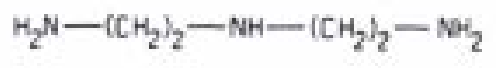

(b)

Figure 2.1 Raw materials for the preparation of epoxy resin [2]. (a) a molecule of DGEBA epoxy resin; (b) a molecule of DETA curing agent

During the cure of epoxy resin, the Hydrogen atoms of the curing agent (DETA) react with the epoxide groups of the DGEBA molecule and open the oxirane ring as shown in figure 2.2(a). With the progress of the curing reaction, the DGEBA molecules form cross-links with each other resulting in a three-dimensional structure. The resulting structure is a solid epoxy resin as shown in figure 2.2(c). The curing time and temperature of cure of the resin depend on the nature and amount of the curing agent used. The properties of a cured epoxy resin depend on the cross-link density, which depends on the chemical structure of the starting liquid resin, the functionality of the curing agent and the reaction conditions such as temperature and time. 


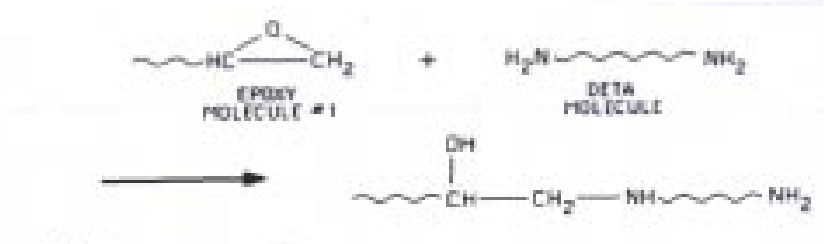

(a)
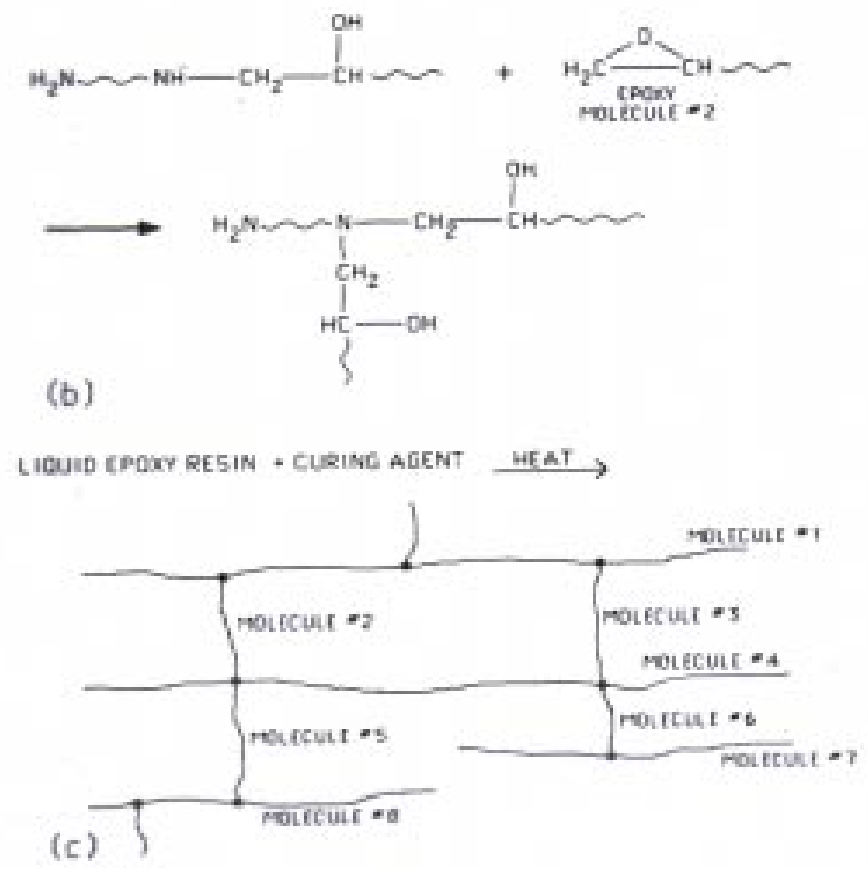

Figure 2.2 Schematic representation of a cross-linked epoxy resin [2] (a) reaction of epoxide group with DETA molecule; (b) formation of cross-links; (c) three-dimensional structure of solid epoxy resin [2]

An epoxy matrix has many advantages over other thermosetting resins:

1. it has a wide variety of properties such as tensile strength, tensile modulus, specific gravity, coefficient of thermal expansion etc. because of a large number of available starting materials, curing agents and modifiers.

2. it has low volumetric shrinkage and absence of volatile materials during cure.

3. it has excellent resistance to chemicals and solvents.

4. it has excellent adhesion to a wide variety of fillers, fibers and other substrates.

Principal disadvantages of epoxy resins are relatively high cost and long cure time. High coefficient of thermal expansion, and property changes due to moisture 
absorption are other disadvantages that can affect composite performance. Epoxy resins are principally used in aerospace, aircraft and structural applications.

\subsubsection{Polyesters}

Unsaturated polyester resins that contain a number of $\mathrm{C}=\mathrm{C}$ bonds are starting materials for the polyester matrix. Typically one reacts maleic anhydride with ethylene glycol or propylene glycol. The resulting liquid is dissolved in a reactive diluent such as styrene that reduces viscosity and acts as a cross-linking agent. An inhibitor such as hydroquinone is added in trace amounts to the liquid mix, to prevent premature polymerization during storage. Figure 2.3 shows the principal ingredients used in the preparation of a polyester resin.

(a)
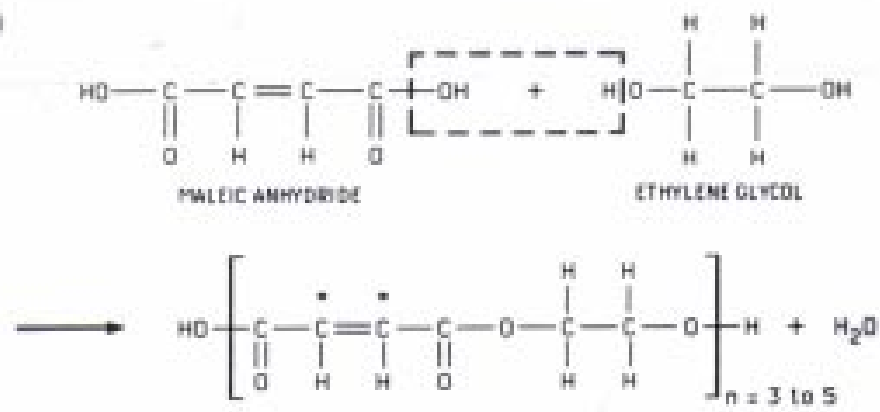

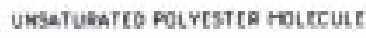

(b)
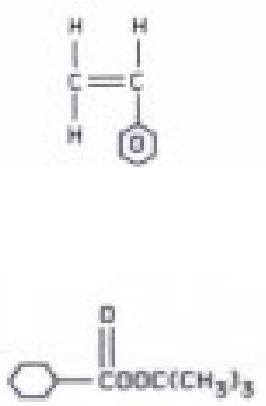

(c)

Figure 2.3: Raw materials for the preparation of a polyester resin [2]. (a) unsaturated polyester molecule; (b) styrene molecule; (c) t-butyl perbenzoate molecule (tBPB).

(The asterisk denotes reactive sites in the molecule) 
The curing reaction is initiated by adding small quantities of a catalyst such as an organic peroxide. The catalyst decomposes into free radicals with the application of heat and the free radicals open the $\mathrm{C}=\mathrm{C}$ bonds of styrene molecules. Styrene radicals in turn join the polyester molecules at their unsaturation points and form cross-links between them. The resulting material is a solid polyester resin. A schematic of a cross-linked polyester resin is shown in figure 2.4 .

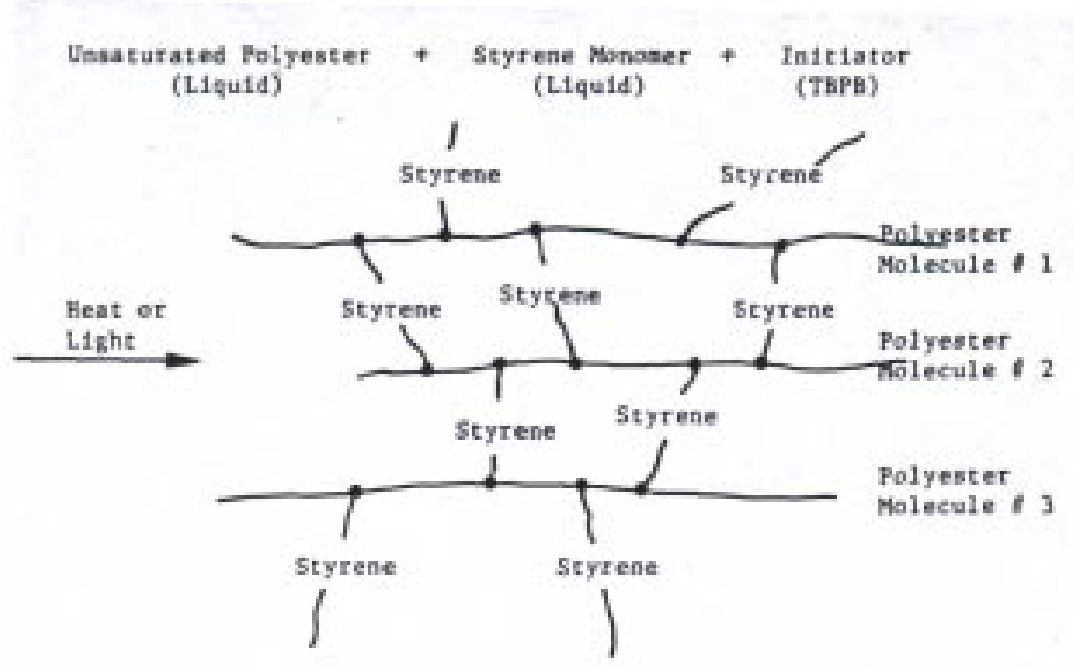

Figure 2.4: Schematic representation of a cross-linked polyester resin [2]

The curing time for polyester resin depends on the decomposition rate of the catalyst, which can be increased by the addition of small quantities of an accelerator such as cobalt naphthanate. The rate of decomposition of the catalyst can also be increased, by increasing the curing temperature upto a certain optimum. The properties of a polyester resin depend on the cross-link density, which primarily depends on the chemical nature of the raw materials, the number of unsaturation points in an unsaturated polyester molecule and the amount and nature of the diluent used.

Polyesters have excellent resistance to many mild acids and alkalis. The advantages of polyester resins are low viscosity, fast cure time, good thermal and impact 
resistance, good moisture resistance and low cost. However, their properties are generally inferior to those of epoxies. The principal disadvantage of polyesters as compared to epoxies is their high volumetric shrinkage. Polyester resins are mostly used in automotive, marine, chemical and electrical applications.

\subsubsection{Phenolic formaldehydes}

Phenol and formaldehyde undergo a condensation reaction producing two types of phenolic resin depending on the molar ratio of the starting materials. With an excess of formaldehyde, resole resin is formed. It can be cross-linked (by heating etc.) without addition of other ingredients. The disadvantage of this resin is limited storage life. With an excess of phenol, novolac resin is produced which has indefinite shelf life because of its inability to polymerize on its own. This resin needs a source of formaldehyde as the hardener for cross-linking.

In the first stage of reaction, formaldehyde reacts with phenol forming methylolphenol as shown in figure 2.5. This stage is essentially a mixture of monomers and dimers, having a water like viscosity. The second stage is the condensation of products of the first stage and contains all sizes of molecules that are still soluble in water. The third stage is considered as one giant molecule, which is the result of chemical

cross-linking of the molecules of the second stage. Figures 2.6 and 2.7 show the formation of novolac resin and resole resin respectively. 


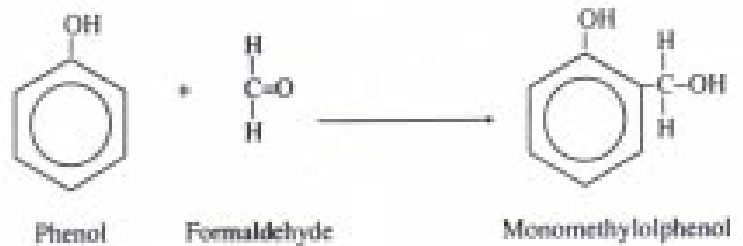

Figure 2.5: Addition of formaldehyde to phenol [3]

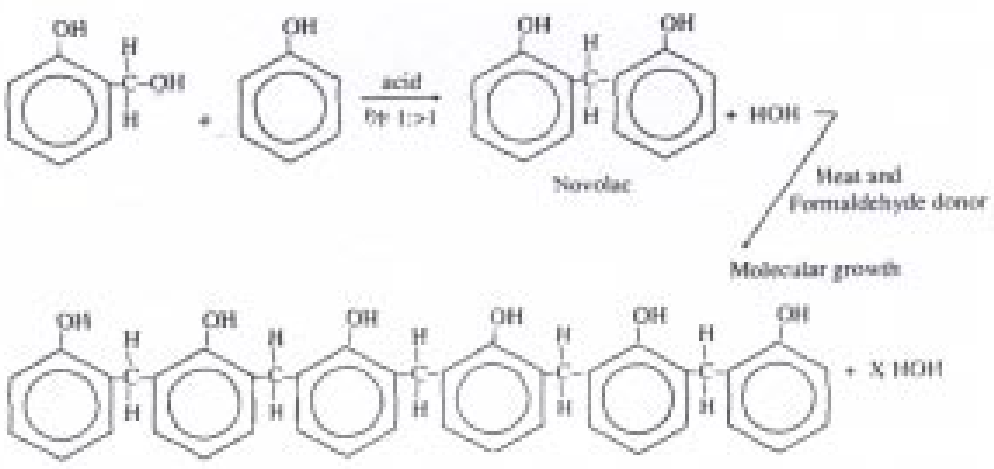

Figure 2.6: Formation of novolac resin [3] 


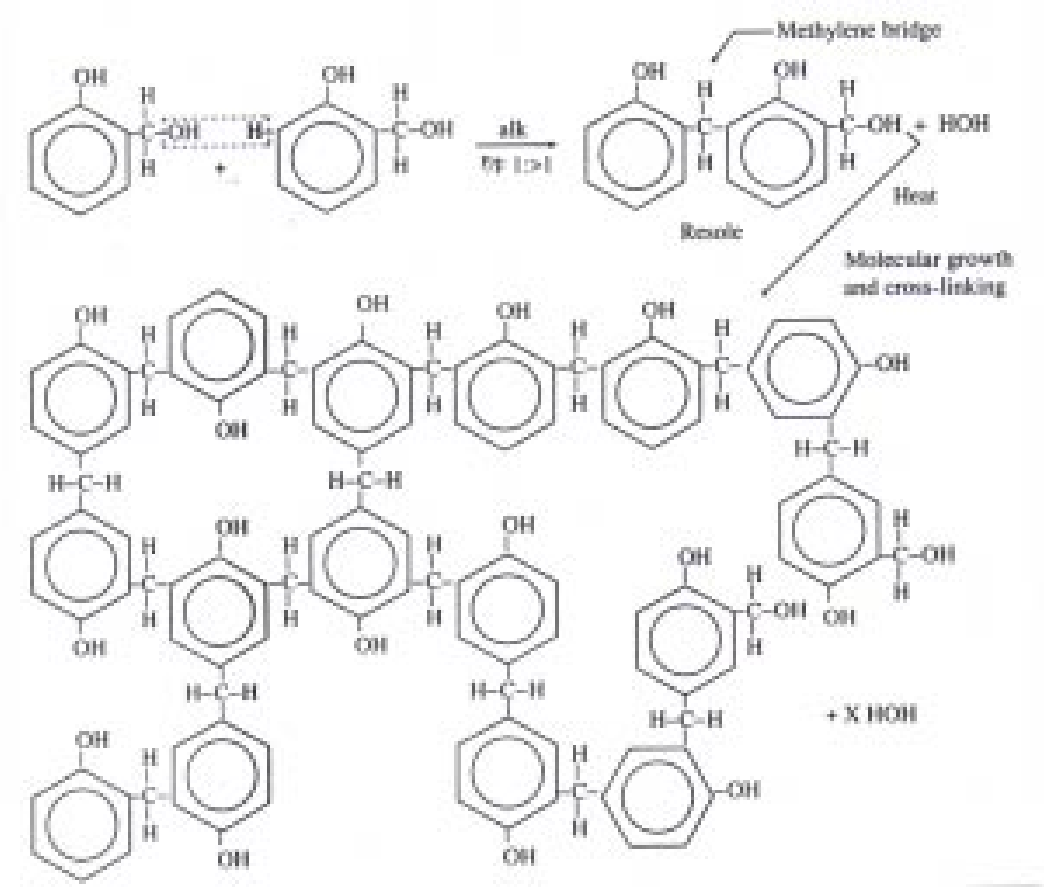

Figure 2.7: Formation of resole resin [3]

The properties of phenolic resins depend on the $\mathrm{pH}$ of the resin and the temperature of cure. The higher the temperature and $\mathrm{pH}$, the faster is the cure. Various types of fillers and extenders such as cereal flour, wood flour, clay and lignin are also added to control the flow and penetration properties of the resin.

Cured phenolic resins provide high mechanical strength and are resistant to degradation, heat, fusion and solvation. The resistance to degradation of phenolic resins is due to the stability of the benzene ring, and $\mathrm{C}-\mathrm{C}$ bonds formed during polymerization. The resistance to heat and fusion and solvation are due to their highly cross-linked structure. They are used in adhesives, coatings, laminates and binders in foundry. 


\subsubsection{Resorcinol-formaldehydes}

Condensation reaction between resorcinol and formaldehyde produces RF (resorcinol-formaldehyde) resin that has properties similar to a phenol formaldehyde resin. The presence of a second hydroxyl group on the benzene ring (as opposed to a single hydroxyl group in the case of phenol) makes resorcinol extremely reactive to formaldehyde in forming the methylol compound and subsequently to the formation of methylene bridges in solidifying. The formation of novolac resin from resorcinol and formaldehyde is shown in figure 2.8 .

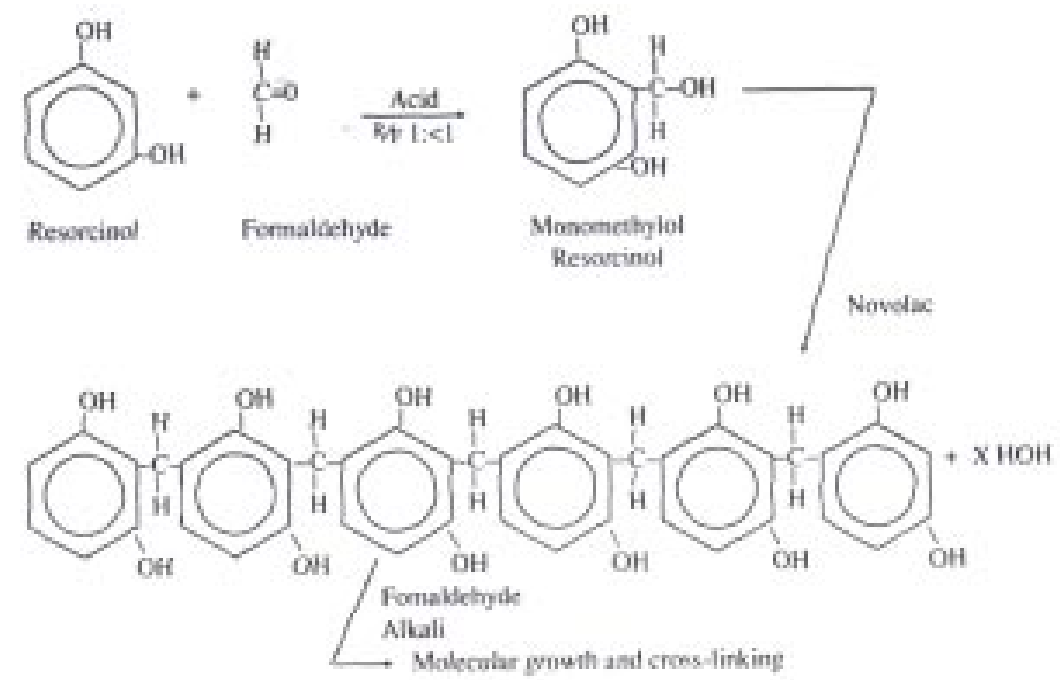

Figure 2.8: Formation of novolac from resorcinol and formaldehyde [3]

The speed of cure of resorcinolic resins depends on the $\mathrm{pH}$ of the resin and temperature of cure. The cure time is generally reduced by increasing the $\mathrm{pH}$ of the resin or by increasing the temperature. The cured state of resorcinolic resins is the same as the 
highly cross-linked structure of phenolics, since resorcinol has the same three reactive hydrogens, which allow molecular growth in three directions. The durability of the RF bond depends on the extent of cure; fully cured RF is considered one of the best adhesives for bonding wood. The principal disadvantage is high cost.

Due to similarity of chemical reactions, copolymerization of resorcinol and phenolic resins is performed. The resulting phenol resorcinol formaldehyde (PRF) has lower cost due to phenolic base and room temperature cure due to resorcinol end groups. PRF resin is widely used in construction, boat building, and gluing any solid wood pieces that would be exposed to severe environmental conditions.

\subsubsection{Vinyl esters}

Unsaturated vinyl ester resin produced by the reaction of an unsaturated carboxylic acid and an epoxy resin is the starting material for vinyl ester resin. The resulting resin is dissolved in styrene monomer for cross-linking of $\mathrm{C}=\mathrm{C}$ bonds at the ends of a molecule and also to reduce viscosity. Peroxides and accelerators are used for curing. The raw materials used and a schematic of the cross-lined vinyl ester resin are presented in Figure 2.9 and Figure 2.10 respectively. 


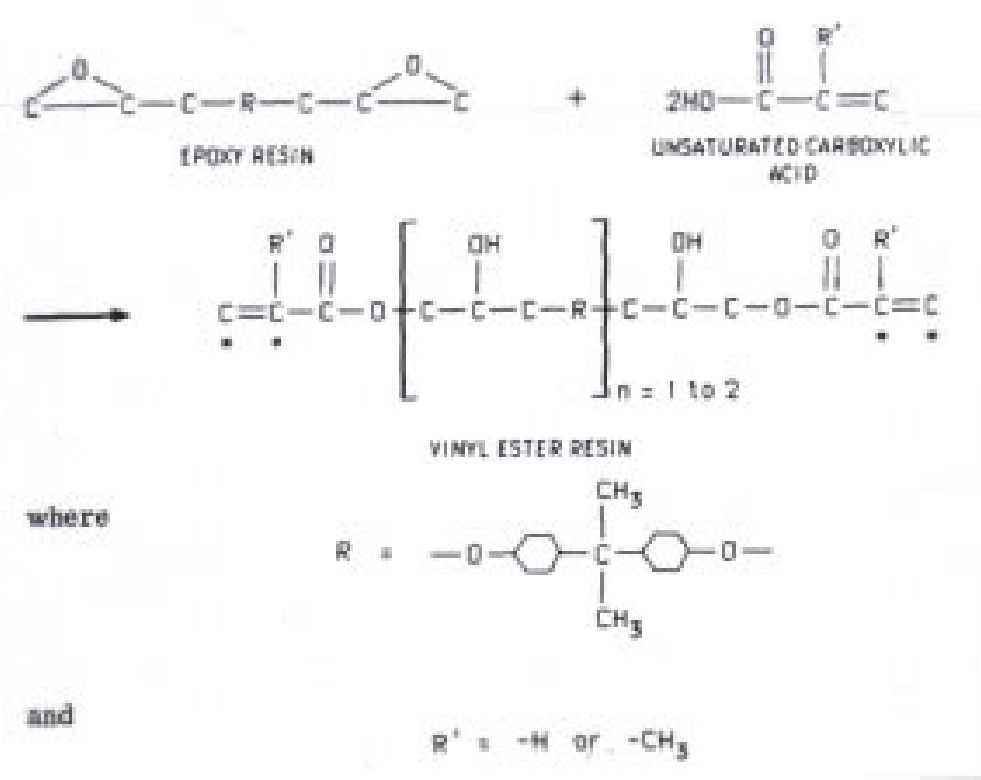

Figure 2.9: Chemistry of a vinyl ester resin [2]. (The asterisk denotes unsaturation points or reactive sites)

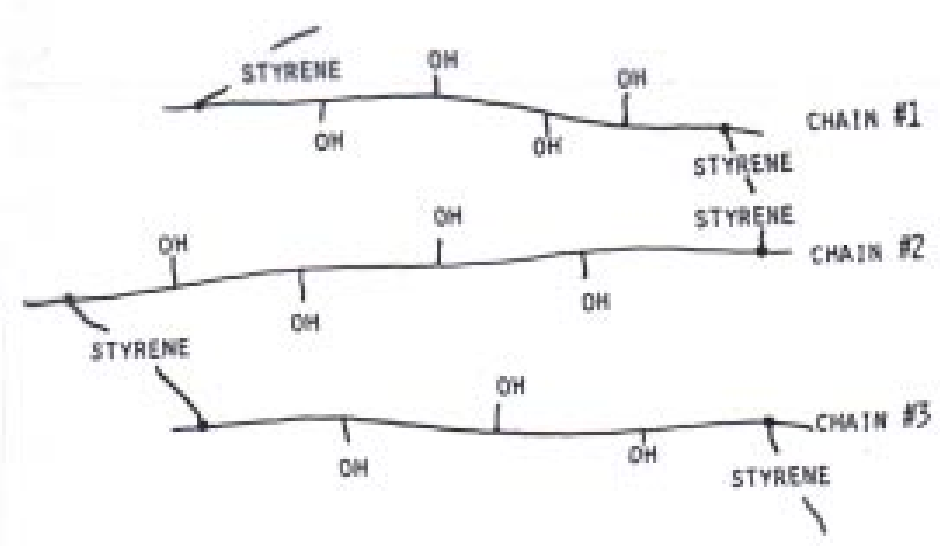

Figure 2.10 : Schematic representation of a cross-linked vinyl ester resin [2]

The curing reaction of vinyl ester resins is similar to that of polyester resins. Due to fewer cross-links, cured vinyl ester resins have greater fracture toughness than polyester resins. The hydroxyl groups along the length of a vinyl ester molecule can form hydrogen bonds with similar groups on glass fiber surface resulting in excellent fiber wet-out and good adhesion with glass fibers. 
Vinyl ester resins possess excellent tensile strength and chemical resistance. They have low viscosity and low curing time. Their principal disadvantage is that they have higher volumetric shrinkage than the parent epoxy resins. They are used in corrosion resistant FRP products, aerospace industry and other exterior applications.

\subsubsection{Urethanes}

Polyurethanes are reaction products of isocyanate, a polyol and a curing agent like diamine. Urethanes are classified based on the polyol (generally polyethers or polyesters) used. Urethanes have excellent abrasion resistance, tear strength, shock absorption, resistance to oxygen aging, and resistance to a variety of solvents. Their life is limited under high temperature and high humidity environments.

They are widely used in flexible foams and insulation materials. Other applications are bumpers, liners of equipment handling abrasives, casting molds, high impact car panels and a variety of reaction injection molding products.

Typical properties of various adhesives are presented in Table 2.2. 
Table 2.2: Properties of thermosetting resins [4]

\begin{tabular}{|c|c|c|c|c|}
\hline Property & epoxy & phenolic & polyester & polyurethane \\
\hline $\begin{array}{l}\text { Specific gravity } \\
(---)\end{array}$ & $1.1-1.40$ & $1.24-1.32$ & $1.04-1.46$ & 1.84 \\
\hline $\begin{array}{l}\text { Water } \\
\text { absorption } \\
(24 \mathrm{hr}) \%\end{array}$ & $0.08-0.15$ & $0.1-0.36$ & $0.15-0.6$ & $0.2-1.5$ \\
\hline $\begin{array}{l}\text { Tensile } \\
\text { Modulus (X } 10^{3} \\
\text { psi) }\end{array}$ & 350 & $400-700$ & $300-640$ & $0-100$ \\
\hline $\begin{array}{l}\text { Tensile yield } \\
\text { strength (psi) }\end{array}$ & ----- & ----- & & \\
\hline 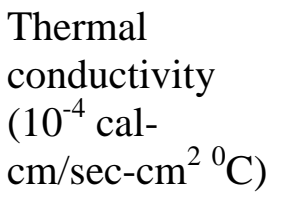 & 4.5 & 3.5 & ----- & 5 \\
\hline $\begin{array}{l}\text { Co-efficient of } \\
\text { linear thermal } \\
\text { expansion } \\
\left(10^{-6} \text { in } / \mathrm{in} /{ }^{0} \mathrm{~F}\right)\end{array}$ & $45-65$ & 68 & $55-100$ & $100-200$ \\
\hline
\end{tabular}

\subsection{Wood}

Wood is a cellular, natural organic material, the porosity and surface condition of which affect its characteristics as a substrate. The bondability of the wood/adhesive system depends on many factors: species, equilibrium moisture content, physiochemical properties of wood (including the changes caused by preservative treatment or exterior exposure), adhesive properties, and the conditions under which the adhesive bond is 
formed.

Northern oak, eastern cotton wood, southern pine, red maple, yellow-poplar and douglas-fir are the most commonly used types of wood for civil engineering structures.

\subsubsection{Composition and structure}

The components of wood are cellulose, hemicellulose and lignin. The arrangement of these components is similar to that of a fiber reinforced composite wherein, the anisotropic cellulose fibers are reinforced in isotropic lignin matrix. The partially oriented hemicelluloses are intimately connected to the other two components. The amount, organization and structure of these components influence the adhesive bonding of wood. A high cellulose content in wood leads to an increased tensile strength and a high lignin content improves compressive strength parallel to the grain.

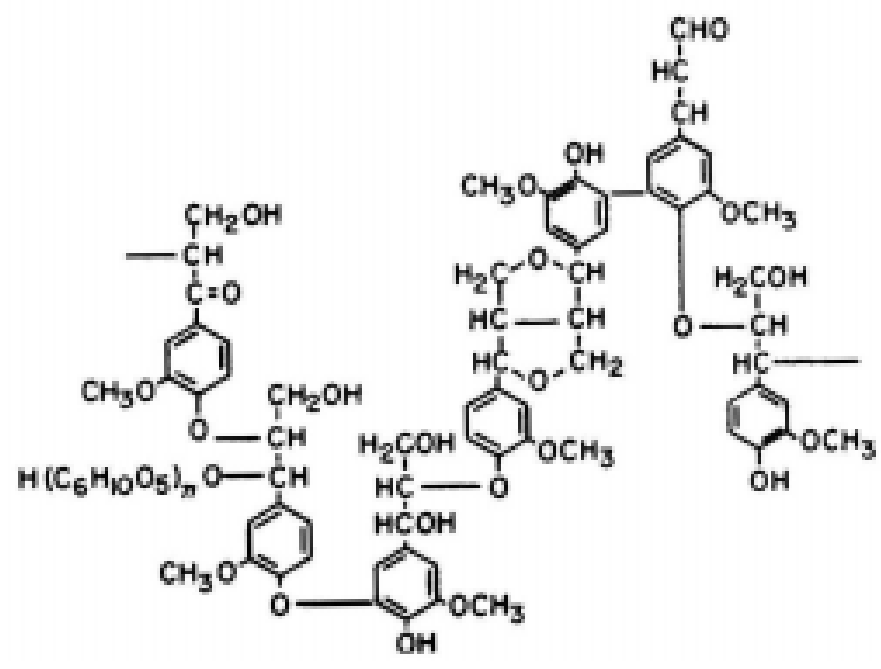

Figure 2.11 Partial structure of a lignin molecule [5] 


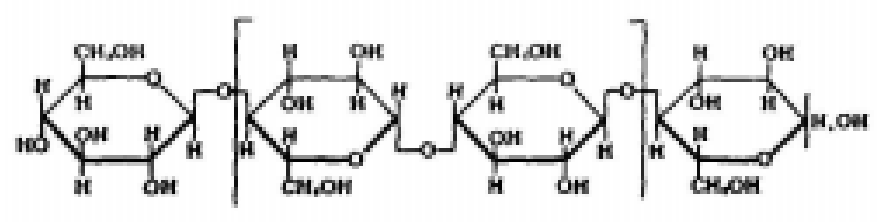

Figure 2.12 Structure of a cellulose molecule [5]

\subsubsection{Preservative Treatment}

Either natural or artificial weathering can produce significant changes in wettability and bondability of wood. Wood used in building construction is generally subjected to fluctuating humidity. The EMC (Equilibrium Moisture Content) is therefore constantly changing, sometimes periodically and at other times, sporadically, such as when wood is exposed to rain. Hence wood is treated with chemicals to enhance performance against fire, fungi and weather.

Chromated copper arsenate, copper naphthenate, creosote, ammoniacal preservative solutions like ammoniacal copper zinc arsenate (ACZA) and ammoniacal copper arsenate(ACA), CuDMAP \{Bis-[1-(dimethylamino)-2-propanolato] copper(II)\}, chromated zinc chloride etc. are some of the preservatives used for the treatment of wood.

Creosotes distilled from tars are widely used in wood preservation, and coal-tar creosote is most effective among the creosotes. High toxicity to wood destroying organisms, relative insolubility in water, low cost and ease of application to wood are the advantages of this preservative. However, the blackish-brown color renders it unsuitable where appearance is important. Also, creosote vapors are harmful to plants. Freshly 
creosote-treated wood can be ignited easily and so creosote cannot be used where fire hazard is a concern.

Water based chromated copper arsenate (CCA) is the most widely used preservative. Experiments conducted at the Wood Research Institute, Michigan Technological University, indicated that wood (southern yellow pine, radiata pine and douglas-fir) thoroughly impregnated with CCA even at low retentions can be protected from damage by formosan subterranean termites, the common termites affecting wood in North America. Also, CCA treated wood is found to provide good resistance to Limnoria and Teredo marine borer attack. CCA is accepted as a very effective preservative treatment with certain wood species like pine wood and douglas-fir. Commercial CCA treatments are also known to contain wax emulsions that greatly increase the waterrepellancy of the treated wood as compared to untreated wood. This is due to the higher contact angle for the CCA treated wood. 


\section{Chapter III}

\section{ADHESION FUNDAMENTALS}

\subsection{Adhesion}

An adhesive is defined as a " substance capable of holding materials together by surface attachment" [5]. Each adhesively bonded joint is a system of two similar or dissimilar solid materials called substrates or adherends, joined by a layer of another material called the adhesive. For structural applications, the adhesive film should be considered as a material in its own right, however thin it may be.

\subsubsection{Adhesive Composition}

Most of the modern adhesives are composed of various components, which have their own specific function. The following components are usually present in a structural adhesive:

\section{Base}

This is the base material from which the adhesive derives its specific name, like epoxy, polyester, polyurethane resins discussed earlier under different types of matrices.

It is usually a solid material that serves as the back bone of the adhesive.

\section{Solvent}

It is used to dissolve or disperse the base and additives to provide a liquid adhesive system. Solvent may not be required if the base is a liquid.

\section{Hardener}

It undergoes a chemical reaction with the base and cures the adhesive during bonding. It is usually added in stoichiometric proportions to the base. 
Other additives are also added to improve adhesive properties:

Fillers are primarily added to thicken a liquid adhesive for satisfactory spreading on the adherend surface. They improve mechanical properties of polymers like hardness and modulus.

Plasticizers are high boiling point liquids or solids that are mixed with polymers to improve flexibility.

Coupling agents are chemicals used to treat the surface of fillers and they improve compatibility between filler and polymeric matrix.

Antioxidants and stabilizers are added to polymeric matrices to protect them against heat, light and oxygen.

Adhesives harden in the joint by several mechanisms such as solvent loss, melting and cooling, and chemical reaction. Thermosetting resins like phenol, resorcinol, epoxy, polyester and polyurethane used in the current experimental work, harden by an irreversible chemical reaction.

\subsubsection{Adhesive Bonding Process}

The adhesive bonding process begins with preparation and application of an adhesive to an adherend that has been prepared for bonding. The process continues with application of necessary curing pressure for the required time. The adhesive is usually applied to the adherend wood in a suitable pattern. The adhesive may be applied to one or both the surfaces that are to be adhered. The steps in an ideal wood adhesive bond development outlined by Marra [3] are, flow, transfer, penetration, wetting and hardening. 


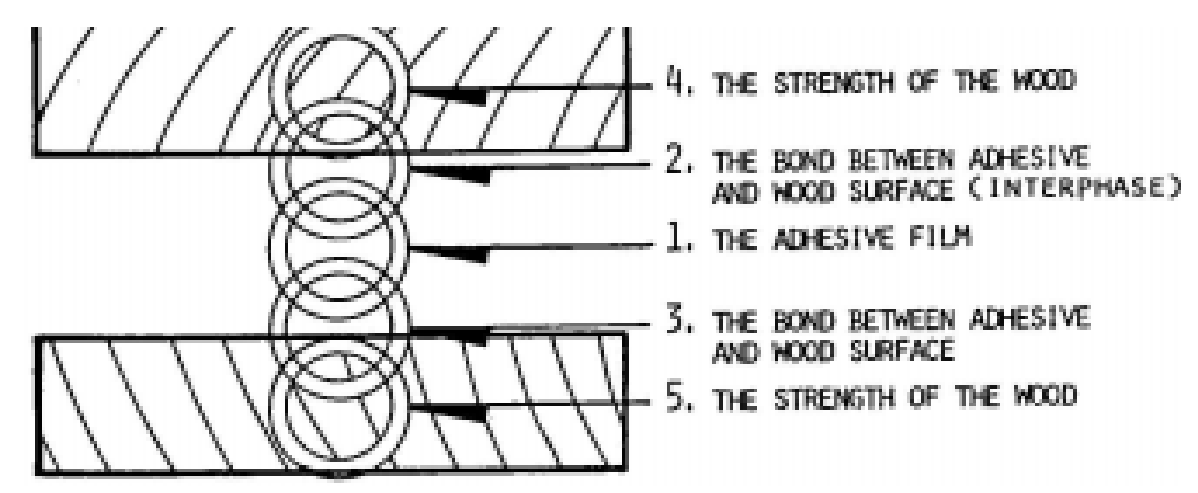

Figure 3.1: An idealized chain link concept of adhesive bond anatomy [5]

During flow, adhesive applied to the wood surface merges into a uniform wet film. When two surfaces of wood to be adhered are brought together and pressurized, the adhesive transfers to both surfaces equally. The adhesive then penetrates into the wood surfaces establishing complete contact between the adhesive and wood surfaces. During wetting, the adhesive develops an extensive and intimate molecular scale contact with the wood surface. Wetting occurs to some extent during all the previous steps. Finally during hardening, the adhesive film sets and develops cohesive strength and environmental resistance in the bond.

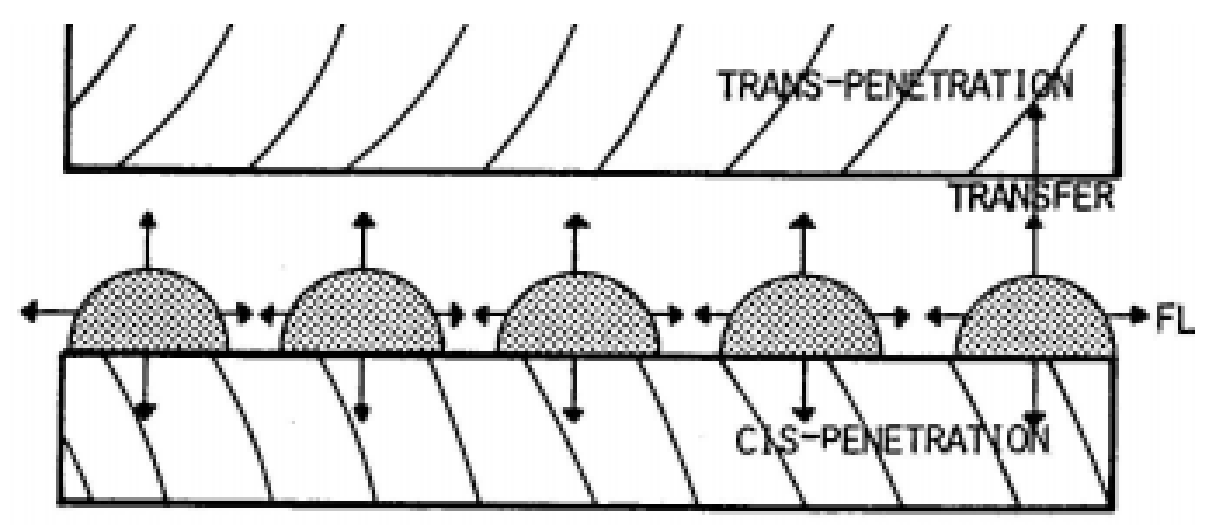

Figure 3.2: A diagrammatic sketch of flow, transfer and penetration functions in wood-adhesive bond development [5] 


\subsubsection{The Quality of an Adhesive Bond}

The quality of an adhesive bond depends not only on the adhesive as supplied by the manufacturer, but also on the surface characteristics of wood and the conditions under which the bond is formed.

\section{Preparation of adherend}

For an adhesive to adhere effectively to the adherend, the surface should be smooth and flat so that a film of adhesive is formed. Wood adherends should be conditioned before bonding, to a moisture content that is close to that expected in service. The conditioned wood should be machined to provide a fresh, flat, smooth surface, free from any torn fibers, and it should be bonded within 24 hours of machining.

\section{Preparation of adhesive}

The components should be mixed with precision in the proportions specified by the manufacturer. Improper proportioning of curing agent, fillers, extenders or solvents can affect viscosity of the adhesive and thereby the quality of the adhesive bond.

\section{Application of adhesive}

Proper amount of the adhesive should be spread on one or both adherends rapidly and uniformly before the viscosity starts to increase. Different types of spreading equipment can be employed depending on type of adhesive, spreading speed, volume of adhesive to be spread and other factors. For small scale or laboratory operations, the adhesive can be brushed by hand or spread using a spatula. For industrial purposes, 
double-roll spreaders, extruders, spraying units etc. are used.

\section{Priming adherend surface}

Priming the wood surface prior to bonding can increase compatibility of adhesives to wood surface. Based on the type of a primer, it can be used to modify different characteristics of an adhesive joint (developing tack, lengthening time between surface preparation and bonding, improving corrosion resistance of adhesive joints etc.). Primers that chemically react with the adherend surface and adhesive are known as adhesion promoters or coupling agents.

\subsubsection{Factors Affecting Performance of an Adhesive}

Most of the thermosetting resins used in structural applications are prepared by mixing the base resin with a curing agent that initiates the reaction within the adhesive. The optimum performance of such adhesives depend on variables such as:

- amount of hardener or curing agent that is added to or mixed in the basic resin

• open and closed assembly time of adhesion

$\bullet$ thickness of glueline

- pressure and temperature of curing

- conditioning after bonding such as post curing

- machining bonded specimen

- treatment given to wood 


\subsection{Use of Coupling Agents for Improved Adhesion}

Coupling agents are used to treat the surface of adherends as well as fibers to improve interfacial properties of a complex composite. In a GFW wood post, the glass fiber/adhesive interface and wood/adhesive interface, have a major influence on the durability of the post.

The bond between glass fibers and the adhesive is improved by surface treatment of glass fibers with a variety of chemicals called sizing agents (eg: silanes). Sizing of fibers is also shown to significantly reduce the moisture attack at the interface [6]. The influence of the coupling agents, chemistry and the role of coupling agents in maintenance of surface properties after exposure to the environment is discussed by Schutte [7].

The bond between the adhesive and wood surface depends on the properties of adhesive and the surface characteristics of the wood. The surface of CCA treated wood consists of hemispherical deposits of oxides of Chromium, Copper and Arsenic [8]. The presence of these insoluble metallic oxides blocks molecular forces of attraction between the wood surface and adhesive. A 5\% aqueous solution of hydroxy methylated resorcinol (HMR), when used on CCA treated wood surface has been found to increase the delamination resistance and wood failure of epoxy bonds [9]. HMR enables phenolresorcinol-formaldehyde, isocyanate, phenol-formaldehyde and resorcinol-formaldehyde adhesives to form strong and durable bonds with CCA treated wood [10]. 


\subsection{Performance Evaluation of Adhesive Bond}

\subsubsection{Introduction}

Testing of bonded assemblies helps characterization of different materials based on their relative performance and determination (or prediction) of their durability. Standard methods are available to measure specific properties of adhesives, bonded assemblies and complex composites. One can use standard test methods of ASTM, AITC, etc. and measure properties like strength, stiffness, creep, etc. in different modes of applied load (shear, tension, compression, impact, bending etc.). Short-term acceleratedaging procedures that simulate long-term exposure conditions are also used to determine the durability of complex composites.

\subsubsection{Test Methods}

Test methods are categorized based on the materials involved, method of loading, time required for testing, equipment used, sample conditions (temperature, pressure, moisture content, and conductivity) and the required sample state after testing. Some test methods produce numerical values, some produce only qualitative results.

\subsubsection{Destructive Testing}

Destructive testing applies load on entire bonded area and evaluates the bond strength as a whole. However it destroys the bonded assembly and the specimen cannot be used further. It is used to reveal changes in strength and strain to failure of bonded assemblies.

The direction of load placed on a test specimen until failure characterizes the 
destructive testing procedure. Adhesive bonded assemblies can be loaded in shear, tension, flexure, peel, cleavage or combinations of these.

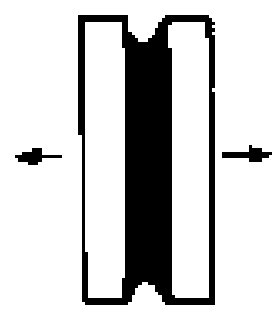

TENSILE

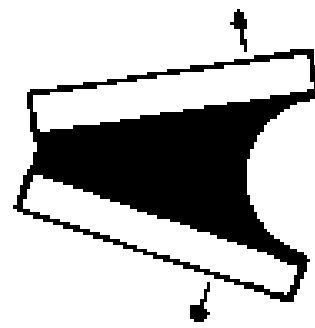

CLEAVAGE

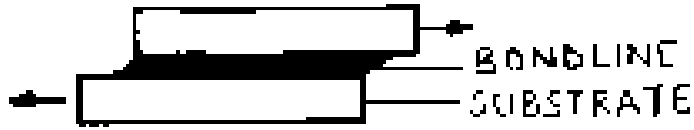

SHEAR

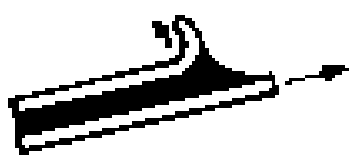

PEEL

Figure 3.3: Test specimen for different types of tests [5]

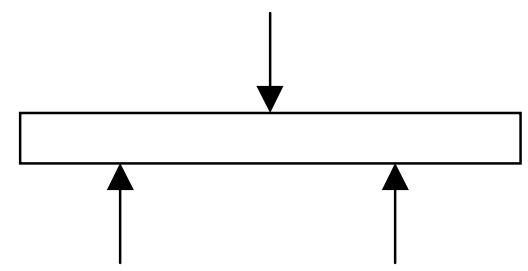

Figure 3.4: Test specimen for flexural test (three point bending)

Shear loading introduces forces parallel to the plane of the bond line. These forces slide the substrates in opposite directions, loading the entire bonded area. Bonded assemblies most often are designed to emphasize the greater efficiency of shear bonding. The shear strength of bonds is determined using ASTM D-905.

Tensile loading applies forces perpendicular to the plane of the bonded area. Tensile loading, in principle transfers the load over the entire bonded area but is difficult 
to apply in a totally axial fashion. Tensile strength of a bond is the tensile load per unit cross-sectional area required to break the bond. ASTM D-897 is used to determine comparative tensile properties of adhesives.

Flexural testing applies force on a simple beam at mid-span, perpendicular to the bond line. Flexural strength of an adhesive-wood bond is the maximum breaking strength sustained by a specimen when subject to bending force. ASTM D-790 provides the typical procedure for flexural testing of complex composites.

Cleavage loading concentrates force along one end of the adhesive bond line. Cleavage strength is the tensile breaking load expressed in force per unit width of bond line. ASTM D-3433 is used to test bonds in cleavage and determine properties like fracture toughness.

Peel testing also applies force along one end of the bond line. Peel strength is a measure of the resistance to stripping of a flexible member of an assembly that is bonded to a flexible or rigid adherend. The stress distribution in a peel test is complex and the application of a constant peel force is influenced by specimen width and bond strength.

$90^{\circ}$ peel, $180^{\circ}$ peel, and T-peel are common peel procedures in use. ASTM D-1876 and ASTM D-903 are used to determine peel testing of adhesive bonds.

Impact testing, creep testing and a variety of other tests are also used for characterizing the mechanical response of adhesive bonds. Different types of tests based on the particular type of loading are discussed in detail by Blomquist et al [5]. The mechanical properties of a few commonly used thermosetting adhesives are presented in Table 3.1. 
Table 3.1: Mechanical properties of thermosetting adhesives [11]

\begin{tabular}{|c|c|c|c|c|c|c|}
\hline Adhesive & $\begin{array}{l}\text { Tensile } \\
\text { yield } \\
\text { strength } \\
\left(10^{3} \mathrm{psi}\right)\end{array}$ & $\begin{array}{l}\text { Tensile } \\
\text { modulus } \\
\left(10^{5} \mathrm{psi}\right)\end{array}$ & $\begin{array}{l}\text { Flexural } \\
\text { yield } \\
\text { strength } \\
\left.\text { ( } 10^{3} \mathrm{psi}\right)\end{array}$ & $\begin{array}{l}\text { Flexural } \\
\text { modulus } \\
\left(10^{5} \mathrm{psi}\right)\end{array}$ & $\begin{array}{l}\text { Compressive } \\
\text { strength } \\
\left(10^{3} \mathrm{psi}\right)\end{array}$ & $\begin{array}{l}\text { Izod } \\
\text { impact } \\
\text { strength } \\
\text { (ft-lb/in) }\end{array}$ \\
\hline $\begin{array}{l}\text { Bisphenol A } \\
\text { epoxy }\end{array}$ & $9.5-11.5$ & 4.5 & 14-18 & $4.5-5.4$ & $16-24$ & $0.2-0.5$ \\
\hline Phenolic & $6.5-7.0$ & $8-13$ & $9-11$ & $11-13$ & $22-36$ & $0.3-0.35$ \\
\hline Polyester & 8.0 & 2.8 & $12-14$ & $2.8-4.0$ & 13 & 0.5 \\
\hline Polyurethane & $2.5-3.0$ & $1.1-1.6$ & $6.0-7.0$ & $1.2-1.7$ & -- & $7-15$ \\
\hline
\end{tabular}

\subsubsection{Non-destructive Testing}

Non-destructive testing is carried out on specimens so that they can be used even after testing. This type of testing does not damage the bond-line but the bond cannot be fully loaded. Non-destructive testing is conducted to understand the causes of strength degradation and the factors affecting it.

Scanning Electron Microscopy (SEM) is used to observe the topography of a fractured specimen and helps detect the site of failure initiation. The failure occurring at the fiber-matrix interface or wood-matrix interface can be detected. Mechanical interlocking of phenolic adhesive in CCA treated wood, for example, was studied using SEM by Vick and Kuster [8]. 
Dynamic Mechanical Spectrometer is used for non-destructive testing of bonded assemblies [12]. A sinusoidal strain is imposed on the sample and the resulting sinusoidal stress is measured. The dynamic mechanical spectrum of the sample is used for calculation of mechanical properties and service life.

Visual examination of bondlines can determine if uniform adhesive squeeze-out had occurred. Squeeze-out can be examined for variations in color, indicating improper mixing or curing. Scraping off the squeeze-out and examining the revealed bondline can reveal voids, cracks or delaminations.

Short pulses of ultrasonic energy can be introduced so that they can be reflected by the bond line or the far surface of the bonded assembly. A large echo or loss of backsurface echo indicates an unbonded area.

Radiographic X-ray inspection and proof loading are other techniques used for non-destructive analysis. Microscopic techniques like Rutherford Back scattering Spectroscopy (RBS), Scanning Acoustic Microscopy, Nuclear Magnetic Resonance (NMR) imaging, Transmission Microscopy and Optical Microscopy are used to observe fractured specimens. 


\section{Chapter IV}

\section{DURABILITY OF BONDED ASSEMBLIES}

\subsection{Introduction}

The effectiveness of the proposed composite wrapping technique depends on the performance of the bond between wood and the composite wrap in the field. When installed in the field, the bond may be affected by several factors like mechanical stress, temperature, $\mathrm{pH}$ variation and moisture. Moisture may dissolve, soften or hydrolyze the adhesive. It can produce variations in dimensions, alter the strength of the wood and even cause decay in the wood structure. These effects are different for different species of wood. Elevated temperatures can soften, further cure or break down the adhesive film. Heat can create temporary or permanent strength loss of wood and it can change the dimensions of dry wood. Chemical attack also damages the adhesive bond, and may even damage the wood.

To ensure that the materials and manufacturing processes lead to a GFW-wood post with requisite strength and durability, testing of bonded assemblies is required. Durability of bonded assemblies can be tested by long-term exposure to atmospheric conditions or short-term exposure to harsh environments. A variety of methods are used by researchers for testing the durability of composites.

Resistance to delamination of adhesive bonds was tested by Vick [13] who employed ASTM specification D-2559-92. This method involves a vacuum soak in water, a pressure soak in water, oven drying and exposure of adhesive bonds to steam. 
The resulting delamination is measured as a percentage of the total end-grain bondline length for each specimen.

Stress corrosion data for PET (polyethylene terephthalate) reinforced with glass fibers was generated by Lhymn and Schultz [14]. Loaded samples were aged in different chemical media (air, $\mathrm{NaOH}, \mathrm{HCl}, \mathrm{H}_{2} \mathrm{SO}_{4}, \mathrm{HNO}_{3}, \mathrm{NaCl}$ ) until part-through failure occurred. The time to failure under a specific initial stress was calculated for each medium.

The durability of concrete cylinders wrapped with FRP was tested by Kshirsagar et al. [15]. Wrapped cylinders were exposed to alkaline media at varying temperature for 1000 to 10,000 hours. The ultimate strength (in compression loading) and strain of aged and unaged cylinders were compared.

Devalpura et al. [16] tested GFRP (Glass Fiber Reinforced Plastic) pultruded rods in acidic and alkaline environments using an accelerated stress rupture procedure derived from ASTM D-2992 and ASTM D 3681. The percent ultimate stress versus time to failure was reported.

Standards are available for testing the durability of composites involving different materials such as concrete, wood, metal, FRPs etc. Modifications to the standards are made by researchers, depending on the expected exposure during the service life of the composite.

In the current research, accelerated aging and chemical aging were performed on bonded specimens. 


\subsection{Accelerated Aging}

Due to changes in the atmospheric temperature, freezing and drying are expected to occur in the field. Vacuum and pressure cycles can induce interfacial stress, capillary diffusion of moisture into wood, fibers and matrix and other similar phenomena. Freezing and drying can accelerate the damage propagation. Considering these aspects, samples were subjected to a six cycle accelerated aging procedure prescribed by Chow et al. [17]. They stated that six cycles of the accelerated aging may be equivalent to more than twenty years of natural aging depending on the properties used to relate accelerated aging and natural aging. The temperature and duration of steps in each cycle were modified according to the sample size. The step of application of steam was eliminated to maintain uniformity with the aging tests being conducted at the Constructed Facilities Center (CFC). The procedure can be called a combination of ASTM D 2559-92, Chow cycle and ASTM D 1101. Each of the six cycles involved changes in temperature, pressure and moisture during which the bond-line is subjected to severe swelling and shrinkage. The following were the steps in each cycle of the accelerated aging process:

- vacuum soaking in water $\left(70^{\circ} \mathrm{F}\right)$ at 25 inches of $\mathrm{Hg}$ for $30 \mathrm{~min}$ samples immersed in water, are placed in the vacuum/pressure cylinder and vacuum is applied to the chamber. The air inside the chamber and also the pores of wood is pulled out. During this process, the voids inside the specimens are opened and water penetrates into the samples.

- pressure soaking in water $\left(70^{\circ} \mathrm{F}\right)$ at $100 \mathrm{psi}$ for $30 \mathrm{~min}$

samples are immersed in water and application of pressure forces water into the specimens 
- freezing for 4 hours

water expands on freezing causing more damage to the specimens

- oven drying for 6 hours at $60^{\circ} \mathrm{C}$

drying evaporates absorbed moisture causing thaw

Four different types of samples were subjected to accelerated aging:

(1) shear coupons of CCA treated wood with adhesive film between

the samples were aged to determine the strength of wood/adhesive bond or the extent of adhesion between the wood and adhesive under long-term exposure to atmospheric conditions

(2) sandwich shear coupons of CCA treated wood with adhesive film and glass fabric in between

these samples were aged to determine the strength of wood/FRP bond or the extent to which the adhesive bonds wood and glass fibers under long-term exposure to atmospheric conditions

(3) GFRP wrapped, CCA treated wooden dowel rods $\left(0.5^{\prime \prime}\right.$ in diameter)

these samples were aged to observe the changes in strength and modulus of GFRP wrapped posts under long-term exposure to atmospheric conditions

(4) GFRP wrapped, CCA treated rectangular wood samples $\left(50 \times 9 \times 4 \mathrm{~mm}^{3}\right)$

these samples were aged to predict the long-term behavior and service life of the proposed GFRP wrapped posts 


\subsection{Chemical Aging}

Use of de-icing salt in winter, moisture changes in the atmosphere, $\mathrm{pH}$ changes in the soil etc., motivate the need for a long-term aging in different liquid media. In the process of chemical aging, samples were immersed in liquid media of different $\mathrm{pH}$ and subjected to the Cyclic Temperature and Humidity Conditioning method. This method involved the exposure of samples to alternating cycles of high and freezing temperatures. These aging conditions were adopted to observe the effect of freeze/thaw cycling in different liquid media. The aging media were, acidic solution of $\mathrm{pH} 3$, alkaline solution of $\mathrm{pH} 13$, water and $3 \%$ salt water. Water and salt water are the most expected conditions in the field. To observe the effect of harsher environments, $\mathrm{pH} 3$ and $\mathrm{pH} 13$ solutions were selected. The equipment was the Thermotron Environmental Test Chamber (4800 Controller). The temperature and humidity changes in the environmental conditioning chamber are depicted in the Figure 4.1. The humidity was $100 \%$ for the current situation because all the samples were immersed in liquid.

The samples subject to 6-cycle accelerated aging and chemical aging were tested by suitable destructive and non-destructive tests. Details of test methods, results and data analysis are discussed in Chapters V through VII. 


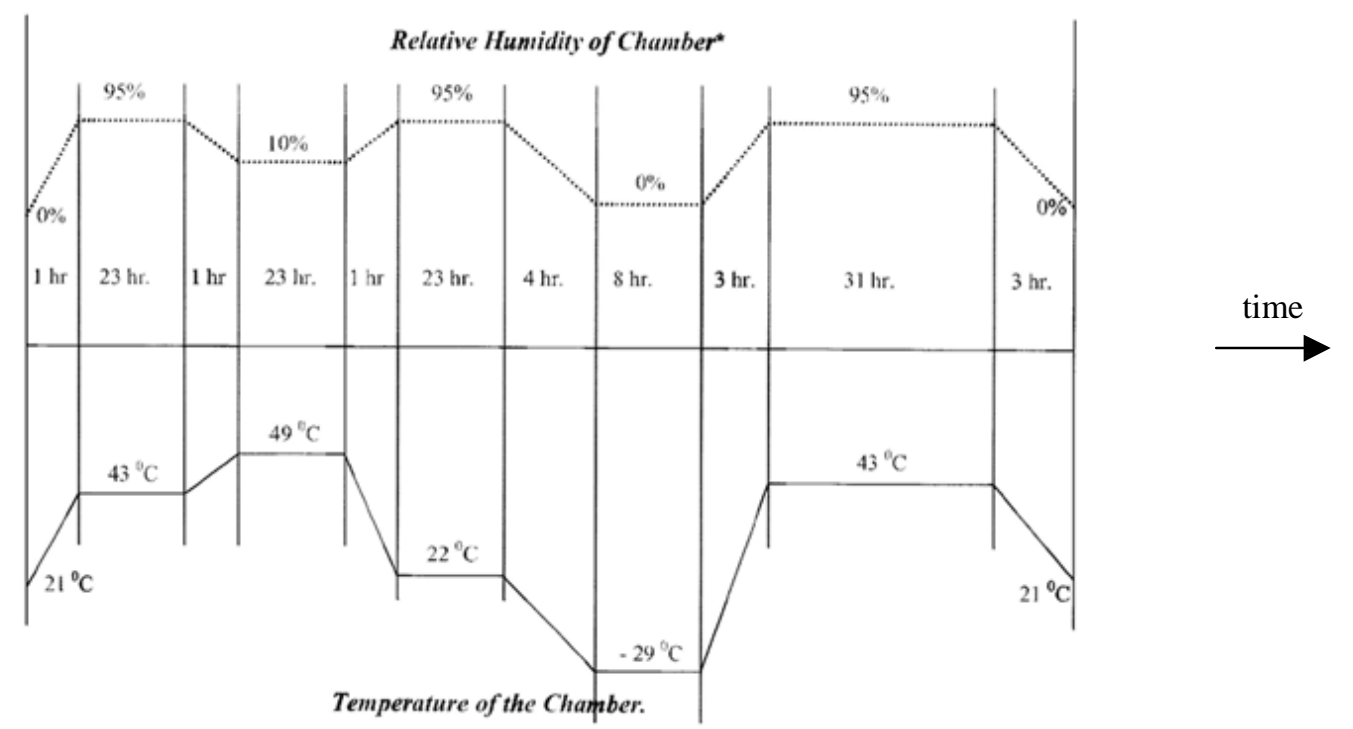

Figure 4.1: temperature and humidity variations in cyclic freeze-thaw conditioning 1 cycle $=121$ hrs $(5$ days +1 hour $)$

\subsection{Summary of Test Methods Used}

\begin{tabular}{|l|l|l|l|}
\hline Test & test type & Method used & Equipment used \\
\hline Shear loading & Destructive & Modified ASTM D-905 & Instron 1011 \\
\hline Flexural loading & Destructive & Modified ASTM D-790 & Instron 4411 \\
\hline Mechanical & Non-destructive & ---- & $\begin{array}{l}\text { Rheometrics } \\
\text { Spectrometer } \\
\text { RMS-800 }\end{array}$ \\
\hline $\begin{array}{l}\text { 6-cycle accelerated } \\
\text { aging }\end{array}$ & Destructive & Modified Chow cycle & Pressure Cylinder \\
\hline Chemical aging & Destructive & Cyclic temperature and & $\begin{array}{l}\text { Thermotron } \\
\text { humidity conditioning }\end{array}$ \\
& & $\begin{array}{l}\text { Tnvironmental } \\
\text { Test Chamber }\end{array}$ \\
\hline
\end{tabular}




\section{Chapter V}

\section{ADHESIVE SCREENING}

\subsection{Overview}

The integrity of the proposed GFW wood post depends largely on the wood/adhesive interface and adhesive/glass-fabric interface. Selection of an adhesive for wrapping glass fabric around a wood post was one of the primary tasks in this research. Six chemically different resins were screened to determine the adhesive that best adheres to CCA-treated wood and glass fibers. Adhesion to the wood surface in the presence of a primer was also investigated. This chapter presents details of sample preparation, the test procedure, different conditions of exposure and test results.

\subsection{Materials Used}

\subsubsection{Wood}

CCA treated southern-pine wood was used to prepare the experimental coupons. Southern pine is easily available and is most commonly used. Water based CCA is the most widely employed wood treatment that provides good resistance to termite attack. The wood was supplied by 84 Lumber (a local lumber company). 


\subsubsection{Glass Fibers}

A woven fabric $\left(0^{0} / 90^{\circ}\right)$, employing E-glass fibers was used in the preparation of sandwich coupons. The fabric incorporated an epoxy-compatible sizing and a phenoliccompatible sizing and was supplied by Johnston Industries. It had a density of 26 oz/sq.yd.

\subsubsection{Adhesives and Primers}

Table 5.1: Resins used in adhesive screening

\begin{tabular}{|l|l|l|}
\hline Resin & Trade Name & Supplier \\
\hline Epoxy & TYFO-S & Hexcel Fyfe \\
\hline Phenol resorcinol formaldehyde & G-1149 & BODEN Chemicals \\
\hline Resorcinol formaldehyde (RF) & G-1131 & BODEN Chemicals \\
\hline Polyester & Polylite & Reichhold \\
\hline Vinyl ester & --- & Creative Pultrusions \\
\hline Polyurethane & --- & Reichhold \\
\hline Phenol formaldehyde & G-1260 & BODEN Chemicals \\
\hline
\end{tabular}

Table 5.1 presents the list of adhesives used in the screening process. Epoxies, polyesters, urethanes and vinyl esters are the principal categories of thermosetting adhesives. Phenol resorcinol formaldehyde and resorcinol formaldehyde, are water-based phenolic adhesives that are widely used in structural applications.

A 5\% solution of HMR (hydroxy methylated resorcinol) in water, RF and G-1260 were used as primers. Most of the adhesives and primers were supplied in two 
components, which were mixed in the specified proportions before bonding. HMR was prepared in the laboratory. Ten grams of a 5\% HMR solution had the following composition:

water

crystalline resorcinol

$40 \%$ formaldehyde

sodium hydroxide
$9.043 \mathrm{~g}$

$0.379 \mathrm{~g}$

$0.334 \mathrm{~g}$

$\underline{0.244 g}$

$10.0 \mathrm{~g}$

These components were allowed to react for 4 hours and the primer was applied to wood surfaces 24 hours prior to adhesive bonding. RF was tested as a primer because of its low viscosity and wide use in structural applications. HMR was used as a primer because of its ability to produce moisture resistant bonds of epoxy and phenolic resins to CCA treated wood [18]. G-1260 was recommended by BODEN Chemicals, as a primer for the adhesive G-1149.

\subsection{Sample Preparation}

Shear block specimens were made using CCA treated wood and each of the six adhesives mentioned earlier. Two types of shear specimens were prepared. Type I (referred as shear coupons) consisted of two wood surfaces glued with an adhesive film in between. Type II (sandwich shear coupons) consisted of a resin-impregnated glassfabric sandwiched between two wood surfaces. Two wood blocks of size 8" X 3 " X $0.5^{\prime \prime}$ were used to make about 30 shear coupons each time. These wood blocks were sliced along the tangential or flat grain direction of $12^{\prime} \mathrm{X} 4^{\prime \prime} \mathrm{X} 2^{\prime \prime}$ lumber pieces. The wood 
blocks were air-sprayed to blow away dust particles on the surface. Primer was applied to the wood surfaces before application of adhesive according to the required specifications. For type I specimens, adhesive was prepared by mixing the components in the specified proportions and was uniformly applied to the surfaces with a metal spatula. For type II specimens, adhesive was prepared by mixing components in specified proportions. Glass fabric cut to the required size was then impregnated with the prepared adhesive and sandwiched between the wood surfaces. In both cases, the wood blocks were glued together following the open and closed assembly time recommended by the manufacturer. Pressure was then applied on the adhesive bonded assembly using a Baldwin machine. After pressure curing for the required time at room temperature, the bonded specimen was post cured in an oven at higher temperatures recommended by the manufacturer of the adhesive. The rectangular billet was cut into shear blocks of size

$0.75^{\prime \prime} \mathrm{X} 0.5^{\prime \prime} \mathrm{X} 0.5^{\prime \prime}$ using a band saw. Figure 5.1 shows the schematic of a rectangular billet and a shear coupon. 

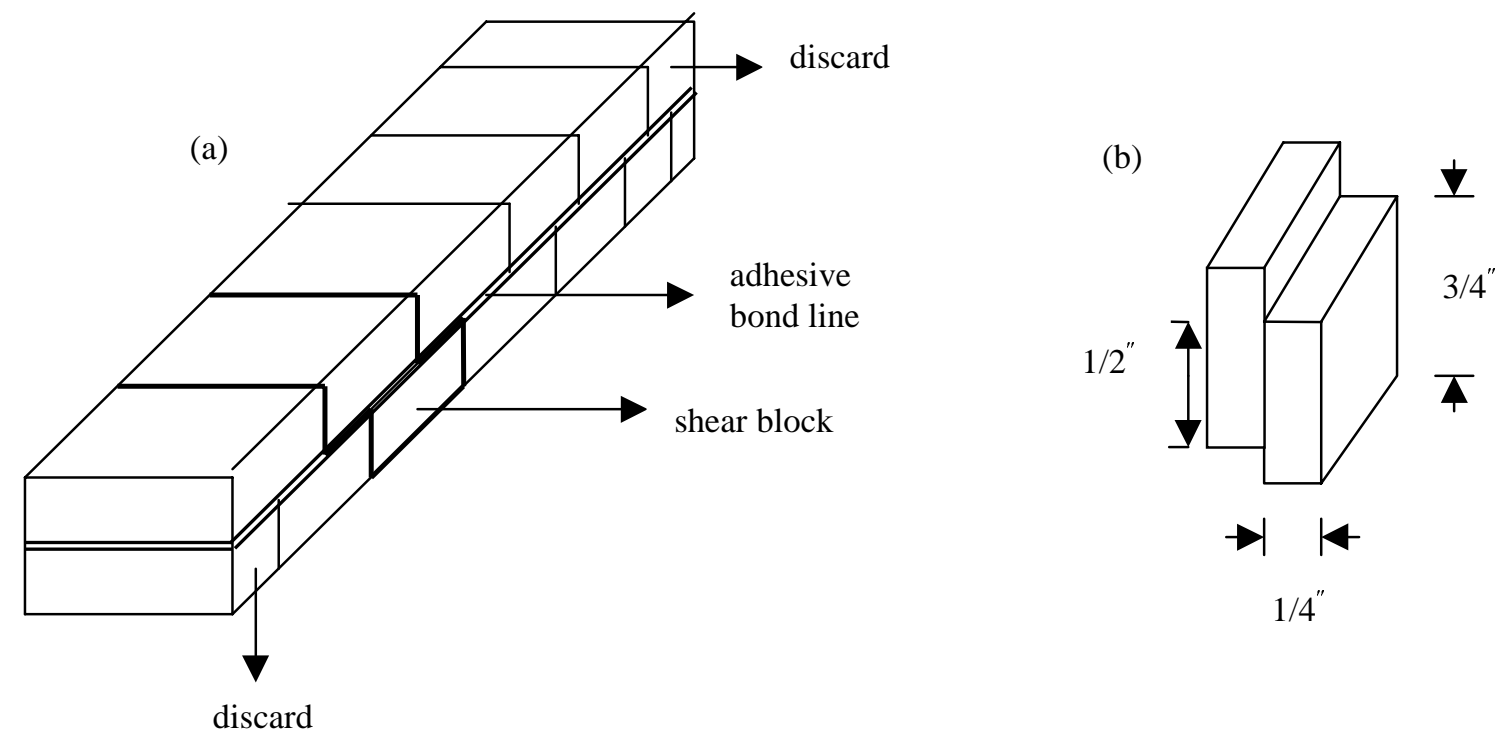

Figure 5.1: (a) rectangular billet with adhesive film in between (b) shear coupon

\subsection{Description of Test Procedure}

Shear loading introduces forces parallel to the plane of the bond line. These forces slide the substrates in opposite directions, loading the entire bonded area. Shear loading of an adhesive bond is therefore an effective measure of the performance of the wood/adhesive interface.

ASTM D-905 is a standard test method for evaluating the performance of wood adhesives based on the shear strength of the wood-wood bond. Therefore shear strength of adhesive bonds was determined using ASTM D-905 standard. The test results reveal the shear strength of the adhesive bond (as load per unit area of bond line in psi) and the percent wood failure (as percent of total fracture area). The failure is said to be cohesive if it is in wood or inside the adhesive film. The failure is said to be adhesive if it occurs at 
the wood/adhesive interface. The desired failure mode for the effectiveness of a wood/adhesive bond is cohesive. The following are the outlines of ASTM D-905:

(1) The apparatus used has a capacity greater than or equal to $15000 \mathrm{lbs}$ in compression and is fitted with a shearing tool that ensures uniform distribution of the load. The specimen is loaded at a uniform rate of $5 \mathrm{~mm} / \mathrm{min}$ with a maximum variation of $+25 \%$.

(2) Wood blocks used for making test specimens are cut to standard size (standard size for this test method being $\left.2^{\prime \prime} \mathrm{X} 0.75^{\prime \prime} \mathrm{X} 0.75^{\prime \prime}\right)$ to suit the dimensions of the shearing tool. These wood blocks are sanded and then air-sprayed to remove dust particles present on them.

(3) Samples are then cured based on curing time of adhesive used. The specimen is then placed in the shearing tool and loaded with a continuous motion of the movable head of the instrument at $5 \mathrm{~mm} / \mathrm{min}$ to failure. Shear stress at failure in pounds per square inch (psi) based on the glue-line area between laminations is calculated.

Precision of this test method is affected by (a) wood species (b) boards selected (c) grain direction (d) growth ring orientation (e) quality of bonded joint (f) condition of shear tool $(\mathrm{g})$ precision of shear tool and operator. Complete details of the testing method are given in "The 1995 Book of ASTM Standards," Vol. 15.06 [19].

In the current experimental work, an Instron machine (model 1011), with a capacity of $1000 \mathrm{lbs}$ was used for testing. In order to suit the capacity of the machine, sample size and cross head speed were modified. Size of shear specimens was $0.75^{\prime \prime} \mathrm{X}$ $0.5^{\prime \prime} \mathrm{X} 0.5^{\prime \prime}$ and cross-head speed was $0.5 \mathrm{in} / \mathrm{min}$. Figure 5.2 shows shear loading of a coupon. 


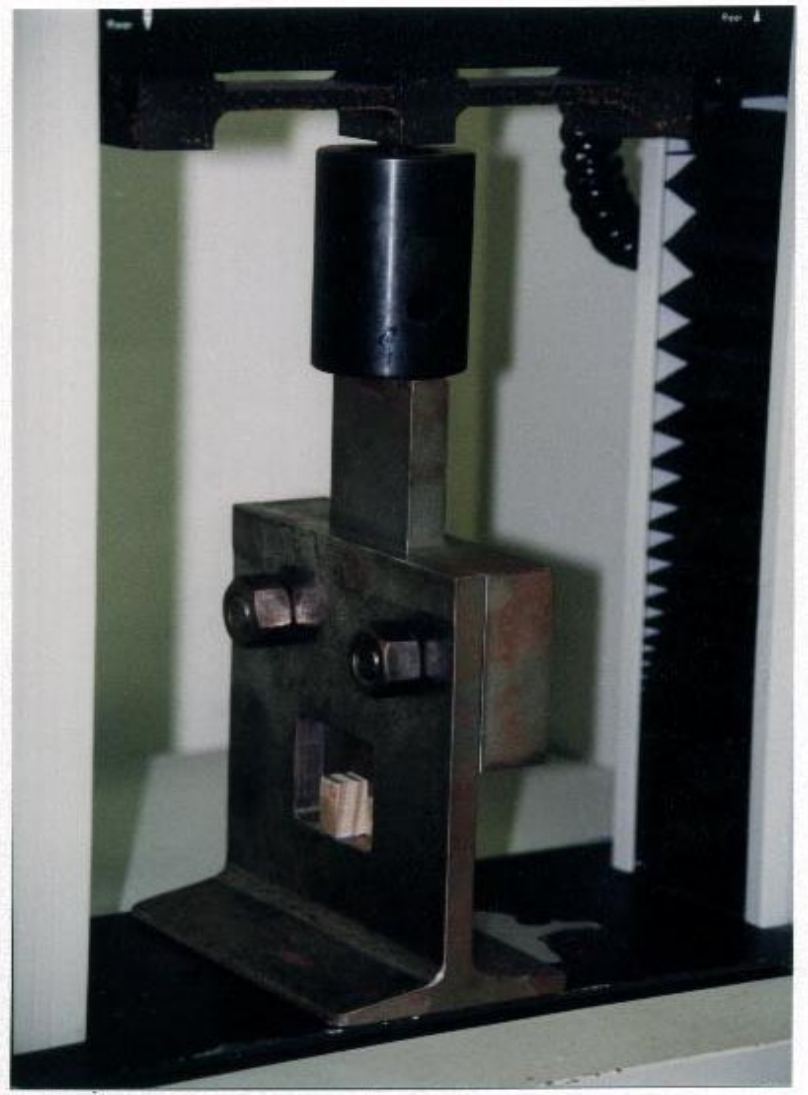

Figure 5.2: Measurement of shear strength by compressive shear loading

\subsection{Sample Conditioning}

Shear coupons were exposed to different conditions before testing:

(1) exposure to 6-cycle accelerated aging described in Section 4.2

(2) exposure to acidic aqueous solution of $\mathrm{pH} 3.0$ for 5 days, 15 days and 25 days in atmospheric chamber (described in Chapter IV, section 4.3) 
(3) exposure to alkaline aqueous solution of $\mathrm{pH} 13.0$ for 5 days, 15 days and 25 days in atmospheric chamber

(4) exposure to solution of $\mathrm{pH} 7.0$ for 5 days, 15 days and 25 days in atmospheric chamber

(5) exposure to $3 \%$ salt water for 5 days, 15 days and 25 days in atmospheric chamber The reasons for the choice of these aging conditions were explained in chapter IV.

\subsection{Summary of Test Results}

\subsubsection{Strength of Unprimed Adhesives at Different Pressures}

As the first step in the process of adhesive screening, shear coupons were prepared using epoxy, phenolic, RF and polyester resins at different curing pressures ranging from 100 psi to 250 psi. At pressures beyond 250 psi, excessive squeeze out of the adhesive took place and hence 250 psi was selected as the upper limit of pressure. The optimum curing pressure of each of these resins was determined. The results are presented in Tables 5.2 through 5.6. A sample calculation of shear strength from experimental data is presented in Appendix B.1. The percent wood failure is the amount of failure in wood. For a good bond between the wood and the adhesive, the desired failure is cohesive. A wood failure value of $100 \%$ indicates that the bonded specimen fails completely in wood and there is no failure at the wood/adhesive interface. The standard error is the value by which the shear strength varies about the average value. 
Table 5.2: Unaged shear strength of epoxy adhesive at varying pressure

\begin{tabular}{|l|l|l|l|l|l|}
\hline Adhesive & $\begin{array}{l}\text { Curing } \\
\text { pressure } \\
(\mathrm{psi})\end{array}$ & $\begin{array}{l}\text { Cure } \\
\text { time } \\
\text { (hours) }\end{array}$ & $\begin{array}{l}\text { No.of } \\
\text { samples } \\
\text { tested }\end{array}$ & $\begin{array}{l}\text { Average unaged } \\
\text { shear strength } \\
\pm \text { Standard error } \\
(\mathrm{psi})\end{array}$ & $\begin{array}{l}\text { Percent } \\
\text { wood } \\
\text { failure } \\
(\%)\end{array}$ \\
\hline Epoxy & 100 & 12 & 15 & $1265 \pm 212$ & 20 \\
\hline Epoxy & 150 & 12 & 15 & $1429 \pm 262$ & 59 \\
\hline Epoxy & 180 & 12 & 15 & $1401 \pm 224$ & 59 \\
\hline Epoxy & 220 & 12 & 15 & $1490 \pm 199$ & 61 \\
\hline Epoxy & 250 & 12 & 15 & $1897 \pm 163$ & 73 \\
\hline
\end{tabular}

Table 5.3: Unaged shear strength of unprimed phenolic adhesive at varying pressure

\begin{tabular}{|l|l|l|l|l|l|}
\hline Adhesive & $\begin{array}{l}\text { Curing } \\
\text { pressure } \\
(\mathrm{psi})\end{array}$ & $\begin{array}{l}\text { Cure } \\
\text { time } \\
\text { (hours) }\end{array}$ & $\begin{array}{l}\text { No.of } \\
\text { samples } \\
\text { tested }\end{array}$ & $\begin{array}{l}\text { Average unaged } \\
\text { shear strength } \\
\pm \text { Standard error } \\
(\mathrm{psi})\end{array}$ & $\begin{array}{l}\text { Percent } \\
\text { wood } \\
\text { failure } \\
(\%)\end{array}$ \\
\hline Phenolic & 100 & 12 & 10 & $1795 \pm 126$ & 68 \\
\hline Phenolic & 150 & 12 & 10 & $2098 \pm 245$ & 76 \\
\hline Phenolic & 180 & 12 & 10 & $2376 \pm 191$ & 70 \\
\hline Phenolic & 220 & 12 & 10 & $1795 \pm 152$ & 64 \\
\hline Phenolic & 250 & 12 & 10 & $1562 \pm 203$ & 50 \\
\hline
\end{tabular}


Table 5.4: Unaged shear strength of polyester adhesive at varying pressure

\begin{tabular}{|l|l|l|l|l|l|}
\hline Adhesive & $\begin{array}{l}\text { Curing } \\
\text { pressure } \\
(\mathrm{psi})\end{array}$ & $\begin{array}{l}\text { Cure } \\
\text { time } \\
\text { (hours) }\end{array}$ & $\begin{array}{l}\text { No.of } \\
\text { samples } \\
\text { tested }\end{array}$ & $\begin{array}{l}\text { Average unaged } \\
\text { shear strength } \pm \\
\text { Standard error } \\
(\mathrm{psi})\end{array}$ & $\begin{array}{l}\text { Percent } \\
\text { wood } \\
\text { failure } \\
(\%)\end{array}$ \\
\hline Polyester & 100 & 12 & 10 & $1335+120$ & 6 \\
\hline Polyester & 150 & 12 & 10 & $1327 \pm 109$ & 26 \\
\hline Polyester & 180 & 12 & 10 & $1565 \pm 114$ & 17 \\
\hline Polyester & 220 & 12 & 10 & $1581 \pm 138$ & 17 \\
\hline Polyester & 250 & 12 & 10 & $1917 \pm 170$ & 32 \\
\hline
\end{tabular}

Table 5.5: Unaged shear strength of $R F$ adhesive at varying pressure

\begin{tabular}{|l|l|l|l|l|l|}
\hline Adhesive & $\begin{array}{l}\text { Curing } \\
\text { pressure } \\
\text { (psi) }\end{array}$ & $\begin{array}{l}\text { Cure } \\
\text { time } \\
\text { (hours) }\end{array}$ & $\begin{array}{l}\text { No.of } \\
\text { samples } \\
\text { tested }\end{array}$ & $\begin{array}{l}\text { Average unaged } \\
\text { shear strength } \\
\pm \text { Standard error } \\
(\mathrm{psi})\end{array}$ & $\begin{array}{l}\text { Percent } \\
\text { wood } \\
\text { failure } \\
(\%)\end{array}$ \\
\hline RF & 100 & 12 & 20 & $1516 \pm 94$ & 58 \\
\hline RF & 150 & 12 & 20 & $1559 \pm 132$ & 56 \\
\hline RF & 180 & 12 & 20 & $1513 \pm 117$ & 48 \\
\hline RF & 220 & 12 & 20 & $1519 \pm 110$ & 50 \\
\hline RF & 250 & 12 & 20 & $1506 \pm 154$ & 60 \\
\hline
\end{tabular}

Table 5.6: Optimum curing pressure of adhesives (based on the average shear strength value at varying curing pressure)

\begin{tabular}{|l|l|}
\hline Adhesive & Optimum curing pressure (psi) \\
\hline Epoxy & 250 \\
\hline Phenolic & 180 \\
\hline RF & 250 \\
\hline Polyester & 250 \\
\hline
\end{tabular}




\subsubsection{Strength of Adhesives at Optimum Curing Pressure}

In the second step, shear coupons were made using different resins at their optimum curing pressures, and tested for shear strength and extent of failure in wood. The minimum cure time for all the resins was about 12 hours. However, curing for longer time does not hurt the adhesive bond performance. Table 5.7 displays the average shear strength and percent failure in wood of different shear coupons (wood/adhesive/wood specimens).

Table 5.7: Unaged shear strength of unprimed resins

\begin{tabular}{|c|c|c|c|c|c|c|c|c|c|}
\hline \multirow[t]{2}{*}{ Adhesive } & \multirow[t]{2}{*}{$\begin{array}{l}\text { Curing } \\
\text { pressure } \\
(\mathrm{psi})\end{array}$} & \multirow[t]{2}{*}{$\begin{array}{l}\text { Cure } \\
\text { time } \\
\text { (hours) }\end{array}$} & \multirow[t]{2}{*}{$\begin{array}{l}\text { No.of } \\
\text { samples } \\
\text { tested }\end{array}$} & \multicolumn{3}{|c|}{$\begin{array}{l}\text { Average unaged shear } \\
\text { strength } \pm \text { Standard error } \\
\text { (psi) }\end{array}$} & \multicolumn{3}{|c|}{$\begin{array}{l}\text { Percent wood } \\
\text { failure } \\
(\%)\end{array}$} \\
\hline & & & & Trial i & Trial ii & $\begin{array}{l}\text { Trial } \\
\text { iii }\end{array}$ & $\mathrm{i}$ & ii & iii \\
\hline Epoxy & 250 & 12 & 15 & $\begin{array}{l}2542 \\
\pm 219\end{array}$ & $\begin{array}{r}2580 \\
\pm 128\end{array}$ & $\begin{array}{l}2165 \\
+226\end{array}$ & 98 & 100 & 53 \\
\hline Phenolic & 180 & 48 & 10 & $\begin{array}{l}1757 \\
\pm 165\end{array}$ & $\begin{array}{r}1517 \\
\pm 130\end{array}$ & $\begin{array}{r}1450 \\
+125\end{array}$ & 90 & 89 & 88 \\
\hline Polyester & 250 & 24 & 15 & $\begin{array}{r}1050 \\
\pm 103\end{array}$ & $\begin{array}{r}1106 \\
+162\end{array}$ & $\begin{array}{l}1504 \\
+181\end{array}$ & 40 & 15 & 68 \\
\hline $\mathrm{RF}$ & 250 & 24 & 15 & $\begin{array}{r}2677 \\
\pm 93\end{array}$ & $\begin{array}{r}1498 \\
+146\end{array}$ & $\begin{array}{r}1457 \\
+139\end{array}$ & 72 & 45 & 99 \\
\hline Urethane & 250 & 48 & 15 & $\begin{array}{r}1343 \\
\pm 140\end{array}$ & --- & ---- & 92 & --- & --- \\
\hline Vinyl ester & 150 & 96 & 6 & $\begin{array}{l}156 \\
\pm 79\end{array}$ & ---- & ---- & 0 & ---- & --- \\
\hline
\end{tabular}


The failure of epoxy and phenolic adhered coupons was mostly in the wood. This suggests good bond formation of epoxy and phenolic resins with wood. RF and polyester adhered coupons exhibited brittle failure, which suggests a poor bond between the resins and wood. Poor bonding between polyester and wood could be due to insufficient penetration of the resin and also due to high volumetric shrinkage of polyester upon curing. Brittle failure or adhesive failure of RF bonds could also be due to poor penetration of RF into CCA treated wood. Urethane resin gave good failure in wood despite its very high viscosity. Most of the vinyl ester coupons delaminated during machining and the few that survived gave $100 \%$ adhesive failure. This eliminated the use of vinyl ester resin in further sample preparation.

\subsubsection{Strength of Adhesives in Combination with Different Primers}

Vick [13] showed that in the presence of HMR primer, adhesives such as epoxy, phenol-resorcinol-formaldehyde and phenolic-formaldehyde form durable bonds with CCA treated wood. Ghasemzadeh et al. [12] conducted chemical and hygrothermal aging of red oak wood-wood joints employing epoxy, polyester, polyurethane, RF and phenolic adhesives. They found the combination of epoxy as adhesive and RF as primer to be superior to all other adhesive/primer systems in terms of strength and durability.

In order to determine the effect of primer on the adhesive bond performance, epoxy, phenolic, $\mathrm{RF}$ and polyester resins were used in combination with different primers in preparing shear coupons. Urethane resin was not used in combination with a primer because of its very high viscosity, which would increase the thickness of the glueline, and ultimately reduce the bond strength. Tables 5.8 through 5.10 display the performance of 
wood/adhesive/wood bonds in the presence of different primers under dry conditions (before aging).

Table 5.8: Unaged shear strength of adhesives using HMR primer

\begin{tabular}{|c|c|c|c|c|c|c|c|c|c|}
\hline \multirow[t]{2}{*}{ Adhesive } & \multirow[t]{2}{*}{$\begin{array}{l}\text { Curing } \\
\text { pressure } \\
\text { (psi) }\end{array}$} & \multirow[t]{2}{*}{$\begin{array}{l}\text { Cure } \\
\text { time } \\
\text { (hours) }\end{array}$} & \multirow[t]{2}{*}{$\begin{array}{l}\text { No.of } \\
\text { samples } \\
\text { tested }\end{array}$} & \multicolumn{3}{|c|}{$\begin{array}{l}\text { Average shear strength } \\
\text { before aging } \pm \text { Standard } \\
\text { error (psi) }\end{array}$} & \multicolumn{3}{|c|}{$\begin{array}{l}\text { Percent wood } \\
\text { failure } \\
(\%)\end{array}$} \\
\hline & & & & Trial i & Trial ii & $\begin{array}{l}\text { Trial } \\
\text { iii }\end{array}$ & $\mathrm{i}$ & ii & iii \\
\hline Epoxy & 250 & 18 & 15 & $\begin{array}{r}2885 \\
+89\end{array}$ & $\begin{array}{l}2022 \\
\pm 205\end{array}$ & $\begin{array}{r}2143 \\
\pm 97\end{array}$ & 96 & 98 & 100 \\
\hline Phenolic & 180 & 18 & 15 & $\begin{array}{l}1224 \\
\pm 190\end{array}$ & $\begin{array}{l}1235 \\
+155\end{array}$ & --- & 84 & 92 & ---- \\
\hline Polyester & 250 & 18 & 15 & $\begin{array}{l}2341 \\
\pm 236\end{array}$ & $\begin{array}{l}975 \\
\pm 129\end{array}$ & ---- & 47 & 56 & --- \\
\hline $\mathrm{RF}$ & 250 & 18 & 15 & $\begin{array}{r}2880 \\
\pm 80\end{array}$ & $\begin{array}{l}2001 \\
\pm 154\end{array}$ & $\begin{array}{l}1461 \\
\pm 200\end{array}$ & 73 & 94 & 86 \\
\hline
\end{tabular}

From Tables 5.7 and 5.8 it can be seen that use of HMR primer increased the strength and cohesive failure of wood/RF/wood specimens under unaged conditions. In the presence of HMR primer, under unaged conditions, the strength of wood/phenolic/wood specimens was reduced and the percent failure in wood was not significantly affected. The effect of HMR on epoxy and polyester resins was not significant under unaged conditions. 
Table 5.9: Unaged shear strength of adhesives using RF primer

\begin{tabular}{|l|l|l|l|l|l|}
\hline Adhesive & $\begin{array}{l}\text { Curing } \\
\text { pressure } \\
(\mathrm{psi})\end{array}$ & $\begin{array}{l}\text { Cure } \\
\text { time } \\
\text { (hours) }\end{array}$ & $\begin{array}{l}\text { No.of } \\
\text { samples } \\
\text { tested }\end{array}$ & $\begin{array}{l}\text { Average shear strength } \\
\text { before aging } \pm \text { Standard } \\
\text { error }(\mathrm{psi})\end{array}$ & $\begin{array}{l}\text { Percent wood } \\
\text { failure } \\
(\%)\end{array}$ \\
\hline Epoxy & 250 & 18 & 12 & $1548 \pm 264$ & 20 \\
\hline Phenolic & 180 & 18 & 12 & $1500 \pm 271$ & 92 \\
\hline Polyester & 250 & 18 & 12 & $485 \pm 50$ & 1 \\
\hline
\end{tabular}

From Tables 5.7 and 5.9, it can be observed that polyester resin gave high adhesive failure and low shear strength with RF as primer. This could be due to high temperature post curing of RF and high volumetric shrinkage of polyester upon curing. Therefore this combination was eliminated from further testing. Epoxy resin showed reduced strength and reduced percent wood failure in the presence of RF primer under unaged conditions. This could be due to poor bonding between RF and epoxy, which resulted in increased adhesive failure. The effect of RF on phenolic resin under dry conditions was to increase the percent failure in wood or to increase the cohesive failure.

Table 5.10: Unaged shear strength of adhesives using G1260 primer

\begin{tabular}{|l|l|l|l|l|l|}
\hline Adhesive & $\begin{array}{l}\text { Curing } \\
\text { pressure } \\
(\mathrm{psi})\end{array}$ & $\begin{array}{l}\text { Cure } \\
\text { time } \\
\text { (hours) }\end{array}$ & $\begin{array}{l}\text { No.of } \\
\text { samples } \\
\text { tested }\end{array}$ & $\begin{array}{l}\text { Average shear strength } \\
\text { before aging } \pm \text { Standard } \\
\text { error }(\mathrm{psi})\end{array}$ & $\begin{array}{l}\text { Percent wood } \\
\text { failure } \\
(\%)\end{array}$ \\
\hline Epoxy & 180 & 18 & 12 & $1283 \pm 111$ & 11 \\
\hline Epoxy & 180 & 18 & 12 & $850 \pm 172$ & 18 \\
\hline Phenolic & 180 & 18 & 12 & $1290 \pm 121$ & 58 \\
\hline
\end{tabular}

From Tables 5.7 and 5.10, it is observed that use of G-1260 primer has reduced cohesive failure of wood/epoxy/wood bond. The high adhesive failure is attributed to a 
weak bond between wood and the combination of epoxy/G-1260. G-1260 is a highly viscous primer that could not have penetrated adequately into wood. Also, high viscosity of both G-1260 and epoxy could have increased the thickness of the glue-line resulting in high adhesive failure. G-1260 also reduced the strength of wood/phenolic/wood bond and gave highly brittle failures. Both the combinations, G-1260/epoxy and G-1260/phenolic were eliminated from further screening.

\subsubsection{Accelerated Aged Strength of Different Combinations}

After testing different primer/resin combinations and preliminary elimination, the remaining combinations were subjected to accelerated aging. During 6-cycle accelerated aging, samples were subjected to vacuum and pressure in water, followed by freezing and drying. The following table shows the unaged shear strength, aged shear strength (shear strength after 6-cycle accelerated aging) and percent decrease in strength after aging of various combinations: 
Table 5.11: Unaged and aged shear strength of different primer/resin combinations

\begin{tabular}{|l|l|l|l|l|l|l|}
\hline Adhesive & Primer & $\begin{array}{l}\text { Average } \\
\text { shear } \\
\text { strength } \\
\text { before aging } \\
\pm \quad \text { Standard } \\
\text { error (psi) }\end{array}$ & $\begin{array}{l}\text { Percent } \\
\text { failure } \\
\text { before } \\
\text { aging }\end{array}$ & $\begin{array}{l}\text { Average } \\
\text { shear } \\
\text { strength after } \\
\text { 6-cycle aging } \\
\pm \text { Standard } \\
\text { error (psi) }\end{array}$ & $\begin{array}{l}\text { Percent } \\
\text { failure } \\
\text { in } \\
\text { wood } \\
\text { after } \\
\text { aging }\end{array}$ & $\begin{array}{l}\text { Percent } \\
\text { decrease } \\
\text { in shear } \\
\text { strength } \\
\text { after } \\
\text { aging }\end{array}$ \\
\hline Epoxy & ----- & $2165 \pm 226$ & 53 & $765 \pm 147$ & 28 & 65 \\
\hline Epoxy & ----- & $1897 \pm 163$ & 73 & $737 \pm 117$ & 14 & 61 \\
\hline Epoxy & RF & $1548 \pm 264$ & 20 & $701 \pm 306$ & 22 & 55 \\
\hline Epoxy & HMR & $1934 \pm 158$ & 100 & $1356 \pm 137$ & 100 & 30 \\
\hline Epoxy & HMR & $2022 \pm 205$ & 98 & $1553 \pm 199$ & 100 & 23 \\
\hline Epoxy & HMR & $1342 \pm 121$ & 85 & $1096 \pm 159$ & 85 & 18 \\
\hline Epoxy & HMR & $1578 \pm 166$ & 100 & $1231 \pm 167$ & 99 & 22 \\
\hline Phenolic & ----- & $1884 \pm 185$ & 100 & $863 \pm 132$ & 100 & 54 \\
\hline Phenolic & ----- & $1450 \pm 125$ & 88 & $685 \pm 73$ & 42 & 53 \\
\hline Phenolic & RF & $1500 \pm 271$ & 92 & $572 \pm 109$ & 88 & 62 \\
\hline Phenolic & RF & $1701 \pm 150$ & 86 & $623 \pm 89$ & 89 & 63 \\
\hline Phenolic & HMR & $1224 \pm 190$ & 84 & $567 \pm 97$ & 54 & 54 \\
\hline Phenolic & HMR & $1235 \pm 155$ & 92 & $479 \pm 56$ & 98 & 61 \\
\hline RF & ----- & $1457 \pm 139$ & 99 & $819 \pm 170$ & 87 & 44 \\
\hline RF & ---- & $1519 \pm 110$ & 74 & $520 \pm 99$ & 43 & 66 \\
\hline RF & HMR & $1588 \pm 164$ & 97 & $867 \pm 104$ & 92 & 45 \\
\hline RF & HMR & $2001 \pm 154$ & 94 & $673 \pm 95$ & 90 & 66 \\
\hline RF & HMR & $1461 \pm 200$ & 86 & $496 \pm 73$ & 80 & 66 \\
\hline Polyester & ----- & $1050 \pm 103$ & 40 & $554 \pm 86$ & 41 & 47 \\
\hline Polyester & ----- & $1106 \pm 162$ & 15 & $269 \pm 64$ & 20 & 76 \\
\hline Polyurethane & ----- & $1343 \pm 140$ & 92 & $711 \pm 84$ & 25 & 47 \\
\hline----- & Wood & $2374 \pm 88$ & ----- & $1574 \pm 83$ & ----- & 34 \\
\hline
\end{tabular}


The factors that govern the selection of an adhesive or an adhesive/primer combination are percent wood failure, percent reduction in strength upon aging and shear strength. From table 5.11 it is understood that the reduction in strength after accelerated aging is minimum for HMR/epoxy combination. This reduction in strength of HMR/epoxy combination is less than the reduction in strength of wood itself. The magnitude of shear strength after accelerated aging is also maximum for the HMR/epoxy combination. The failure of wood/HMR/epoxy/HMR/wood bond, before and after aging is highly cohesive (100\% in wood). These results show that the combination of HMR as primer and epoxy as adhesive produces stronger bonds and desirable failures compared to other adhesive/primer systems.

In the case of phenolic resin, both HMR and RF primers do not significantly increase the strength retention upon aging. It seems like phenolic resin performs better without the use of a primer. The combination of RF and viscous phenolic resin increased the glueline thickness, which could have resulted in low strength and high adhesive failure. Low retention of shear strength of wood/phenolic/wood bond in presence of HMR primer, could be due to poor penetration of viscous phenolic resin into HMR primed wood.

The combination of HMR/RF shows high percent wood failure even though the reduction in strength due to accelerated aging is high. This suggests that HMR primer increases penetration of RF into CCA treated wood and produces high failure in wood. The percent failures in wood and the reduction in strength due to aging are similar for RF and phenolic resins. The similarity is found whether or not a primer is used. This can be attributed to the similar chemical nature of phenolic (phenol-resorcinol-formaldehyde) 
and RF (resorcinol-formaldehyde) resins. The combination of RF and epoxy shows low failures in wood even though the aged shear strength of the combination seems comparable to the aged shear strength of RF and phenolic resins.

Unprimed urethane resin, even though shows less than 50\% reduction in strength after aging, failed in adhesion (at the wood/urethane interface) after accelerated aging. Unprimed polyester resin also shows low shear strength and low failure in wood after aging.

As a result, unprimed urethane resin, unprimed polyester resin and the combination of RF/epoxy were eliminated from testing. For further investigation, epoxy, RF, phenolic resins and their combinations with HMR primer were tested for performance under water and saltwater conditions. This was done because water and salt water are the most likely conditions in the field. The coupons were immersed in water and 3\% salt water and subjected to freeze-thaw cycling. During freeze-thaw cycling, the samples immersed in liquid were exposed to temperatures between $-29^{\circ} \mathrm{C}$ and $50^{\circ} \mathrm{C}$ (see Section 4.3). The test results are presented in Tables 5.12 and 5.13. 
Table 5.12: Strength of different primer/resin combinations exposed to freeze-thaw cycling in water and $3 \%$ saltwater

\begin{tabular}{|c|c|c|c|c|c|c|c|c|c|c|}
\hline \multirow[t]{3}{*}{ Primer } & \multirow[t]{3}{*}{ Adhesive } & \multirow{3}{*}{$\begin{array}{l}\text { Average } \\
\text { shear } \\
\text { strength } \\
\text { before } \\
\text { aging } \pm \\
\text { Standard } \\
\text { error } \\
\text { (psi) }\end{array}$} & \multicolumn{8}{|c|}{ Aged shear strength \pm Standard error $(\mathrm{psi})$} \\
\hline & & & \multicolumn{4}{|c|}{ Water } & \multicolumn{4}{|c|}{$3 \%$ salt water } \\
\hline & & & $\begin{array}{l}5 \\
\text { days }\end{array}$ & $\begin{array}{l}15 \\
\text { days }\end{array}$ & $\begin{array}{l}25 \\
\text { days }\end{array}$ & $\mathrm{A}^{*}$ & $\begin{array}{l}5 \\
\text { days }\end{array}$ & $\begin{array}{l}15 \\
\text { days }\end{array}$ & $\begin{array}{l}25 \\
\text { days }\end{array}$ & $\mathrm{B}^{*}$ \\
\hline--- & Epoxy & $\begin{array}{r}1639 \\
+109\end{array}$ & $\begin{array}{r}1042 \\
+198\end{array}$ & $\begin{array}{r}905 \\
+18\end{array}$ & $\begin{array}{l}877 \\
\pm 274\end{array}$ & 46 & $\begin{array}{r}1416 \\
+482\end{array}$ & $\begin{array}{r}1205 \\
+152\end{array}$ & $\begin{array}{r}1248 \\
+254\end{array}$ & 24 \\
\hline--- & Phenolic & $\begin{array}{r}1884 \\
+185\end{array}$ & $\begin{array}{l}1320 \\
+59\end{array}$ & $\begin{array}{r}1221 \\
\pm 100\end{array}$ & $\begin{array}{r}1153 \\
+162\end{array}$ & 39 & $\begin{array}{r}1358 \\
+118\end{array}$ & $\begin{array}{l}1369 \\
+57\end{array}$ & $\begin{array}{r}1313 \\
\pm 138\end{array}$ & 30 \\
\hline---- & $\mathrm{RF}$ & $\begin{array}{r}1359 \\
+133\end{array}$ & $\begin{array}{r}1255 \\
+232\end{array}$ & $\begin{array}{l}948 \\
+144\end{array}$ & $\begin{array}{l}878 \\
+200\end{array}$ & 35 & $\begin{array}{r}1058 \\
+110\end{array}$ & $\begin{array}{l}946 \\
\pm 247\end{array}$ & $\begin{array}{l}870 \\
+129\end{array}$ & 36 \\
\hline HMR & Epoxy & $\begin{array}{r}1934 \\
+158\end{array}$ & $\begin{array}{r}1605 \\
\pm 245\end{array}$ & $\begin{array}{r}1447 \\
+114\end{array}$ & $\begin{array}{r}1290 \\
+123\end{array}$ & 33 & $\begin{array}{r}1604 \\
+100\end{array}$ & $\begin{array}{l}1541 \\
\pm 40\end{array}$ & $\begin{array}{r}1473 \\
+379\end{array}$ & 24 \\
\hline HMR & Phenolic & $\begin{array}{r}1235 \\
\pm 155\end{array}$ & $\begin{array}{l}1139 \\
\pm 84\end{array}$ & $\begin{array}{l}805 \\
\pm 129\end{array}$ & $\begin{array}{r}1063 \\
\pm 101\end{array}$ & 14 & $\begin{array}{r}1203 \\
\pm 201\end{array}$ & $\begin{array}{r}1212 \\
\pm 147\end{array}$ & $\begin{array}{r}1192 \\
\pm 146\end{array}$ & 3 \\
\hline HMR & $\mathrm{RF}$ & $\begin{array}{r}2001 \\
+154\end{array}$ & $\begin{array}{r}1221 \\
+226\end{array}$ & $\begin{array}{r}1089 \\
+218\end{array}$ & $\begin{array}{l}645 \\
\pm 291\end{array}$ & 68 & $\begin{array}{r}1083 \\
+246\end{array}$ & $\begin{array}{l}937 \\
\pm 106\end{array}$ & $\begin{array}{l}969 \\
+187\end{array}$ & 51 \\
\hline
\end{tabular}

$\mathrm{A}^{*}=\%$ reduction in shear strength after 25 days of freeze-thaw cycling in water $\mathbf{B}^{*}=\%$ reduction in shear strength after 25 days of freeze-thaw cycling in salt water 
Table 5.13: Wood failure of different primer/resin combinations exposed to freezethaw cycling in water and $3 \%$ saltwater

\begin{tabular}{|c|c|c|c|c|c|c|c|c|}
\hline \multirow[t]{3}{*}{ Primer } & \multirow[t]{3}{*}{ Adhesive } & \multirow{3}{*}{$\begin{array}{l}\text { Wood failure } \\
\text { before aging } \\
(\%)\end{array}$} & \multicolumn{6}{|c|}{ Wood failure after aging (\%) } \\
\hline & & & \multicolumn{3}{|c|}{ Water } & \multicolumn{3}{|c|}{$3 \%$ salt water } \\
\hline & & & $\begin{array}{l}5 \\
\text { days }\end{array}$ & $\begin{array}{l}15 \\
\text { days }\end{array}$ & $\begin{array}{l}25 \\
\text { days }\end{array}$ & $\begin{array}{l}5 \\
\text { days }\end{array}$ & $\begin{array}{l}15 \\
\text { days }\end{array}$ & $\begin{array}{l}25 \\
\text { days }\end{array}$ \\
\hline--- & Epoxy & 100 & 0 & 0 & 2 & 28 & 32 & 25 \\
\hline --- & Phenolic & 100 & 76 & 31 & 47 & 75 & 72 & 49 \\
\hline--- & $\mathrm{RF}$ & 76 & 48 & 95 & 57 & 66 & 87 & 35 \\
\hline HMR & Epoxy & 100 & 89 & 96 & 92 & 75 & 93 & 89 \\
\hline HMR & Phenolic & 92 & 92 & 75 & 37 & 91 & 63 & 44 \\
\hline HMR & $\mathrm{RF}$ & 94 & 37 & 49 & 33 & 83 & 100 & 68 \\
\hline
\end{tabular}

Under accelerated aging conditions (Table 5.11), wood/HMR/RF/HMR/wood coupons showed slightly greater cohesive failure compared to wood/RF/wood coupons. The effect of HMR on reduction of strength due to aging was not clear. From Table 5.12, it is seen that wood/RF bond performs slightly better with the use of HMR primer when it is exposed to freeze-thaw under water and salt water conditions.

Under accelerated aging conditions (Table 5.11), both wood/phenolic/wood coupons, and wood/HMR/phenolic/HMR/wood coupons showed high reduction in strength due to aging. From Table 5.12 it can be seen that HMR greatly improves the retention of strength of wood/phenolic bond when exposed to freeze-thaw under water and saltwater. However the shear strength of wood/HMR/phenolic/HMR/wood coupons is lower than the strength wood/HMR/phenolic/HMR/wood coupons. This suggests that in the absence of HMR, the penetration of phenolic resin is low even though the shear strength of the wood/phenolic bond is high. Considering retention to be more important 
than the magnitude of shear strength, it is predicted that the wood/HMR/phenolic bond performs better than wood/phenolic bond under long-term aging.

Tables 5.11 and 5.12 show that wood/HMR/epoxy/HMR/wood performs better than the wood/epoxy/wood bond under accelerated aging conditions and also freeze-thaw cycling under water and saltwater conditions.

It can be observed from Table 5.13 that the combination of HMR and epoxy gave relatively high failure in wood.

\subsubsection{Strength of Sandwich Samples}

From the results of section 5.6.4, HMR/epoxy emerged as the best possible combination that produces strong and durable bonds to wood under accelerated aging conditions. HMR/phenolic and HMR/RF combinations displayed the next best performance. The next step was to select the primer/resin system that adheres well to glass fibers. To keep the experimental effort manageable, sandwich samples were prepared using HMR/epoxy and HMR/phenolic only. Also because phenolic and RF resins are similar in chemical nature, use of one of these resins was considered reasonable. Sandwich samples were prepared using the two combinations and subjected to 6-cycle accelerated aging. 
Table 5.14 : Shear strength of sandwiches prepared with chosen combination(s)

\begin{tabular}{|c|c|c|c|c|c|c|}
\hline Primer & Adhesive & $\begin{array}{l}\text { Average } \\
\text { shear } \\
\text { strength } \\
\text { before aging } \\
\pm \quad \text { Standard } \\
\text { error (psi) }\end{array}$ & $\begin{array}{l}\text { Percent } \\
\text { failure } \\
\text { in } \\
\text { wood } \\
\text { before } \\
\text { aging }\end{array}$ & $\begin{array}{l}\text { Average shear } \\
\text { strength after } \\
\text { 6-cycle aging } \pm \\
\text { Standard error } \\
\text { (psi) }\end{array}$ & $\begin{array}{l}\text { Percent } \\
\text { failure } \\
\text { in } \\
\text { wood } \\
\text { after } \\
\text { aging }\end{array}$ & $\begin{array}{l}\text { Percent } \\
\text { decrease } \\
\text { in shear } \\
\text { strength } \\
\text { after } \\
\text { aging }\end{array}$ \\
\hline HMR & Epoxy & $2222 \pm 250$ & 100 & $1325 \pm 141$ & 100 & 40 \\
\hline HMR & Epoxy & $1726 \pm 234$ & 99 & $1240 \pm 152$ & 100 & 28 \\
\hline HMR & Phenolic & $1268 \pm 120$ & 33 & $532 \pm 62$ & 20 & 58 \\
\hline
\end{tabular}

Glass fabric with a density of $26 \mathrm{oz} / \mathrm{sq} . \mathrm{yd}$ and corresponding (epoxy compatible or phenolic compatible, as appropriate) sizing was used in the preparation of sandwich samples. Table 5.13 shows that the wood/HMR/epoxy/glass/epoxy/HMR/wood bond retains greater strength compared to the wood/HMR/phenolic/glass/phenolic/HMR/wood bond under accelerated aging conditions. Also, the failure of the wood/HMR/epoxy/glass/epoxy/HMR/wood bond was completely in the wood (cohesive). The failure of the wood/HMR/phenolic /glass/phenolic/HMR/wood bond was partially inside the sandwiched fabric and partially at the wood/sandwich interface. This could be due to improper wetting of fabric by the viscous phenolic resin or poor bond between phenolic resin and glass fabric. The use of higher volume of resin for increased wetting would increase the glueline thickness. Longer assembly time for increased fabric wetting would build up the resin viscosity and reduce penetration of the resin into wood. Observation of fractured surfaces also showed that the thread used in stitching of the glass fabric prevented proper adhesion of the resin to glass fibers.

From sections 5.6.4 and 5.6.5, it was concluded that HMR/epoxy has the 
advantages of high retention of shear strength after aging and high cohesive failure in wood compared to all other combinations. In other words, the combination of HMR as the primer and epoxy as the adhesive provides the best possible adhesion to glass fibers and CCA treated wood.

\subsubsection{Chemical Reactions at Wood/Adhesive Interface}

The quality of the wood/adhesive bond largely depends on the viscosity and chemical nature of the adhesive, curing conditions and the preservative treatment given to the wood. Wood cellulose and lignin are rich in $\mathrm{CH}_{2} \mathrm{OH}$ and $\mathrm{OH}$ groups, which are capable of forming ether linkages and hydrogen bonds with the polar groups of the adhesives. During the treatment of wood with CCA, metallic oxides of $\mathrm{Cr}, \mathrm{Cu}$ and $\mathrm{As}$ are produced on the wood surface. These non-polar deposits block the polar, hydrophilic bonding sites of cellulose and lignin present in wood. The bonded CCA reduces intermolecular forces of attraction between the wood surface and the adhesives. This is assumed to be the reason for poor adhesion of most of the thermosetting adhesives to CCA treated wood.

Vick [9] demonstrated that adhesives such as epoxy, phenol-resorcinolformaldehyde and resorcinol-formaldehyde develop strong and durable bonds to CCA treated wood in the presence of HMR primer. Figure 5.3 shows the chemical linkages formed by epoxy resin and wood. 


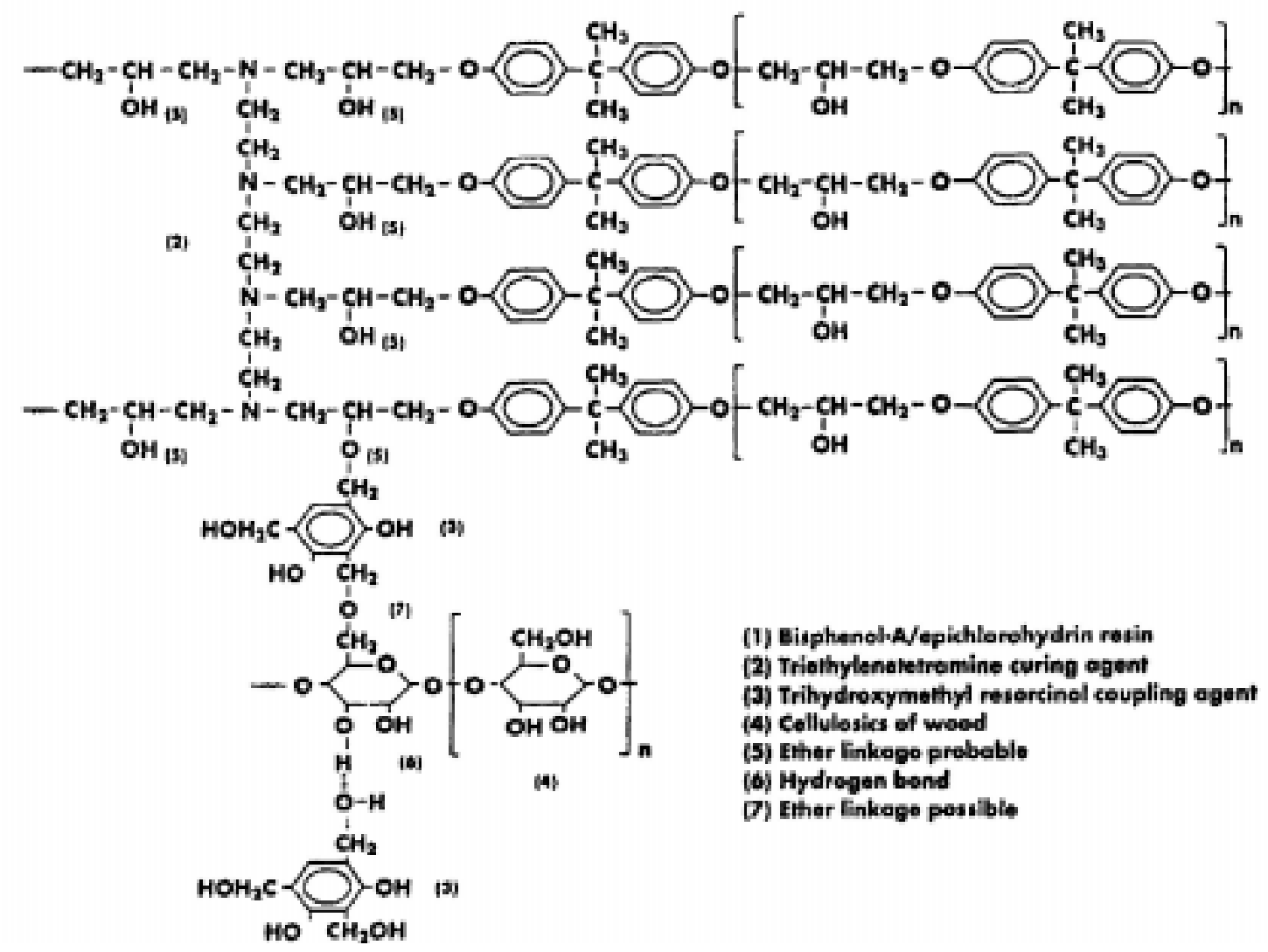

Figure 5.3: Covalent and hydrogen bonding of HMR with epoxy resin and cellulosics of wood [9]

From Figure 5.3 it can be seen that $\mathrm{CH}_{2} \mathrm{OH}$ groups on the primer can condense with $\mathrm{OH}$ groups on epoxy resin and form ether linkages. $\mathrm{CH}_{2} \mathrm{OH}$ groups on the primer can form ether linkages with $\mathrm{CH}_{2} \mathrm{OH}$ groups and hydrogen bonds with $\mathrm{OH}$ groups on wood. These chemical bond forces are responsible for the high retention of shear strength of the wood/HMR/epoxy/HMR/wood specimens subjected to accelerated aging and freeze-thaw cycling.

Phenol-resorcinol-formaldehyde resin is rich in $\mathrm{OH}$ and $\mathrm{CH}_{2} \mathrm{OH}$ groups and can also form similar linkages with HMR primed wood. It was observed (from Table 5.12) that the retention of shear strength of the wood/HMR/phenolic bond was higher than the 
wood/phenolic bond under freeze-thaw conditions. The magnitude of strength of the wood/HMR/phenolic bond was lower than the strength of the wood/phenolic bond under freeze-thaw cycling and also accelerated aging conditions. This suggests that in the presence of HMR primer, the durability of the wood/phenolic bond is increased (moisture resistance is increased) but the strength is reduced. This could be related to the $\mathrm{pH}$ of HMR primed wood and the hydrophilic nature of the wood/adhesive interface.

Resorcinol-formaldehyde resin can also form ether linkages and hydrogen bonds with HMR. Though the shear strength of the wood/RF bond increased (Tables 5.11 and 5.12) with the use of HMR primer, the retention of strength did not increase. This suggests that HMR increases the strength but not the durability of wood/RF bond.

\subsubsection{Performance of Chosen Combination under 6-cycle Accelerated Aging}

Due to the high retention of shear strength after accelerated aging, high failure in wood and relatively high values of aged shear strength, HMR/epoxy was chosen as the primer/resin combination that would be used for composite wrapping of wood posts. To study the bond performance with progressive aging, sandwich samples prepared using HMR/epoxy combination were tested after each cycle of the 6-cycle accelerated aging. 
Table 5.15: Performance of wood/HMR/epoxy/glass/epoxy/HMR/wood sandwich samples exposed to 6-cycle aging

\begin{tabular}{|c|c|c|c|c|c|c|c|c|}
\hline \multirow[t]{2}{*}{ Primer } & \multirow[t]{2}{*}{ Adhesive } & \multirow{2}{*}{$\begin{array}{l}\text { Unaged } \\
\text { shear } \\
\text { strength } \pm \\
\text { Standard } \\
\text { error (psi) }\end{array}$} & \multicolumn{6}{|c|}{ Aged shear strength \pm Standard error $(\mathrm{psi})$} \\
\hline & & & $\begin{array}{l}\text { cycle } \\
1\end{array}$ & $\begin{array}{l}\text { cycle } \\
2\end{array}$ & $\begin{array}{l}\text { cycle } \\
3\end{array}$ & $\begin{array}{l}\text { cycle } \\
4\end{array}$ & $\begin{array}{l}\text { cycle } \\
5\end{array}$ & $\begin{array}{l}\text { cycle } \\
6\end{array}$ \\
\hline HMR & Epoxy & $\begin{array}{r}2570 \\
\pm 304\end{array}$ & $\begin{array}{l}1717 \\
\pm 197\end{array}$ & $\begin{array}{r}1607 \\
+234\end{array}$ & $\begin{array}{r}1659 \\
\pm 80\end{array}$ & $\begin{array}{r}1596 \\
\pm 188\end{array}$ & $\begin{array}{r}1375 \\
\pm 85\end{array}$ & $\begin{array}{r}1497 \\
+70\end{array}$ \\
\hline \multicolumn{2}{|c|}{ Wood failure (\%) } & 97 & 97 & 92 & 96 & 85 & 93 & 91 \\
\hline \multicolumn{2}{|c|}{$\begin{array}{l}\text { Reduction in strength } \\
\text { due to aging }(\%)\end{array}$} & ----- & 33 & 38 & 35 & 38 & 46 & 42 \\
\hline
\end{tabular}

The decrease in strength of sandwich shear samples was found to be maximum after the first cycle in the 6-cycle aging process. The strength decreased gradually from cycle 2 to cycle 5 and increased between cycle 5 and cycle 6 . The increase in strength between cycle 5 and cycle 6 may be considered as erroneous data. Due to the 6-cycle accelerated aging, there was about $45 \%$ reduction in shear strength of the wood/HMR/epoxy/glass/epoxy/HMR/wood specimens. Since the 6-cycle aging simulates about 20 years of natural aging, this means that after a service life of approximately 20 years in the field, the strength of the wood/HMR/epoxy/glass bond would be half of the original strength. Flexural tests of wrapped dowels (representing a scaled down version of the guard-rail posts) reveal the change in mechanical properties due to aging. These data are presented in chapter VI. 


\subsubsection{Performance of Chosen Combination under Chemical Aging}

The 6-cycle accelerated aging was used to predict durability. Freeze-thaw cycling in chemical solutions was conducted to observe the effect of different high and low temperature liquid media on the wood/HMR/epoxy interface and the wood/HMR/epoxy/glass interface(s). Shear coupons (sandwich and non-sandwich) prepared using HMR/epoxy combination were subjected to freeze thaw cycles in water, salt water, acidic and alkaline solutions.

Table 5.16: Shear strength of wood/HMR/epoxy/glass/epoxy/HMR/wood sandwiches exposed to different conditions

\begin{tabular}{|c|c|c|c|c|c|c|c|}
\hline Medium & $\begin{array}{l}\text { Shear } \\
\text { strength } \\
\text { after } 5 \text { days } \\
\text { of aging } \pm \\
\text { Standard } \\
\text { error (psi) }\end{array}$ & $\mathrm{A}^{*}$ & $\begin{array}{l}\text { Shear } \\
\text { strength } \\
\text { after } 15 \\
\text { days of } \\
\text { aging } \quad \pm \\
\text { Standard } \\
\text { error (psi) }\end{array}$ & $\mathrm{B}^{*}$ & $\begin{array}{ll}\text { Shear } & \\
\text { strength } & \\
\text { after } & 25 \\
\text { days } & \text { of } \\
\text { aging } & \pm \\
\text { Standard } & \\
\text { error (psi) } & \end{array}$ & $\mathrm{C}^{*}$ & $\begin{array}{l}\% \\
\text { reduction } \\
\text { in } \\
\text { strength } \\
\text { after } 25 \\
\text { days of } \\
\text { aging }\end{array}$ \\
\hline Unaged & \multicolumn{6}{|c|}{$2222 \pm 250(100 \%)$} & $\begin{array}{ll}---- \\
\end{array}$ \\
\hline $\begin{array}{l}\text { Accelerated } \\
\text { aging }\end{array}$ & \multicolumn{6}{|c|}{$1325 \pm 141(100 \%)$} & 40 \\
\hline $\mathrm{pH} 3$ & $1497 \pm 337$ & 100 & $\begin{array}{ll}---- \\
\end{array}$ & ----- & $990 \pm 355$ & 100 & 55 \\
\hline $\mathrm{pH} 13$ & $878 \pm 54$ & 100 & $\begin{array}{l}---- \\
\end{array}$ & $\begin{array}{ll}---- \\
\end{array}$ & $654 \pm 132$ & 100 & 70 \\
\hline $\mathrm{pH} 7$ & $1442 \pm 363$ & 100 & $1422 \pm 319$ & 97 & $1008 \pm 197$ & 100 & 55 \\
\hline $\begin{array}{ll}\% & \text { salt } \\
\text { water } & \end{array}$ & $1367 \pm 232$ & 100 & $1130 \pm 188$ & 100 & $867 \pm 98$ & 97 & 61 \\
\hline
\end{tabular}

$A^{*}=\%$ wood failure after 5 days of aging

$\mathrm{B}^{*}=\%$ wood failure after 15 days of aging

$\mathrm{C}^{*}=\%$ wood failure after 25 days of aging 
Table 5.17: Shear strength of wood/HMR/epoxy/HMR/wood samples exposed to different conditions

\begin{tabular}{|c|c|c|c|c|c|c|c|}
\hline Medium & $\begin{array}{l}\text { Shear } \\
\text { strength } \\
\text { after } 5 \text { days } \\
\text { of aging } \pm \\
\text { Standard } \\
\text { error (psi) }\end{array}$ & $\mathrm{A}^{*}$ & \begin{tabular}{ll}
\multicolumn{2}{l}{ Shear } \\
strength \\
after 15 \\
days of \\
aging $\quad \pm$ \\
Standard \\
error (psi)
\end{tabular} & $\mathrm{B}^{*}$ & $\begin{array}{ll}\begin{array}{l}\text { Shear } \\
\text { strength }\end{array} \\
\text { after } & 25 \\
\text { days } \quad \text { of } \\
\text { aging } \quad \pm \\
\text { Standard } \\
\text { error (psi) }\end{array}$ & $\mathrm{C}^{*}$ & $\begin{array}{l}\% \\
\text { reductio } \\
\mathrm{n} \quad \text { in } \\
\text { strength } \\
\text { after } 25 \\
\text { days of } \\
\text { aging }\end{array}$ \\
\hline Unaged & \multicolumn{6}{|c|}{$1934 \pm 158(100 \%)$} & $\begin{array}{l}---- \\
\end{array}$ \\
\hline $\begin{array}{l}\text { Accelerated } \\
\text { aging }\end{array}$ & \multicolumn{6}{|c|}{$1356 \pm 137(100 \%)$} & 30 \\
\hline $\mathrm{pH} 3$ & $1719 \pm 199$ & 100 & $1532 \pm 105$ & 100 & $1265 \pm 304$ & 100 & 34 \\
\hline pH 13 & $1107 \pm 150$ & 100 & $881 \pm 80$ & 100 & $791 \pm 26$ & 77 & 59 \\
\hline pH 7 & $1605 \pm 245$ & 89 & $1447 \pm 114$ & 96 & $1290 \pm 123$ & 92 & 33 \\
\hline $\begin{array}{ll}3 \% & \text { salt } \\
\text { water } & \end{array}$ & $1604 \pm 100$ & 75 & $1541 \pm 40$ & 93 & $1473 \pm 379$ & 89 & 24 \\
\hline
\end{tabular}

Data of Tables 5.16 and 5.17 reveal the damage caused to the wood/HMR/epoxy/glass fabric bond is greater than the damage caused to the wood/HMR/epoxy bond in all aging media. This is due to the degradation of both the wood/adhesive interface and the adhesive/glass interface in the wood/HMR/epoxy/glass/epoxy/HMR/wood specimens. Based on the average shear strength value after aging, it is found that the degradation of the wood/HMR/epoxy bond strength is similar in acidic and neutral media. However, based on the standard error and wood failure values, the acidic medium seems slightly more damaging than neutral medium. The degradation was maximum in alkaline medium of $\mathrm{pH} 13$. Degradation of 
the wood/HMR/epoxy/glass fabric bond strength is also similar in acidic and neutral media. Maximum degradation of the wood/HMR/epoxy/glass fabric bond was in alkaline medium of $\mathrm{pH} 13$ followed by salt water. Under accelerated aging conditions (from Tables 5.11 through 5.16), it is observed that the strength of the wood/HMR/epoxy/glass bond reduced by 28 - $42 \%$ while the strength of wood reduced by $34 \%$. However, the strength of the wood/HMR/epoxy bond reduced only by $30 \%$, suggesting that the wood/HMR/epoxy bond is at least as strong as wood itself and the wood/HMR/epoxy/glass bond is almost as strong as wood. Also the wood failure of wood/HMR/epoxy/glass/epoxy/HMR/wood samples due to freeze-thaw cycling in all aging media was $97-100 \%$ (Table 5.16). This suggests that wood is damaged more than the wood/HMR/epoxy/glass fabric bond in all the aging media. However, the wood failure of wood/HMR/epoxy/HMR/wood samples (Table 5.17) show that alkaline medium and salt water damage the wood/HMR/epoxy bond.

Lhymn and Schultz [14] studied the stress corrosion of glass/PET composites under acidic, alkaline and salt water conditions. They concluded that acids $\left(10 \% \mathrm{HNO}_{3}\right.$, $\left.10 \% \mathrm{HCl}, 10 \% \mathrm{H}_{2} \mathrm{SO}_{4}\right)$ attack glass fibers the most and alkali $(10 \% \mathrm{NaOH})$ attacks the matrix the most. Maximum damage to the composite was caused by alkali $(10 \% \mathrm{NaOH})$ and the least damage was caused by $10 \% \mathrm{NaCl}$ solution.

Kajorncheappunngam [20] studied the aging effects of epoxy resin and glass/epoxy composites in acidic, alkaline, water and salt water media. She found that at high temperatures, minimum damage to the composite was caused by salt water and maximum damage was caused by alkaline medium. From SEM observation of aged samples she proposed that the alkaline medium primarily damages the epoxy matrix and 
glass/epoxy interface.

Based on the experimental results and literature survey, the following conclusions are drawn:

In freeze-thaw cycling, samples are exposed to high temperature liquid $\left(50{ }^{0} \mathrm{C}\right)$ and low temperature liquid $\left(-29{ }^{0} \mathrm{C}\right)$. At low temperature, all the absorbed solutions expand and damage the wood and probably the glass/epoxy interface. The effect of all solutions is assumed to be similar during freezing. At high temperature, the damage effects are increased due to increased liquid diffusion into the specimen. The alkaline medium attacks the epoxy matrix, the wood, the wood/HMR/epoxy bond and also damages the glass/epoxy interface, producing maximum degradation of the wood/HMR/epoxy/glass/epoxy/HMR/wood specimens. $\mathrm{H}^{+}$ions from water and acid attack the glass fiber surface and undergo ion exchange reaction with the $\mathrm{OH}$ groups on the glass fibers and primarily damage the glass/epoxy interface. Water also plasticizes the epoxy matrix and damages the wood/HMR/epoxy interface. Salt water damages the wood/HMR/epoxy interface.

\subsection{Summary}

Screening of six resins and three primers showed that the combination of HMR primer and epoxy adhesive provides the best possible adhesion to glass fibers and CCA treated wood. Under accelerated aging conditions, the wood/HMR/epoxy bond is at least as strong as wood and the wood/HMR/epoxy/glass bond is almost as strong as wood. Chemical aging showed that in acid medium, wood, glass fibers and the epoxy/glass interface are primarily damaged. In alkaline medium, the epoxy matrix, the wood, the 
wood/HMR/epoxy bond and the epoxy/glass interface are damaged. In salt water, the wood/HMR/epoxy interface is damaged the most. Water damages the wood/HMR/epoxy bond, the glass fibers and the epoxy/glass interface. Maximum damage to the wood/HMR/epoxy/glass/epoxy/HMR/wood sandwich samples and the wood/HMR/epoxy/HMR/wood samples is caused by alkaline medium. 


\section{Chapter VI}

\section{STRENGTH AND STIFFNESS EVALUATION OF WRAPPED POSTS}

\subsection{Overview}

The values of the ultimate flexural strength and modulus of a wrapped post are essential to properly establish the dynamic response of the proposed GFW guard-rail post. HMR primed wood posts wrapped with epoxy impregnated glass fabric were evaluated using flexure tests. This chapter presents the details of materials employed, sample preparation, test procedure and data analysis.

\subsection{Materials Used}

A CCA treated southern pine dowel of diameter $0.5^{\prime \prime}$ was used as the core in the preparation of test specimens. The surface of the dowel was primed with HMR,

24 hours prior to wrapping the core with glass fabric. A woven fabric $\left(0^{0} / 45^{0}\right)$, employing E-glass fibers with epoxy compatible sizing was used for wrapping. The fabric was supplied by Johnston Industries and had a density of 12oz/sq.yd. Epoxy (TYFO-S) supplied by Hexcel Fyfe (now Fyfe Co) was used as the adhesive.

\subsection{Sample Preparation}

The set up for wrapping the posts consisted of a banding machine, glass fabric ribbon (2.5" wide) supported on a stand and a resin bath with a fiber guide. A primed wooden dowel of diameter 0.5 " was mounted on the machine between the jaws, one of which is fixed and the other adjustable. The fabric ribbon passing through the resin bath 
was wrapped on the dowel by rotating the dowel at constant speed. Figure 6.1 shows the set up for wrapping the CCA treated dowel rods.

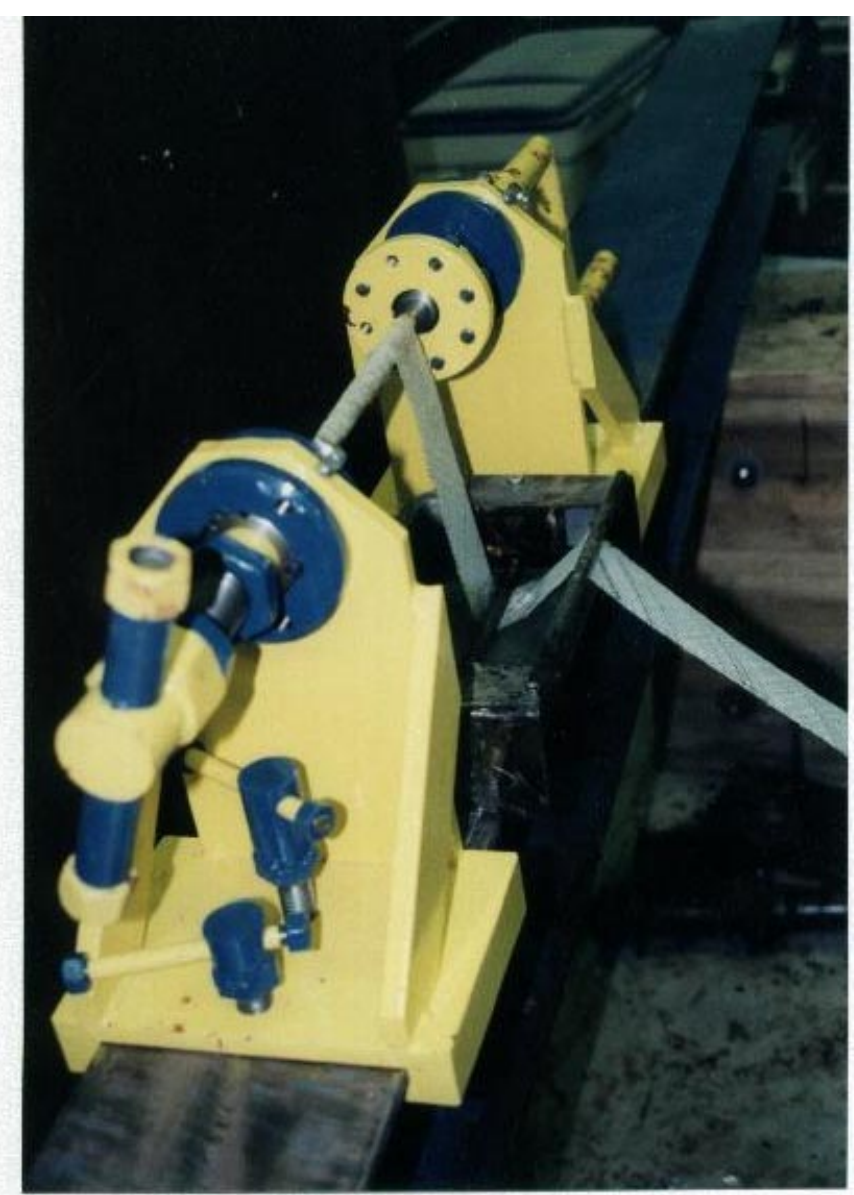

Figure 6.1: Glass fiber wrapping of a wood post using banding machine

The wrapped dowel was mounted on a drying set up that consisted of two rotating circular discs connected to a motor. The discs were provided with adjustable screws to hold the sample. The mounted sample was rotated on this set up to prevent dripping of resin and promote uniform curing. After curing, the wrapped dowel was cut to the required length using a band saw. The finished sample was 7.5" long. The average thickness of the GFRP wrap around the dowel was $0.0475^{\prime \prime}$. The fiber volume fraction in 
the composite wrap was approximately 26\% (Appendix A.1). These wrapped specimens are also referred to as wood/HMR/epoxy/glass hybrids later in the chapter. A schematic of the wrapped sample is shown in the following figure:
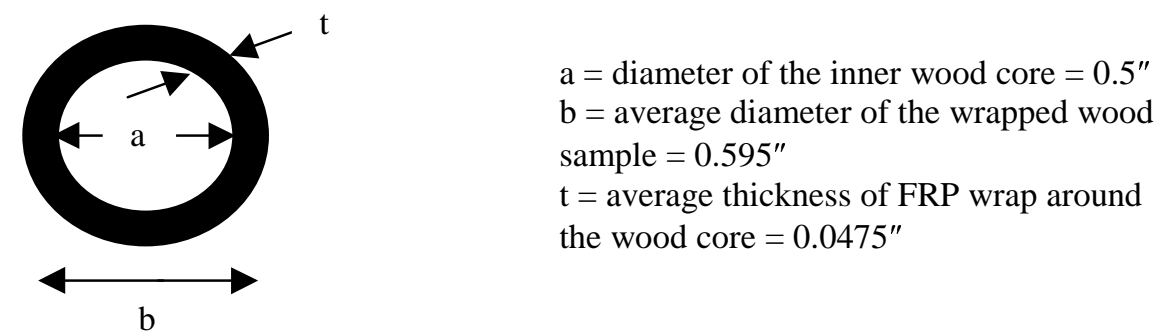

Figure 6.2: Schematic of the cross-section of a wrapped sample

\subsection{Description of Test Procedure}

ASTM D-790 is a standard test method used for evaluating flexural properties of high modulus composites that are in the form of sheets, plates or molded shapes. The standard is applicable to all rigid and semi-rigid materials. This standard is applicable only when the test specimen fails in the outer fibers. The standard describes two test methods, a three-point loading system and a four-point loading system. The test reveals the flexural strength and strain at failure of the composite.

To suit the small dimensions of test specimens, the three-point loading system was used for laboratory testing. All test specimens failed in the outer fibers which justified the use of the three-point loading system.

The following are the outlines of the three-point loading method of ASTM D-790:

(1) The apparatus should be properly calibrated and should be operated at constant speed of cross-head motion. 
(2) The loading noses and supports should have cylindrical surfaces. To avoid stress concentration under the loading noses, the radius of the supports should be atleast $3.2 \mathrm{~mm}$ (0.125 in) for all specimens.

(3) The specimens may be cut from sheets, plates, molded shapes or may be molded to the desired final dimensions.

(4) The width and depth of the untested specimen are measured to the nearest 0.001in. The support span-to-depth ratio is chosen such that failures occur in the outer fibers of the specimen. The machine is set to the corresponding rate of cross-head motion.

(5) The loading nose and supports are aligned so that the axes of the cylindrical surfaces are parallel and the loading nose is midway between the supports. The load is applied at the specified cross-head rate and load-deflection data are simultaneously recorded.

(6) The flexural strength and maximum strain at failure are calculated.

Complete details of the testing method are given in "The 1995 Book of ASTM Standards," Vol. 8.01 [21].

In the current experimental work, an Instron machine (model 4411), with a capacity of $1000 \mathrm{lbs}$, was used for testing. In order to represent the proposed posts, wrapped dowels were tested instead of wrapped bars. Modifications were incorporated in the calculations to account for the circular cross-section of the specimens. The length of the specimens was 7.5" and their average outer diameter was $0.595 "$. Thickness of wrap was approximately $0.0475^{\prime \prime}$. The support span-to-depth ratio was approximately 10:1. The rate of cross-head motion was $0.16^{\prime \prime} / \mathrm{min}$. Figure 6.2 shows the flexural loading of a GFRP wrapped specimen. 


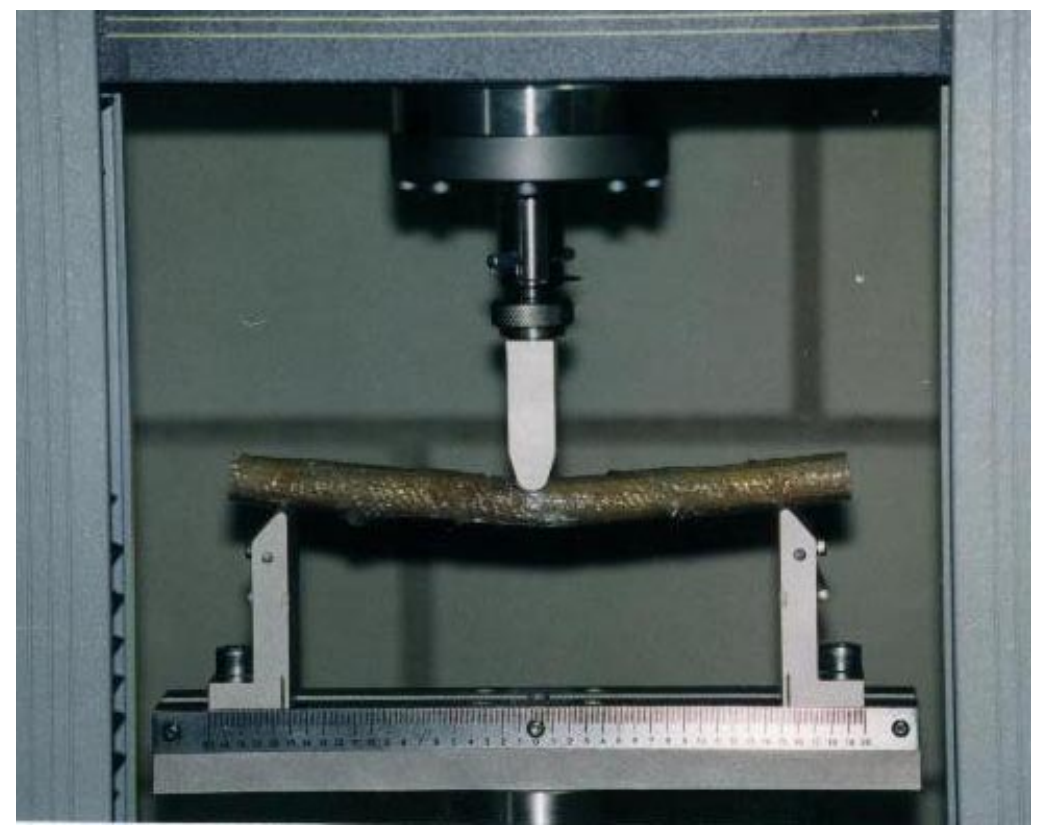

Figure 6.3: Three-point flexural loading of a wrapped specimen

\subsection{Sample Conditioning}

Wrapped specimens were subjected to the following conditions before testing:

(1) exposure to 6-cycle accelerated aging (described in section 4.2).

(2) exposure to freeze thaw cycles in acidic solution of $\mathrm{pH} 3.0$ for 5 days, 15 days and 25 days in the atmospheric chamber (described in Chapter IV, section 4.3)

(3) exposure to freeze thaw cycles in alkaline solution of $\mathrm{pH} 13.0$ for 5 days, 15 days and 25 days in the atmospheric chamber

(4) exposure to freeze thaw cycles in solution of $\mathrm{pH} 7.0$ for 5 days, 15 days and 25 days in the atmospheric chamber

(5) exposure to freeze thaw cycles in 3\% salt water for 5 days, 15 days and 25 days in the atmospheric chamber 


\subsection{Summary of Test Results}

\subsubsection{Accelerated Aging}

The primary objective of wrapping was to improve the mechanical properties and durability of wood. To demonstrate the effectiveness of wrapping, wood and wood/HMR/epoxy/glass hybrid specimens were subjected to 6-cycle accelerated aging. As explained earlier (section 4.2), 6-cycle accelerated aging simulates approximately 20 years of natural aging conditions. The samples were tested after each cycle to observe the rate of degradation or improvement in mechanical properties with increase in the number of aging cycles. The samples were dried at room temperature for about 10 days before they were tested. Wood/epoxy/glass hybrid specimens were also tested to observe the effectiveness of HMR in improving the bond between the wood and the GFRP wrap. The test results are presented in Table 6.1. Graphical representation of these results is given in Figures 6.4 and 6.5. A set of sample calculations of flexural strength and modulus are given in Appendix B.2. 
Table 6.1: Comparison of strength and modulus of wood, wood/epoxy/glass hybrid and wood/HMR/epoxy/glass hybrid specimen exposed to 6-cycle accelerated aging

\begin{tabular}{|c|c|c|c|c|c|c|c|}
\hline Property & specimen & unaged & $\begin{array}{l}\text { cycle } \\
1\end{array}$ & $\begin{array}{l}\text { cycle } \\
2\end{array}$ & $\begin{array}{l}\text { cycle } \\
3\end{array}$ & $\begin{array}{l}\text { cycle } \\
4\end{array}$ & $\begin{array}{l}\text { cycle } \\
6\end{array}$ \\
\hline \multirow{3}{*}{$\begin{array}{l}\text { Ultimate } \\
\text { flexural } \\
\text { strength, } \sigma \\
\text { (psi)X10 }\end{array}$} & Wood & 0.0163 & 0.0180 & 0.0201 & 0.0189 & 0.0210 & 0.0196 \\
\hline & Wood/epoxy/glass hybrid & 0.0205 & 0.0087 & 0.0088 & 0.0092 & 0.0075 & 0.0098 \\
\hline & $\begin{array}{l}\text { Wood/HMR/epoxy/glass } \\
\text { hybrid }\end{array}$ & 0.0169 & 0.0131 & 0.0171 & 0.0168 & 0.0133 & 0.0114 \\
\hline \multirow{3}{*}{$\begin{array}{l}\text { Flexural } \\
\text { modulus, } \\
\text { E } \\
(\mathrm{psi}) \times 10^{6}\end{array}$} & Wood & 1.09 & 1.13 & 1.38 & 1.60 & 1.39 & 1.26 \\
\hline & Wood/epoxy/glass hybrid & 1.79 & 0.72 & 0.89 & 0.72 & 0.52 & 0.69 \\
\hline & $\begin{array}{l}\text { Wood/HMR/epoxy/glass } \\
\text { hybrid }\end{array}$ & 1.13 & 0.90 & 1.12 & 1.08 & 0.96 & 0.97 \\
\hline \multirow{3}{*}{$\begin{array}{l}\text { Flexural } \\
\text { Rigidity, } \\
\text { EI } \\
\left(1 \mathrm{~b}-\text { in }^{2}\right) \quad X \\
10^{3}\end{array}$} & Wood & 3.35 & 3.48 & 4.23 & 4.13 & 4.27 & 3.87 \\
\hline & Wood/epoxy/glass hybrid & 11.47 & 5.98 & 5.46 & 4.01 & 3.35 & 5.38 \\
\hline & $\begin{array}{l}\text { Wood/HMR/epoxy/glass } \\
\text { hybrid }\end{array}$ & 8.78 & 6.99 & 10.71 & 7.24 & 8.59 & 6.86 \\
\hline
\end{tabular}




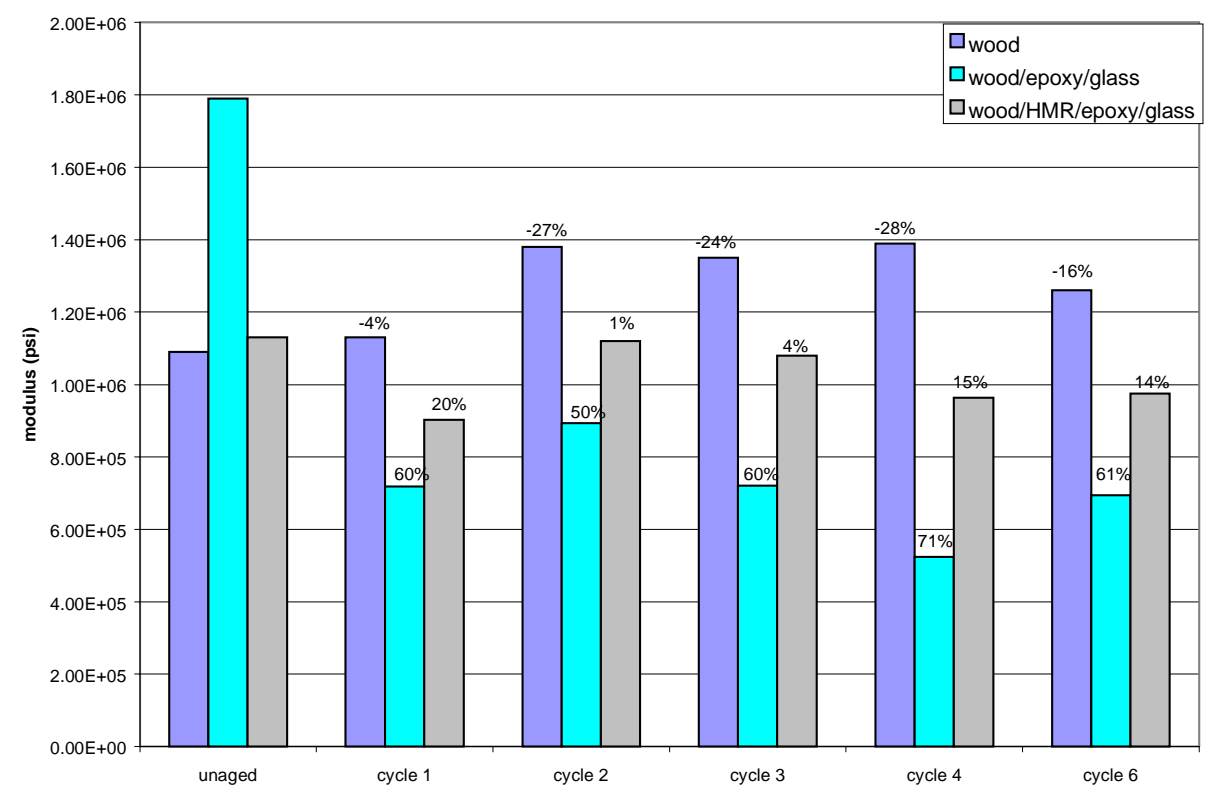

Figure 6.4: Comparison of elastic modulus (in bending) of wood, hybrid specimen after each cycle of 6-cycle aging

(\% value indicates the \% change in modulus compared to the unaged value. A +'ve sign indicates decrease in modulus, a -'ve sign indicates an increase in modulus)

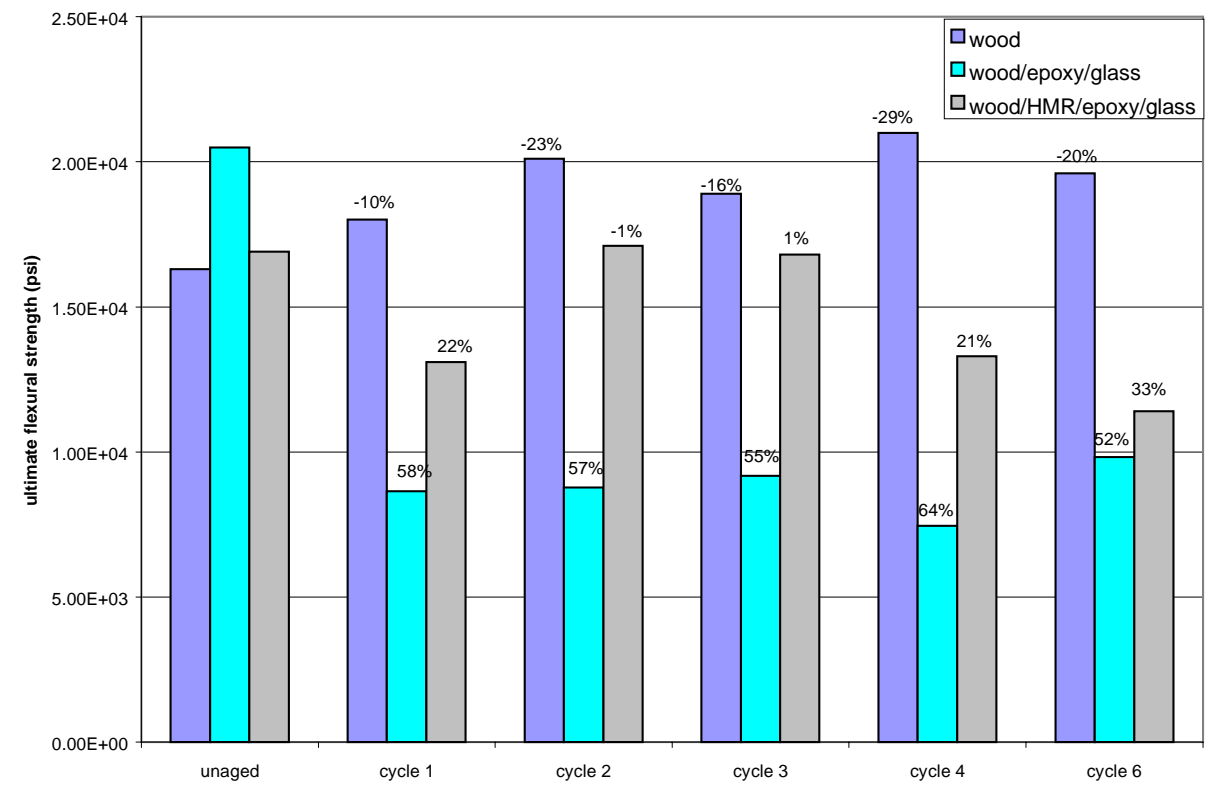

Figure 6.5: Comparison of flexural strength of wood, hybrid specimen after each cycle of 6-cycle aging

(\% value indicates the $\%$ change in strength compared to the unaged value. A +'ve sign indicates decrease in strength, a -'ve sign indicates an increase in strength) 
From Figures 6.4 and 6.5, it can be seen that the flexural strength and modulus of wood/epoxy/glass hybrid have decreased gradually due to the 6-cycle aging. The increase in strength and modulus between cycle 1 and cycle 2, cycle 3 and cycle 4 can be attributed to changes in moisture content, curing of epoxy resin and (or) imperfections in sample preparation. In the case of a wood/HMR/epoxy/glass specimen, the mechanical properties decreased after cycle 1 and increased to a maximum after cycle 2 . The properties after cycle 2 decreased gradually. This suggests that the curing of epoxy resin in the wood/HMR/epoxy/glass specimen is nearly complete in the vicinity of cycle 2 . The amount of decrease in both strength and modulus of the wood/epoxy/glass hybrid samples is greater than the decrease in the wood/HMR/epoxy/glass hybrid samples. Therefore it is concluded that priming with HMR increases the strength, modulus and retention of the wood/epoxy/glass hybrid specimens under accelerated aging conditions.

Composite wrapping of wood slightly increases the strength and modulus of the wood under unaged conditions. With the progress of aging, the mechanical properties of the wrapped hybrid decrease. An important observation from the data is that the strength and modulus of the wood increased with the progress of 6-cycle aging. The strength and modulus values of the wood are higher than those of the wrapped hybrid at the end of 6cycle aging. All of these findings suggest that the properties of wood have not improved significantly by wrapping. However, Talakanti [22] showed that under a maximum applied strain of 4500 microstrains, after 2 million fatigue cycles, a GFRP wrapped wood specimen retains about $60 \%$ stiffness while an unwrapped wood specimen fails at 0.5 million cycles. Work currently in progress, being done by researchers at the Constructed Facilities Center (Chamarthy [23] and Laosiriphong [24]) also showed that the GFRP 
wrapping increases the properties of wood upto $100 \%$. We speculate that the unusually low values of wrapped wood compared to unwrapped wood after 6-cycle aging are due to variation of moisture content of wood in the wrapped hybrid and unwrapped wood samples.

Observation of the failed wrapped specimens under three point bending showed that the failure was entirely in the outer fibers. The samples were sliced at the region of failure and at other regions along the length of the sample. Observation of the crosssection showed that there was no delamination at the wood/FRP interface. Visual examination of the wood samples showed clearly visible longitudinal cracks in the aged wood even before testing. Most of the cracks were along the length of the samples. These cracks began to appear from cycle 3 onwards. It is therefore concluded that the cracks produced during aging from the drying of wood, result in an increase in the mechanical properties of the wood.

The wood for the sample preparation was stored at room temperature. The unwrapped wood samples were prepared about four months after the preparation of wrapped samples. Therefore it is very likely that the moisture content of wood in the wrapped samples is higher than the unwrapped ones even though they were prepared from the same log of wood. The strength of the wood varies with the moisture content of the wood. At very low moisture content (6 to10\%), the strength begins to decrease. The strength is maximum at about $12 \%$ moisture content and begins to decrease gradually when the moisture content increases beyond the equilibrium level (18\%).

It is therefore assumed that in the unaged wood samples, the moisture content was very low $(10 \%)$ resulting in the low strength and modulus values compared to the values 
in the literature [5]. During 6-cycle aging, the moisture content in the wood could have reached the $12 \%$, which could have increased the strength and modulus. Such increases in mechanical properties due to changes in moisture content could have dominated the decrease in properties during 6-cycle aging. In short, the increases in strength and modulus of wood are due to a combination of the aging effect and the percent moisture fluctuation.

For a better understanding of the aging of wood and wood composites, flexural rigidity (EI) of the test samples was compared. Figure 6.6 shows the variation of rigidity of wood and wrapped hybrid specimens during 6-cycle aging.

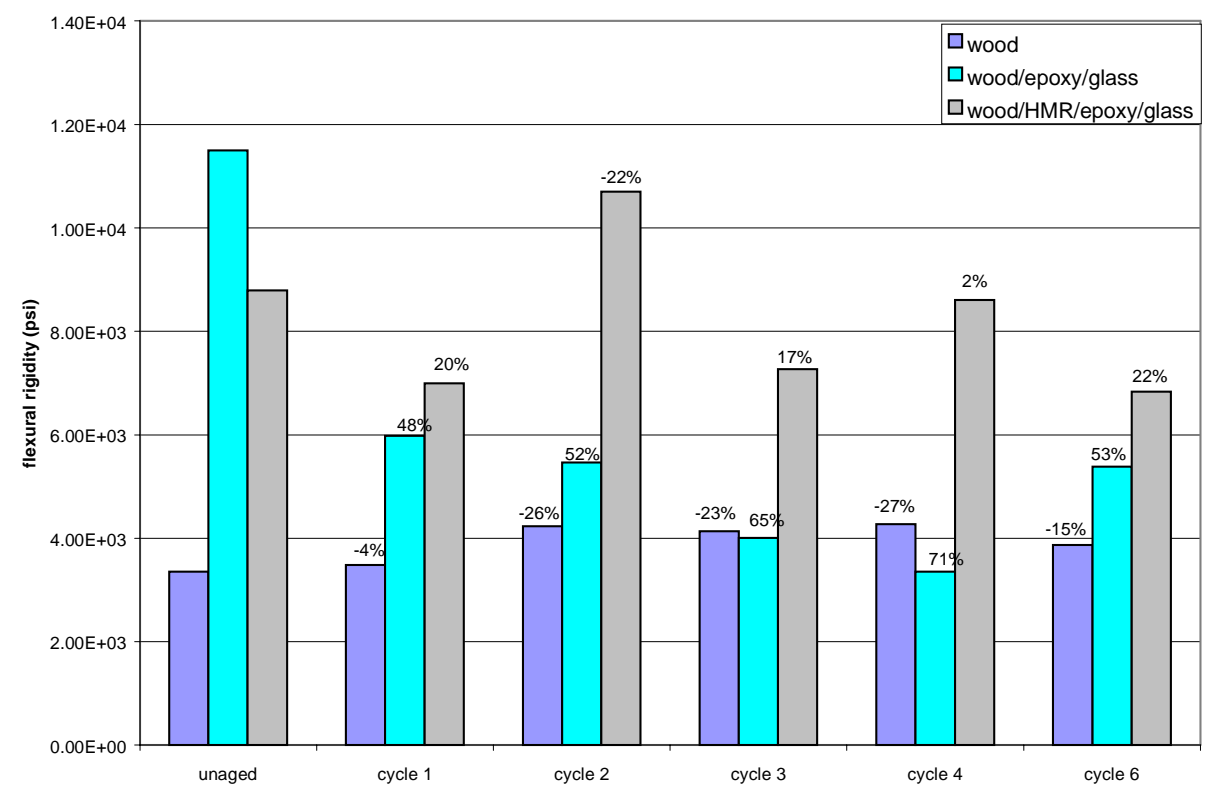

Figure 6.6: Comparison of flexural rigidity of wood, hybrid specimen after each cycle of 6-cycle aging (\% value indicates the \% change in flexural rigidity compared to the unaged value. A +'ve sign indicates decrease in rigidity, a -'ve sign indicates an increase in rigidity) 
The following observations were made from Figure 6.6:

The rigidity of wood has increased due to composite wrapping under both unaged and 6-cycle aged conditions. The increase in rigidity due to wrapping with HMR/epoxy/glass is higher than the increase due to wrapping with epoxy/glass. From Table 6.1, the ratio of $\mathrm{EI}_{\text {hybrid }}$ to $\mathrm{EI}_{\text {wood }}$ under unaged and 6-cycle aged conditions was calculated. It was found that in the present situation, i.e. for $25 \%$ fiber volume fraction in the GFRP wrap and $0.0475^{\prime \prime}$ thick wrap around a $0.5^{\prime \prime}$ wood core, wrapping of wood with the HMR/epoxy/glass system improves the flexural rigidity by 2.62 times under unaged conditions and 1.77 times under 6-cycle aged conditions (from Table 6.1).

\subsubsection{Prediction of Flexural Rigidity using Rule of Mixtures}

Assuming a perfect bond between epoxy resin and glass fibers, wood/FRP wrap, the properties of a wood/epoxy/glass specimen can be estimated using the following rule of mixtures:

$$
\begin{aligned}
(\mathrm{EI})_{\text {hybrid }} & =(\mathrm{EI})_{\mathrm{wood}}+(\mathrm{EI})_{\mathrm{wrap}} \\
& =\mathrm{E}_{\mathrm{wood}}\left[\mathrm{I}_{\mathrm{wood}}+\left(\mathrm{E}_{\mathrm{wrap}} / \mathrm{E}_{\mathrm{wood}}\right) \mathrm{I}_{\mathrm{wrap}}\right]
\end{aligned}
$$

Using this formula, the properties of a hybrid wood/epoxy/glass specimen consisting of a $0.5^{\prime \prime}$ diameter wood core and a $0.0475^{\prime \prime}$ epoxy/glass fiber wrap can be estimated.

Under unaged conditions,

$\mathrm{E}_{\mathrm{wood}}=1.31 \times 10^{6}$ psi from reference [3]

The value for a specimen as small as $0.5^{\prime \prime}$ in diameter would be in the range of

$2.0 \times 10^{6}$ psi to $2.4 \times 10^{6} \mathrm{psi}$ 


$$
\begin{aligned}
& E_{\text {wrap }}=E_{f} v_{f}+\left(1-v_{f}\right) E_{m} \\
& \text { where } v_{f}=\text { fiber volume fraction } \\
& =0.25 \text { (for } 25 \% \text { volume fraction }) \\
& E_{\mathrm{f}}=\text { elastic modulus of glass fibers under unaged conditions } \\
& =10.5 \times 10^{6} \mathrm{psi} \\
& E_{m}=\text { elastic modulus of epoxy resin under accelerated aging conditions } \\
& =0.45 \times 10^{6} \mathrm{psi} \\
& \mathrm{G}=\mathrm{E} / 2(1+v) \text { where } \mathrm{G}=\text { shear modulus and } v \text { is Poisson's ratio } \\
& \mathrm{G}_{\mathrm{f}}=4.18 \times 10^{6} \mathrm{psi} \\
& v_{\mathrm{f}}=0.26 \\
& \mathrm{G}_{\mathrm{m}}=0.16 \times 10^{6} \mathrm{psi} \\
& v_{\mathrm{f}}=0.38 \\
& \text { from micro mechanics approach [25] } \mathrm{E}_{\text {wrap }}=1.92 \times 10^{6} \mathrm{psi} \\
& \mathrm{E}_{\mathrm{wrap}} / \mathrm{E}_{\mathrm{wood}}=0.96 \\
& \mathrm{I}_{\mathrm{wood}}=\left(\pi \mathrm{r}^{4} / 4\right)=0.0031 \mathrm{in}^{4} \\
& \mathrm{I}_{\text {wrap }}=\pi\left[(\mathrm{r}+\mathrm{t})^{4}-\mathrm{r}^{4}\right] / 4=3.049 \times 10^{-3} \mathrm{in}^{4}
\end{aligned}
$$

Therefore

$$
\begin{aligned}
(\mathrm{EI})_{\text {hybrid }} & =2.0 \times 10^{6}\left[0.0031+0.96\left(3.049 \times 10^{-3}\right)\right] \\
& =12.05 \times 10^{3}{\mathrm{lb}-\mathrm{in}^{2}}^{2}
\end{aligned}
$$

Under aged conditions,

$\mathrm{E}_{\mathrm{wood}}=0.87\left(2.0 \times 10^{6} \mathrm{psi}\right)$ (assuming a 13\% decrease in properties of wood as found 
from DMA of 6-cycle aged wood)

$$
=1.74 \times 10^{6} \mathrm{psi}
$$

Assuming a maximum of $10 \%$ decrease in the properties of glass fibers due to aging,

$$
\begin{aligned}
\mathrm{E}_{\mathrm{f}} & =0.9\left(10.5 \times 10^{6}\right) \mathrm{psi} \\
& =9.45 \times 10^{6} \mathrm{psi} \\
\mathrm{G}_{\mathrm{f}} & =0.9\left(4.18 \times 10^{6}\right) \mathrm{psi} \\
& =3.76 \times 10^{6} \mathrm{psi} \\
v_{\mathrm{f}} & =0.26
\end{aligned}
$$

Kajorncheappunngam [20] plotted the master curve of epoxy resin aged in water at room temperature for 5 months under no sustained stress. Using those master curves, the properties of epoxy resin at a service life of 20 years for unaged and water aged specimen were compared. A $11 \%$ decrease in the storage modulus was observed due to aging in water at room temperature for 5 months. Assuming a $11 \%$ decrease in the properties of epoxy resin under 6-cycle aged conditions,

$$
\begin{aligned}
\mathrm{E}_{\mathrm{m}} & =0.89\left(0.45 \times 10^{6}\right) \mathrm{psi} \\
& =0.4 \times 10^{6} \mathrm{psi} \\
\mathrm{G}_{\mathrm{m}} & =0.89\left(0.16 \times 10^{6}\right) \mathrm{psi} \\
& =0.14 \times 10^{6} \mathrm{psi} \\
v_{\mathrm{f}} & =0.38
\end{aligned}
$$

from the micro mechanics approach, [25]

$$
\begin{aligned}
& \mathrm{E}_{\text {wrap }}=1.73 \times 10^{6} \mathrm{psi} \\
& \mathrm{E}_{\text {wrap }} / \mathrm{E}_{\text {wood }}=0.865
\end{aligned}
$$


$\mathrm{I}_{\mathrm{wood}}=\left(\pi \mathrm{r}^{4} / 4\right)=0.0031 \mathrm{in}^{4}$ (assuming no variation in sample dimensions due to aging)

$\mathrm{I}_{\mathrm{wrap}}=\pi\left[(\mathrm{r}+\mathrm{t})^{4}-\mathrm{r}^{4}\right] / 4=3.049 \times 10^{-3} \mathrm{in}^{4}$ (assuming no variation in dimensions of the sample due to aging)

Therefore

$$
\begin{aligned}
(\mathrm{EI})_{\text {hybrid }} & =2.0 \times 10^{6}\left[0.0031+0.865\left(3.049 \times 10^{-3}\right)\right] \\
& =11.47 \times 10^{3} \mathrm{lb}-\mathrm{in}^{2}
\end{aligned}
$$

Table 6.2: Comparison of flexural rigidity of unaged and aged wood/epoxy/glass hybrid obtained using rule of mixtures and from experiments at different values of $\mathbf{E}_{\text {wood }}$

\begin{tabular}{|l|l|l|l|l|l|l|}
\hline $\mathrm{E}_{\text {wood }}$ & unaged $_{\text {rom }}$ & aged $_{\text {rom }}$ & $\mathrm{A}^{*}$ & unaged $_{\text {expt }}$ & aged $_{\text {expt }}$ & $\mathrm{B}^{*}$ \\
\hline $2.0 \times 10^{6}$ & $12.05 \times 10^{3}$ & $11.47 \times 10^{3}$ & $4.8 \%$ & $11.47 \times 10^{3}$ & $5.37 \times 10^{3}$ & $53 \%$ \\
\hline $2.2 \times 10^{6}$ & $12.65 \times 10^{3}$ & $12.12 \times 10^{3}$ & $4.2 \%$ & $11.47 \times 10^{3}$ & $5.37 \times 10^{3}$ & $53 \%$ \\
\hline $2.4 \times 10^{6}$ & $13.29 \times 10^{3}$ & $12.71 \times 10^{3}$ & $4.4 \%$ & $11.47 \times 10^{3}$ & $5.37 \times 10^{3}$ & $53 \%$ \\
\hline
\end{tabular}

rom = value calculated using rule of mixtures

expt $=$ experimental value

$\mathrm{A}^{*}=$ percent decrease in value calculated using rule of mixtures

$\mathrm{B}^{*}=$ percent decrease in value obtained from experiments

The values obtained from rule of mixtures for wood/epoxy/glass can be compared with wood/HMR/epoxy/glass to observe the effect of HMR primer in bringing the rigidity of the specimen closer to the values obtained using rule of mixtures. This is based on the assumption that according to rule of mixtures, the rigidity of wood/epoxy/glass is the same as the rigidity of wood/HMR/epoxy/glass hybrid specimens. 
Table 6.3: Comparison of flexural rigidity of unaged and aged wood/HMR/epoxy/glass hybrid obtained using rule of mixtures and from experiments at different values of $\mathbf{E}_{\text {wood }}$

\begin{tabular}{|c|c|c|c|c|c|c|}
\hline $\begin{array}{l}\mathrm{E}_{\text {wood }} \\
\text { (psi) }\end{array}$ & 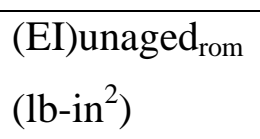 & (EI)aged ${ }_{\text {rom }}$ & $\mathrm{A}^{*}$ & (EI)unaged $d_{\text {expt }}$ & (EI)aged expt $_{\text {t }}$ & $\mathrm{B}^{*}$ \\
\hline $2.0 \times 10^{6}$ & $12.05 \times 10^{3}$ & $11.47 \times 10^{3}$ & $4.8 \%$ & $8.78 \times 10^{3}$ & $6.86 \times 10^{3}$ & $22 \%$ \\
\hline $2.2 \times 10^{6}$ & $12.65 \times 10^{3}$ & $12.12 \times 10^{3}$ & $4.2 \%$ & $8.78 \times 10^{3}$ & $6.86 \times 10^{3}$ & $22 \%$ \\
\hline $2.4 \times 10^{6}$ & $13.29 \times 10^{3}$ & $12.71 \times 10^{3}$ & $4.4 \%$ & $8.78 \times 10^{3}$ & $6.86 \times 10^{3}$ & $22 \%$ \\
\hline
\end{tabular}

From Tables 6.2 and 6.3 it is observed that the rigidity of a wood/FRP specimen decreases by $53 \%$ compared to a $4-5 \%$ decrease under perfect bonding conditions. With the use of HMR primer, the amount of decrease in rigidity is reduced from $53 \%$ to $22 \%$. It is also observed that due to the presence of HMR primer, the performance of the wood/epoxy/glass specimen before aging is lowered. This suggests that epoxy resin bonds very well to wood but the bonds are not strong enough to withstand moisture penetration. We suspect that HMR primer reduces the affinity of the wood surface to the epoxy resin and thereby reduces the rigidity under unaged conditions. In other words, HMR primer chemically bonds to the wood surface and leaves fewer sites on wood for the epoxy resin to form bonds. Therefore, epoxy resin forms bonds mainly with HMR primer on wood. Under aged conditions, the coupling action of HMR provides moisture resistance to the wood/HMR/epoxy interface. It is concluded that the major effect of HMR primer is to improve the moisture resistance of wood/epoxy interface.

In the computation of the theoretical values of rigidity after aging, only the effect of degradation of epoxy matrix and glass fibers was considered. The effect of bond degradation at the wood/FRP interface was not included. This could be a major reason for the difference between the percent decrease in rigidity of the theoretical (4-5\%) and 
experimental (53\% and 22\%) values. If one accounts for the degradation of structural compositeness at the wood/FRP interface, the experimental values of rigidity could be much closer to the theoretical values.

\subsubsection{Chemical Aging}

To study the effect of different aging media, wood/HMR/epoxy/glass hybrid specimens, representing a scaled down version of the proposed GFW guard-rail posts were subjected to chemical aging. The hybrid specimens were immersed in water, salt water, acidic and alkaline media and subjected to freeze-thaw cycling. The samples were dried at room temperature for about 30 days before they were tested. Tables 6.4 through 6.6 show the performance of wood/HMR/epoxy/glass hybrid in different media.

Table 6.4: Flexural strength of wood/HMR/epoxy/glass hybrid exposed to freezethaw cycling in different solutions

\begin{tabular}{|c|c|c|c|c|}
\hline \multirow[t]{2}{*}{ Aging medium } & \multicolumn{3}{|c|}{ Ultimate flexural strength (psi) X $10^{6}$} & \multirow[t]{2}{*}{$\mathrm{A}^{*}$} \\
\hline & $\begin{array}{l}\text { After } 5 \text { days } \\
\text { of aging }\end{array}$ & $\begin{array}{ll}\text { after } & 15 \\
\text { days } & \text { of } \\
\text { aging } & \end{array}$ & $\begin{array}{ll}\text { after } & 25 \\
\text { days } & \text { of } \\
\text { aging } & \end{array}$ & \\
\hline Unaged & \multicolumn{3}{|l|}{0.0169} & \\
\hline Acidic solution of $\mathrm{pH} 3$ & 0.0155 & 0.0103 & 0.0096 & 43 \\
\hline Alkaline solution of $\mathrm{pH} 13$ & 0.0172 & 0.0143 & 0.0116 & 31 \\
\hline Water & 0.0133 & 0.0088 & 0.0115 & 32 \\
\hline $3 \%$ salt water & 0.0164 & 0.0143 & 0.0128 & 24 \\
\hline
\end{tabular}

$\mathrm{A}^{*}=$ percent reduction in strength after 25 days of aging 
Table 6.5: Flexural modulus of wood/HMR/epoxy/glass hybrid exposed to freezethaw cycling in different solutions

\begin{tabular}{|l|l|l|l|l|}
\hline \multirow{2}{*}{ Aging medium } & \multicolumn{3}{|l|}{ Flexural modulus (psi) X $10^{6}$} & \multirow{2}{*}{ * $^{*}$} \\
\cline { 2 - 4 } & $\begin{array}{l}\text { after } \\
5 \text { days of } \\
\text { aging }\end{array}$ & $\begin{array}{l}\text { after 15 } \\
\text { days of } \\
\text { aging }\end{array}$ & $\begin{array}{l}\text { after 25 } \\
\text { days of } \\
\text { aging }\end{array}$ & \\
\hline Unaged & 1.13 & 0.89 & 0.78 & 31 \\
\hline Acidic solution of pH 3 & 1.08 & 0.89 & 0.89 & 21 \\
\hline Alkaline solution of pH 13 & 1.18 & 0.52 & 0.88 & 22 \\
\hline Water & 0.69 & 1.03 & 0.92 & 18 \\
\hline 3\% salt water & 1.08 & & \\
\hline
\end{tabular}

$\mathrm{B}^{*}=$ percent reduction in modulus after 25 days of aging (\%)

Table 6.6: Flexural rigidity of wood/HMR/epoxy/glass hybrid exposed to freezethaw cycling in different solutions

\begin{tabular}{|l|l|l|l|l|}
\hline \multirow{2}{*}{ Aging medium } & \multicolumn{3}{|l|}{ Flexural rigidity (psi) X 10 } & \multirow{2}{*}{ * $^{*}$} \\
\cline { 2 - 4 } & $\begin{array}{l}\text { after } \\
5 \text { days of } \\
\text { aging }\end{array}$ & $\begin{array}{l}\text { After 15 } \\
\text { days of } \\
\text { aging }\end{array}$ & $\begin{array}{l}\text { after 25 } \\
\text { days of } \\
\text { aging }\end{array}$ & \\
\hline Unaged & 8.79 & 5.97 & 5.49 & 38 \\
\hline Acidic solution of pH 3 & 7.66 & 5.99 & 6.24 & 29 \\
\hline Alkaline solution of pH 13 & 8.16 & 3.58 & 5.90 & 33 \\
\hline Water & 4.77 & 7.44 & 6.19 & 30 \\
\hline 3\% salt water & 7.88 & & & \\
\hline
\end{tabular}

$\mathrm{C}^{*}=$ percent reduction in rigidity after 25 days of aging (\%) 


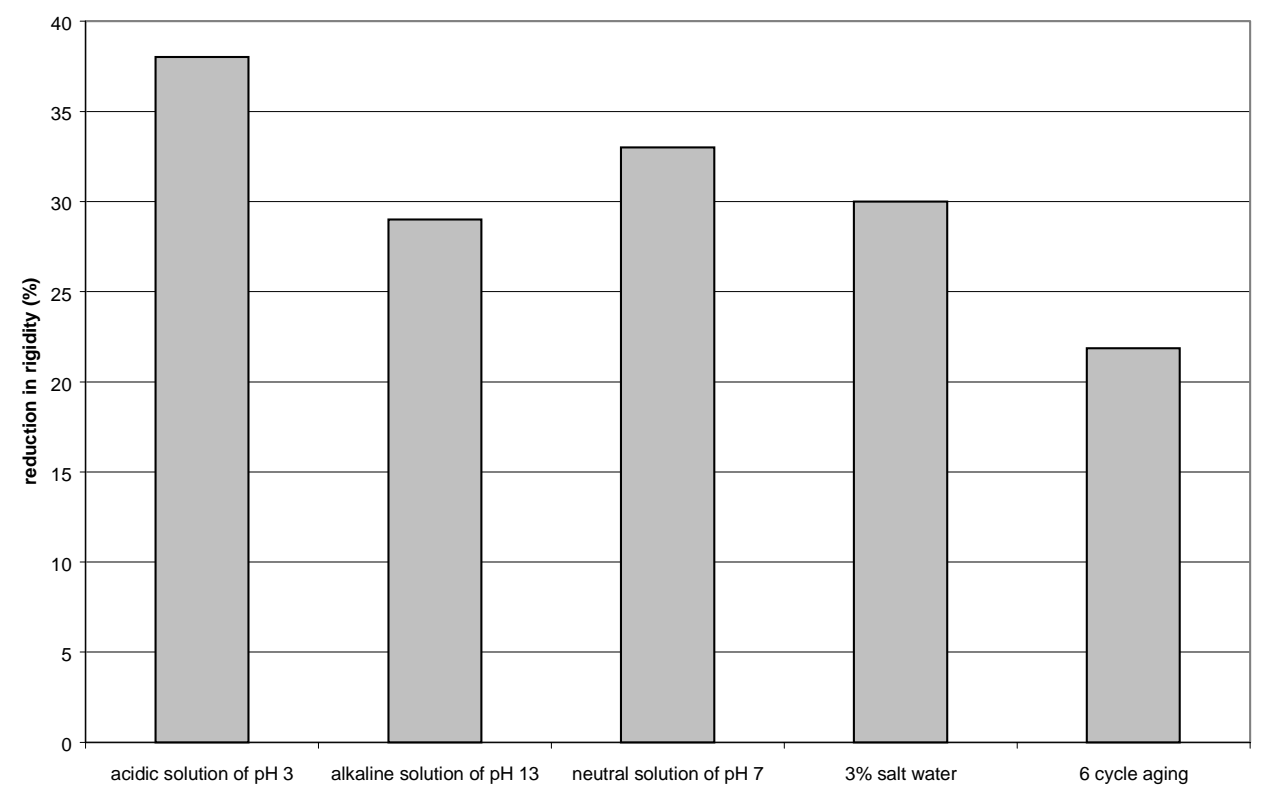

Figure 6.7: Variation of flexural rigidity of wood/HMR/epoxy/glass hybrid exposed to freeze-thaw cycling in different media for 25 days

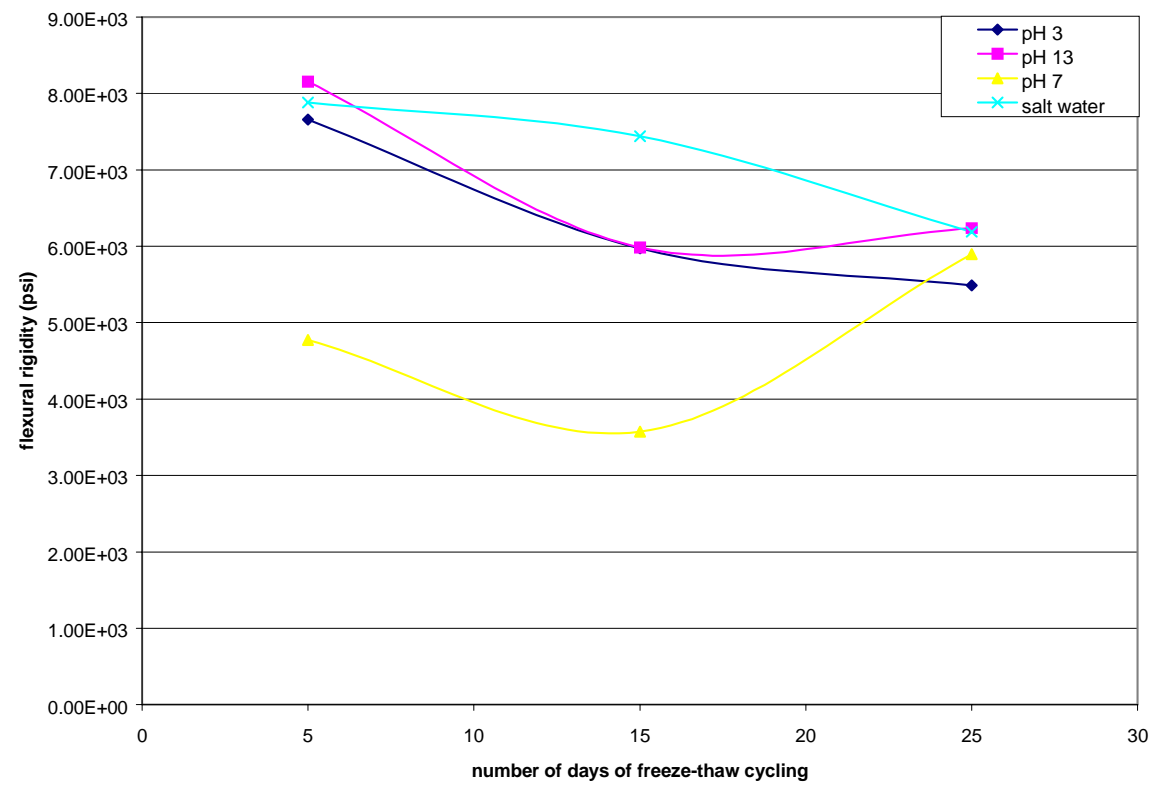

Figure 6.8: Variation of flexural rigidity of wood/HMR/epoxy/glass hybrid with time in different media 
From Tables 6.4 through 6.6 and Figures 6.7 and 6.8, it can be observed that in acidic medium, flexural strength of the hybrid decreased rapidly by $39 \%$ after 15 days of aging; this value increased to $43 \%$ after 25 days of aging. Elastic modulus (in bending) and rigidity under acidic medium decreased gradually by $31 \%$ and $38 \%$ respectively after 25 days of aging. The decrease in flexural strength, modulus and rigidity, under acidic medium is maximum compared to the decrease in other aging media. From shear tests of sandwich samples (Table 5.16), a 55\% decrease in wood/FRP bond strength was observed in acidic medium compared to a maximum of $70 \%$ decrease in alkaline medium of $\mathrm{pH}$ 13. The failure of sandwich samples in acidic medium was completely in the wood. This suggests that the wood/FRP interface is not damaged in acidic medium. Kajorncheappunngam [20] found that the Tg (glass transition temperature) of epoxy aged in $10 \mathrm{M} \mathrm{HCl}$ solution for 1 month at room temperature increased from $76^{0} \mathrm{C}$ to $120^{\circ} \mathrm{C}$. This increase in $\mathrm{Tg}$ was attributed to the progress of the curing reaction of the epoxy matrix. This suggests that the maximum decrease in mechanical properties of the wood/HMR/epoxy/glass hybrid in acidic medium could be due to the following reasons:

$\mathrm{H}^{+}$ions in acid form hydrogen bonds with $\mathrm{OH}$ groups of epoxy resin and increase the $\mathrm{Tg}$ of the matrix. The high temperature acid solution during freeze-thaw also aids curing of the epoxy matrix and increases the $\mathrm{Tg}$. The decrease in modulus despite the increase in $\mathrm{Tg}$ suggests that acid causes irreversible damage to the hybrid. The low temperature acid solution causes expansion of absorbed liquid in the sample. This produces stresses at the epoxy/glass interface and also at the wood/HMR/epoxy interface. Protons in the diffused acid damage the glass fibers and the epoxy/glass interface by reacting with $\mathrm{OH}$ groups on the glass fibers. In short, acid diffuses through the epoxy 
matrix and primarily damages the glass fibers and glass/epoxy interface.

In alkaline medium, the flexural strength decreased gradually with increase in aging cycles. The modulus again reduced initially and then did not change between 15 days and 25 days of aging. The rigidity also reduced initially and slightly increased between 15 days and 25 days of aging, suggesting that the modulus and rigidity did not change much between 15 days and 25 days of aging. Shear tests of sandwich samples (Table 5.16) show maximum decrease of $70 \%$ in the wood/FRP bond strength. Also, the wood failure of wood/HMR/epoxy/HMR/wood samples was $77 \%$. This suggests that alkaline medium primarily damages the epoxy resin and the wood.HMR/epoxy bond. Kajorncheappunngam [20] found that in alkaline medium, the properties of the epoxy/glass interface are reduced due to damage of the epoxy matrix and also the epoxy/glass interface.

It is thought that alkali diffuses through the epoxy matrix and facilitates the curing of epoxy matrix. The Tg and modulus increase due to curing. The alkali further diffuses through the matrix and damages the HMR/epoxy interface. At longer aging periods, the modulus decreases due to increased damage of the glass/epoxy interface and the wood/FRP interface.

In neutral medium, all the properties decreased initially and later increased between 15 days and 25 days of aging. Shear tests of sandwich samples (Table 5.16) aged in water indicate a $55 \%$ reduction in wood/FRP bond strength compared to a maximum of $70 \%$ reduction in alkaline medium. The wood failure of the samples was $92 \%$. This shows that the wood/FRP interface is not damaged as much by water. It is assumed that water diffuses into the epoxy matrix and causes plasticization. Plasticization reduces the 
$\mathrm{Tg}$ and facilitates molecular mobility. With the progress of aging from 15 days to 25 days, the curing reaction of the epoxy matrix proceeds and forms a more cross-linked structure with increased $\mathrm{Tg}$ and modulus. The modulus thus increases until the matrix is completely cured. Upon prolonged aging, one can expect a further increase followed by a decrease in modulus of the wrapped composite.

In salt water, the strength and modulus of wrapped specimens reduced gradually. Saltwater medium caused minimum decrease in the properties. However, the percent of decreases in modulus and rigidity in salt water were similar to those caused by alkaline medium and water. This suggests that salt water does not highly reduce the strength of the composite but lowers the stiffness or makes the hybrid more ductile. There was a $61 \%$ decrease in shear strength of the wood/FRP bond and 24\% (minimum) decrease in shear strength of the wood/HMR/epoxy bond due to aging in salt water. This suggests that the damage caused by salt water to the glass/epoxy interface is higher than the damage caused to the wood/FRP interface. Salt water is least damaging to the epoxy matrix.

Irrespective of the amount of damage caused by aging, the failure of hybrid specimens aged in all media occurred in the outer fibers. There was no delamination between the GFRP wrap and HMR primed wood surface after aging. This shows that the GFRP wrap protects wood when exposed to freeze-thaw cycles in pure water, salt water, acidic and alkaline conditions. 


\subsubsection{Effect of Primer}

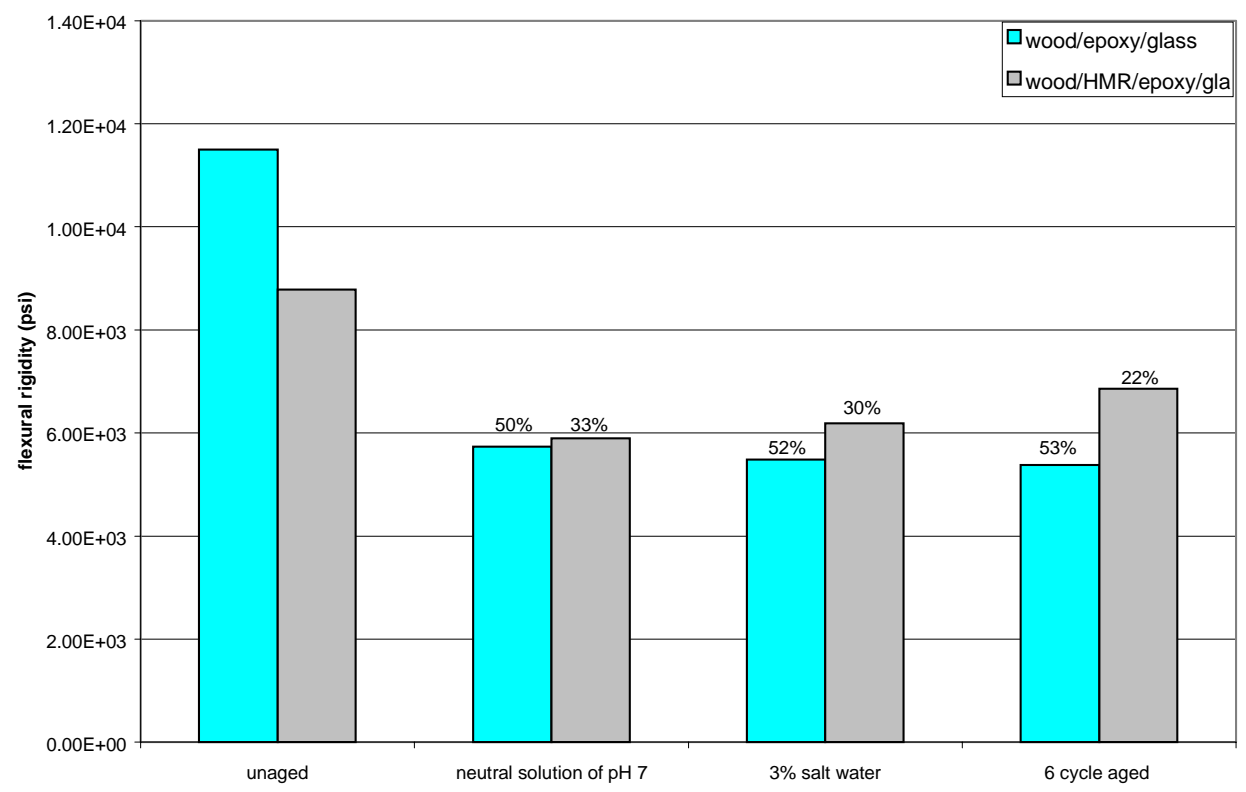

Figure 6.9: Comparison of flexural rigidity of wood/epoxy/glass hybrid and wood/HMR/epoxy/glass hybrid exposed to different conditions

Figure 6.9 compares performance of the wood/epoxy/glass bond with and without the use of HMR primer. Under unaged conditions, the rigidity of the wood/epoxy/glass is reduced by $24 \%$ with the use of HMR. However, in all aging media, the wood/epoxy/glass hybrid showed a higher percentage reduction in stiffness compared to the wood/HMR/epoxy/glass hybrid. This shows that HMR primer increases the retention of properties of wood/epoxy/glass hybrid under aged conditions. With the use of HMR primer, the rigidity of the wood/epoxy/glass hybrid specimen was increased by $3 \%$ in neutral medium, $13 \%$ in salt water and by $28 \%$ under 6-cycle accelerated aging conditions. 


\subsection{Cost Analysis}

The following discussion presents a brief idea about the cost of a GFW wood post in comparison with the cost of an unwrapped wood post and a steel post.

From the 1999 statistics of the West Virginia Department of Transportation, the approximate cost of a W6/9 galvanized 7' long steel guard-rail post $=\$ 25$

From Southern States (a local lumber company), the approximate cost of a 5" diameter, 7' long pressure treated wooden guard-rail post $=\$ 7$

$\rho_{\mathrm{wrap}}=\mathrm{v}_{\mathrm{f}} \rho_{\mathrm{f}}+\left(1-\mathrm{v}_{\mathrm{f}}\right) \rho_{\mathrm{m}}$

where

$\rho_{\text {wrap }}=$ density of the FRP wrap

$\rho_{\mathrm{f}}=$ density of glass fibers $=2627 \mathrm{~kg} / \mathrm{m}^{3}$

$\rho_{\mathrm{m}}=$ density of epoxy resin $=1160 \mathrm{~kg} / \mathrm{m}^{3}$

$\mathrm{v}_{\mathrm{f}}=$ fiber volume fraction $=0.25$ (for the present situation)

therefore, $\rho_{\text {wrap }}=0.25(2627)+0.75(1160)$

$$
\begin{aligned}
& =1526.75 \mathrm{~kg} / \mathrm{m}^{3} \\
& =95.18 \mathrm{lb} / \mathrm{ft}^{3}
\end{aligned}
$$

From communications with the industry, it is assumed that the thickness of an FRP wrap produced by a 40oz fabric is approximately $0.047 "$. Therefore the thickness of an FRP wrap produced by 2 layers of a $12 \mathrm{oz}$ fabric is $0.028^{\prime \prime}$

Volume of the wrap $=\pi h\left(R^{2}-r^{2}\right)$

where 
$\mathrm{h}=$ length of the wrapped section of the CCA treated wood post

$\mathrm{r}=$ radius of the bare wood core

$\mathrm{R}=$ radius of the wrapped wood section $=\mathrm{r}+\mathrm{t}=(2.5+0.028)=2.528^{\prime \prime}$

Assuming the length of the wrapped portion of a $7^{\prime}$ long CCA treated wood post to be $3^{\prime}$,

Volume of the wrap $=\pi \times 3 \times\left((2.528 / 12)^{2}-(2.5 / 12)^{2}\right)$

$$
=9.21 \times 10^{-03} \mathrm{ft}^{3}
$$

Weight of the wrap $=$ volume of wrap X density of wrap

$$
\begin{aligned}
& =9.21 \times 10^{-03} \times 95.18 \\
& =0.88 \mathrm{lb}
\end{aligned}
$$

From communications with the industry, the approximate cost of FRP wrap/lb (including material and labor costs $)=\$ 1.5$

Cost of the wrap = weight of the wrap X cost of wrap/lb

$$
\begin{aligned}
& =0.88 \times 1.5 \\
& =\$ 1.32 \text { per post. }
\end{aligned}
$$

Therefore

The cost of a 5" diameter, $7^{\prime}$ long unwrapped wood post $=\$ 7$

The cost of 5" diameter, 7'long wrapped post (with a 3' long FRP wrap of thickness $\left.0.028^{\prime \prime}\right)=\$ 8.32$

The cost of a W6/9 galvanized 7' long steel guard-rail post $=\$ 25$

As seen from the above calculations, the cost of a glass fabric wrapped CCA treated wood post is much lower than the cost of a conventional steel guard-rail post. 


\subsection{Summary}

Composite wrapping of wood with HMR/epoxy/glass fibers (using $25 \%$ fiber volume fraction in GFRP wrap and 0.0475 " thick wrap around $0.5^{\prime \prime}$ wood core) increases the flexural rigidity of wood by 2.62 times under unaged conditions and by 1.77 times under 6-cycle aging conditions (from section 6.6.1). Use of HMR primer increases the retention of mechanical properties of the wood/epoxy/glass hybrid after aging, as shown by the results of chapter V. However, the performance of the wood/epoxy/glass specimens under unaged conditions is lowered by the presence of HMR primer. Chemical aging showed that the wood/HMR/epoxy/glass hybrid is damaged the most by freezethaw cycling in acidic medium. In acidic medium, the glass fibers and the epoxy/glass interface are damaged the most. In alkaline medium, the epoxy/glass interface and the wood/HMR/epoxy bond, are damaged the most. In water, the glass fibers and the epoxy/glass interface are primarily damaged. In salt water, the wood/HMR/epoxy interface is damaged the most. The cost of a glass fabric wrapped CCA treated wood post is lower than the cost of a conventional steel guard-rail post (from section 6.7). 
Chapter VII

\section{DYNAMIC MECHANICAL THERMAL ANALYSIS OF WRAPPED COMPOSITES}

\subsection{Overview}

To ensure the long-term durability of wrapped posts, accelerated aging and chemical aging were performed on coupons representing a scaled down version of the proposed glass fabric wrapped wood posts. In addition, non-destructive testing of the aged test specimens was conducted using a Rheometrics Mechanical Spectrometer (RMS 800). Dynamic spectra of aged and unaged samples were compared. Changes in the test samples due to aging and possible reasons for changes are discussed in this chapter. Details of sample preparation and test procedure are also presented, herein.

\subsection{Materials Used}

CCA treated southern pine strips of cross-section $10.0 \mathrm{~mm} \mathrm{X} 2.0 \mathrm{~mm}$, primed on all surfaces with HMR primer, were used as the core. Though the actual guard-rail posts to be implemented in the field are circular in cross-section, coupons used for DMTA were rectangular in cross-section. This was done to suit the requirements of the Spectrometer (RMS 800). Also, considering the size of the test coupons and the thickness of the wrap, we believe that the aging effects on circular and rectangular cross-sections would not be very different. E-glass fiber roving with epoxy compatible sizing, supplied by PPG, was used for wrapping. The diameter of glass fibers in the roving was $30 \mu \mathrm{m}$. Epoxy (TYFO-S) supplied by Hexcel Fyfe was used as the adhesive. 


\subsection{Sample Preparation}

A lathe was used to prepare wrapped coupons using filament winding. The wood core was held between grips fitted to the lathe and rotated at constant speed. Fibers from a roving were allowed to pass through a resin bath and wrap around the rotating wood core. Wrapped specimens were dried using a motorized drying wheel to prevent dripping of the resin and to promote uniform curing. After curing, the wrapped specimens were cut to the required length. The edges of the specimens were sanded to fit them into the fixtures of the Spectrometer. The length of each specimen was $50 \mathrm{~mm}$ and the length of the wrapped portion was approximately $40 \mathrm{~mm}$. The thickness of the wrap around the $2 \mathrm{~mm}$ wood core was approximately $0.75 \mathrm{~mm}$. The fiber volume fraction of the wrap was approximately $32 \%$ (see Appendix A.2).

\subsection{Description of Test Procedure}

In the dynamic mechanical analysis (DMA) of a test specimen, the stress response to a sinusoidal strain is recorded. Two types of runs were conducted on the specimens:

(a) temperature sweep: a sinusoidal strain of fixed amplitude is imposed at a constant frequency and the temperature of the sample is increased at a constant rate.

(b) frequency-temperature sweep: a sinusoidal strain of fixed amplitude is imposed as a function of frequency at a series of constant temperatures

Dividing the stress amplitude in phase with the strain by the strain amplitude gives the storage modulus $\left(\mathrm{G}^{\prime}\right)$. The storage modulus is a measure of the inherent stiffness of the wrapped specimen. Dividing the stress amplitude out of phase with the strain by the strain amplitude gives the loss modulus $\left(\mathrm{G}^{\prime \prime}\right)$. Typically during a temperature sweep, $\mathrm{G}^{\prime}$, 
$\mathrm{G}^{\prime \prime}$ and $\tan \delta$ (or $\mathrm{G}^{\prime \prime} / \mathrm{G}^{\prime}$ ) are plotted as a function of temperature. These plots display changes in $T_{g}$, damping factor $\left(G^{\prime \prime} / G^{\prime}\right)$ and modulus which may be due to structural changes that the composite has undergone during aging. During a frequency-temperature sweep, $\mathrm{G}^{\prime}$ as a function of frequency is plotted at various constant temperatures. These curves are superimposed onto a single curve at a chosen temperature called the reference temperature. This generates a master curve of $\mathrm{G}^{\prime}$ as a function of frequency at the chosen reference temperature. Comparison of master curves of the aged and unaged samples are used in identification of changes produced by aging with time. Figure 7.1 shows a wrapped coupon loaded in the RMS -800 .

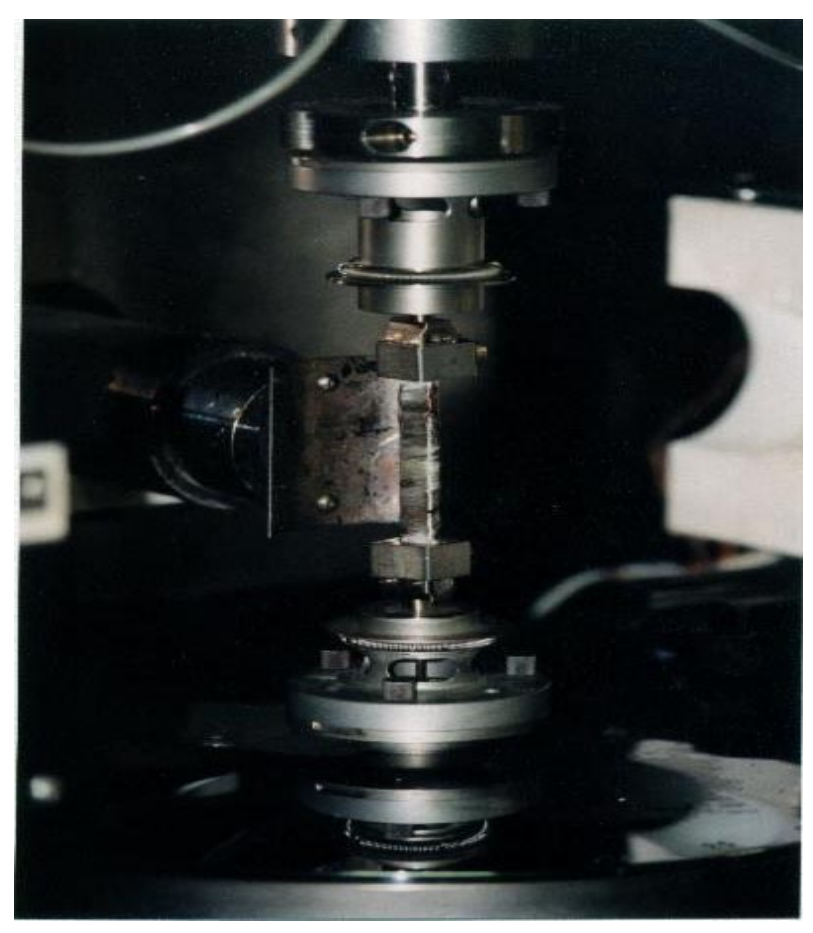

Figure 7.1: Loaded sample in the DMTA set up 


\subsection{Sample Conditioning}

Wrapped specimens were subjected to the following conditions before testing:

(1) exposure to freeze thaw cycles in acidic solution of $\mathrm{pH} 3.0$ for 5 days, 15 days and 25 days in the atmospheric chamber (described in Chapter IV, section 4.3)

(2) exposure to freeze thaw cycles in alkaline solution of $\mathrm{pH} 13.0$ for 5 days, 15 days and 25 days in the atmospheric chamber

(3) exposure to freeze thaw cycles in solution of $\mathrm{pH} 7.0$ for 5 days, 15 days and 25 days in the atmospheric chamber

(4) exposure to freeze thaw cycles in $3 \%$ salt water for 5 days, 15 days and 25 days in the atmospheric chamber

(5) exposure to 6-cycle accelerated aging

The duration of steps in each cycle of the 6-cycle accelerated aging was altered to suit the smaller dimensions of coupons. Each cycle of the 6-cycle accelerated aging consisted of the following steps:

(a) vacuum soaking (25 inches $\mathrm{Hg}$ ) for $30 \mathrm{~min}$

(b) pressure soaking (100 psi) for 30min

(c) freezing for 3 hours at $-10^{0} \mathrm{C}$

(d) oven drying for 2 hours at $50^{\circ} \mathrm{C}$

The reasons for the choice of these aging conditions are mentioned in chapter IV. 


\subsection{Summary of Test Results}

\subsubsection{Accelerated Aging of Wood and Wood/HMR/Epoxy/Glass Hybrid Specimens}

In order to estimate the long-term performance, wood and wood/HMR/epoxy/glass hybrid specimens were subjected to the 6-cycle accelerated aging procedure. During accelerated aging, the samples were subjected to vacuum and pressure cycles in water, freezing and oven drying. All the samples were dried at room temperature for about 3 weeks before testing. Figures 7.2 and 7.3 show the comparison of dynamic spectra of wood and the wood/HMR/epoxy/glass hybrid under unaged and 6cycle aged conditions.

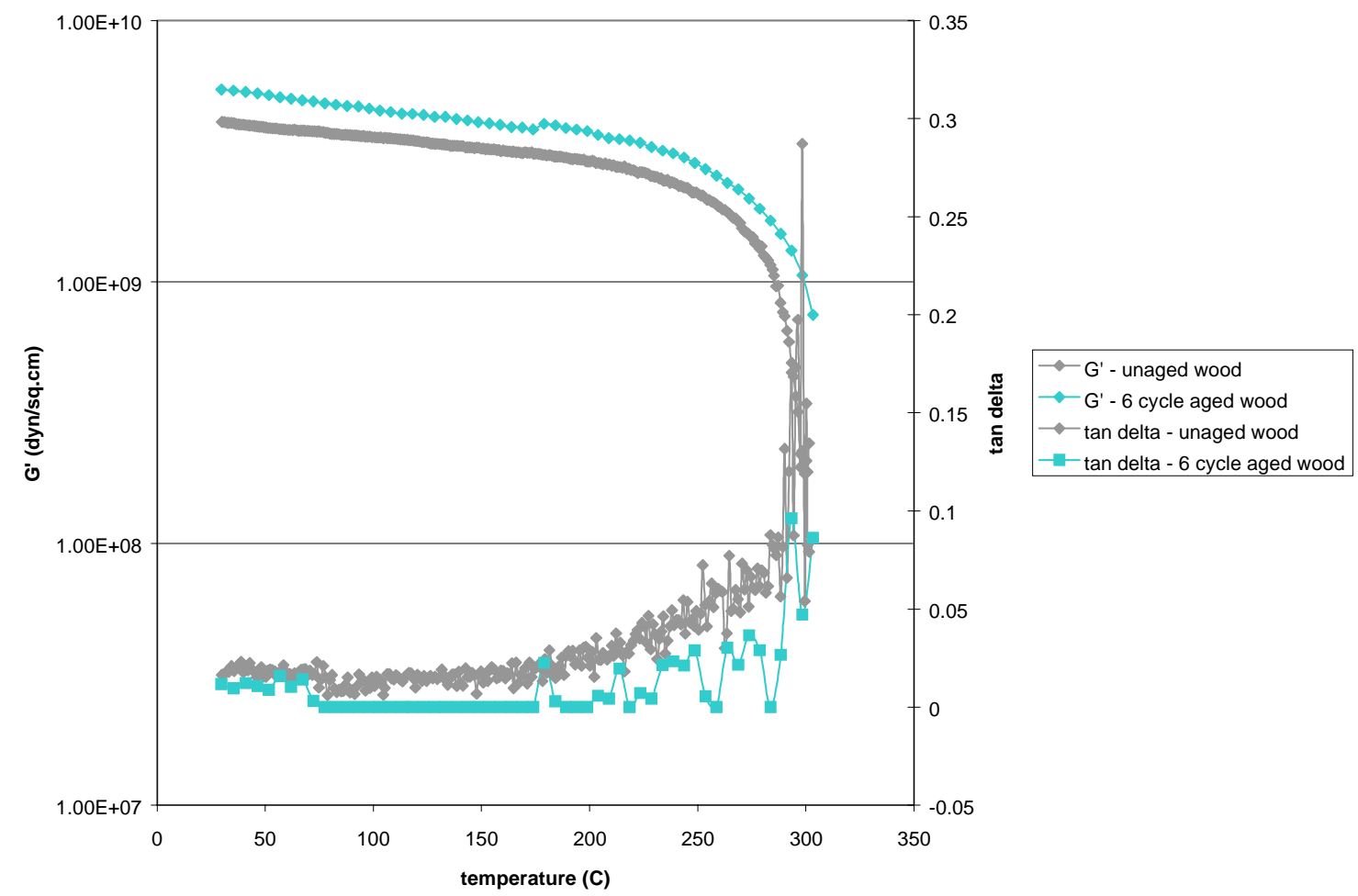

Figure 7.2: Dynamic properties of wood under unaged and 6-cycle aged conditions 


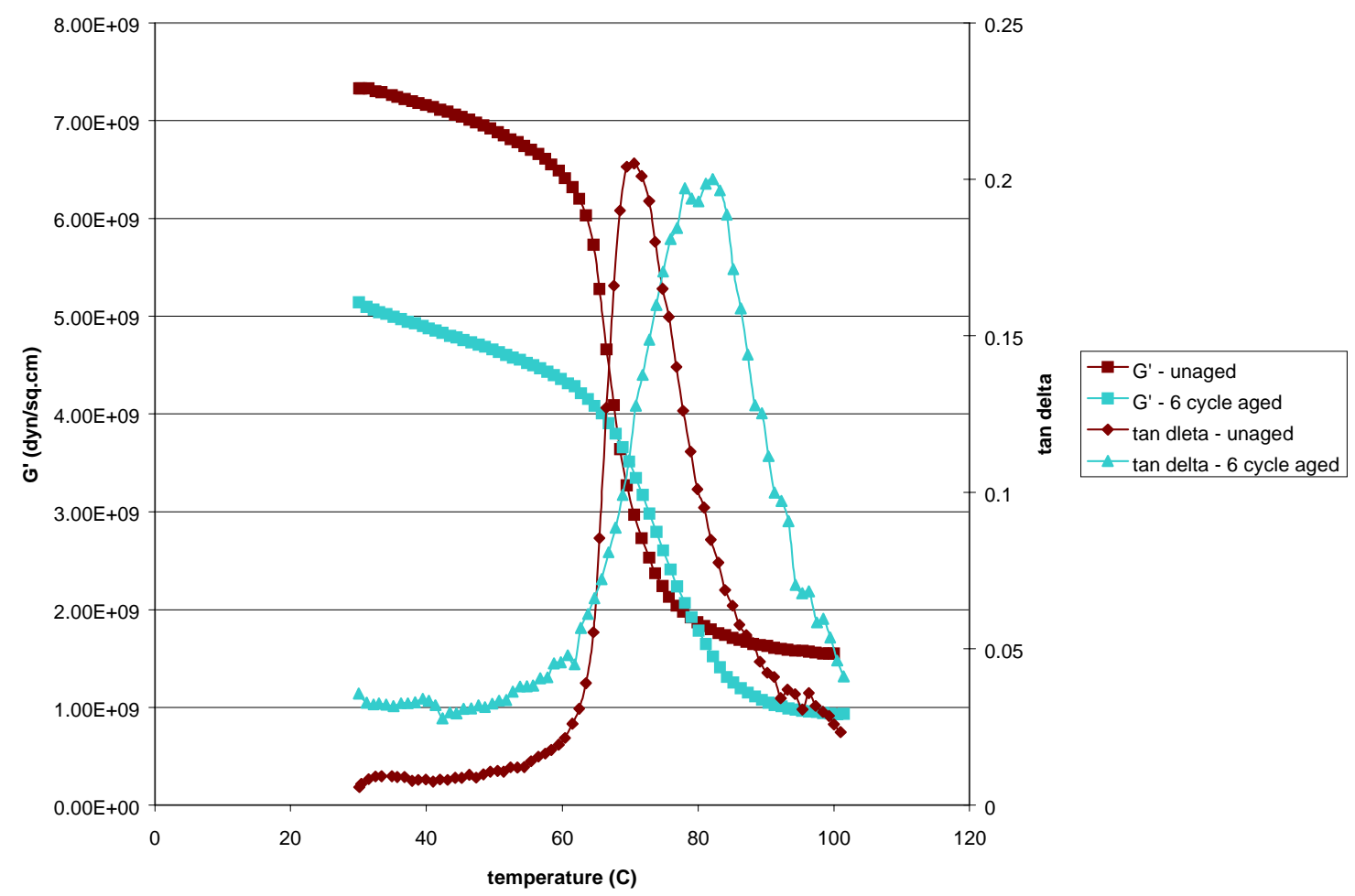

Figure 7.3: Dynamic properties of wood/HMR/epoxy/glass hybrid under unaged and 6-cycle aged conditions

Figure 7.2 shows the dynamic spectra of unaged and 6-cycle aged wood. It can be seen that the modulus of wood slightly increased due to 6-cycle accelerated aging (the $\mathrm{G}^{\prime}$ curve of 6-cycle aged wood sample is above the G' curve of the unaged wood sample). The Tg reduced from $298^{0} \mathrm{C}$ to $293^{0} \mathrm{C}$. Figure 7.3 shows the dynamic spectra of the unaged hybrid and the hybrid subjected to 6-cycle accelerated aging. It can be observed that due to 6-cycle aging, the $\mathrm{Tg}$ increased from $70.6^{0} \mathrm{C}$ to $82.2^{0} \mathrm{C}$. This is attributed to the progress of the cross-linking reaction of epoxy matrix. The modulus decreased meaning the stiffness of the hybrid reduced due to 6-cycle aging. The decrease in modulus and the increase in Tg suggest that 6-cycle aging produces irreversible changes in the hybrid. The primary observation was that the modulus of wood was higher than the modulus of the wrapped specimen after 6-cycle aging which is in contradiction with the 
expectations. This suggests that the wrap does not improve the mechanical properties of wood. The durability of wood and the wrapped specimen is yet to be compared. However, flexure tests of wrapped dowels (Section 6.6.1) showed that the flexural rigidity of bare wood has increased by about 2.6 times under unaged conditions and by 1.8 times under 6-cycle aging conditions due to wrapping. There was no delamination at the wood/wrap interface even after 6-cycle aging. Shear strength measurements also showed that the retention in strength of the wood/HMR/epoxy/glass/epoxy/HMR/wood samples is greater than or equal to the retention in strength of the solid wood samples. The failure of the wood/HMR/epoxy/glass/epoxy/HMR/wood samples was completely in the wood. In order to observe the wood/wrap interface after 6-cycle aging, the DMTA samples (wood/HMR/epoxy/glass hybrids) were sectioned using a band saw. Some of the samples showed partial delamination at the wood/wrap interface. The observations showed that the delamination occurred due to improper fiber wetting by the epoxy resin during sample preparation. Lack of confinement of the wrap to the wood core could also be due to a weak wood/HMR/epoxy/glass bond. It is assumed that the low value for the modulus of the wood/HMR/epoxy/glass specimen was primarily due to improper fiber wet out and lack of proper contact between different components of the hybrid specimen. With a good bond between HMR primed wood and the GFRP wrap, and a thorough fiber wetting, the storage modulus of a wood/HMR/epoxy/glass specimen is expected to be higher than the storage modulus of an unwrapped wood sample. 


\subsubsection{Chemical Aging of Wood/HMR/Epoxy/Glass Hybrid Specimen}

To study the effect of different aging media, wood/HMR/epoxy/glass hybrid specimens were immersed in water, salt water, acidic and alkaline media and subjected to freeze-thaw cycling. The aged samples were analyzed by non-destructive DMTA using Rheometrics Spectrometer (RMS 800). Figures 7.3 through 7.7 show a comparison of storage modulus and $\tan \delta$ curves of the wood/HMR/epoxy/glass hybrid samples aged in different liquid media. These plots were obtained during the temperature sweep of the samples.

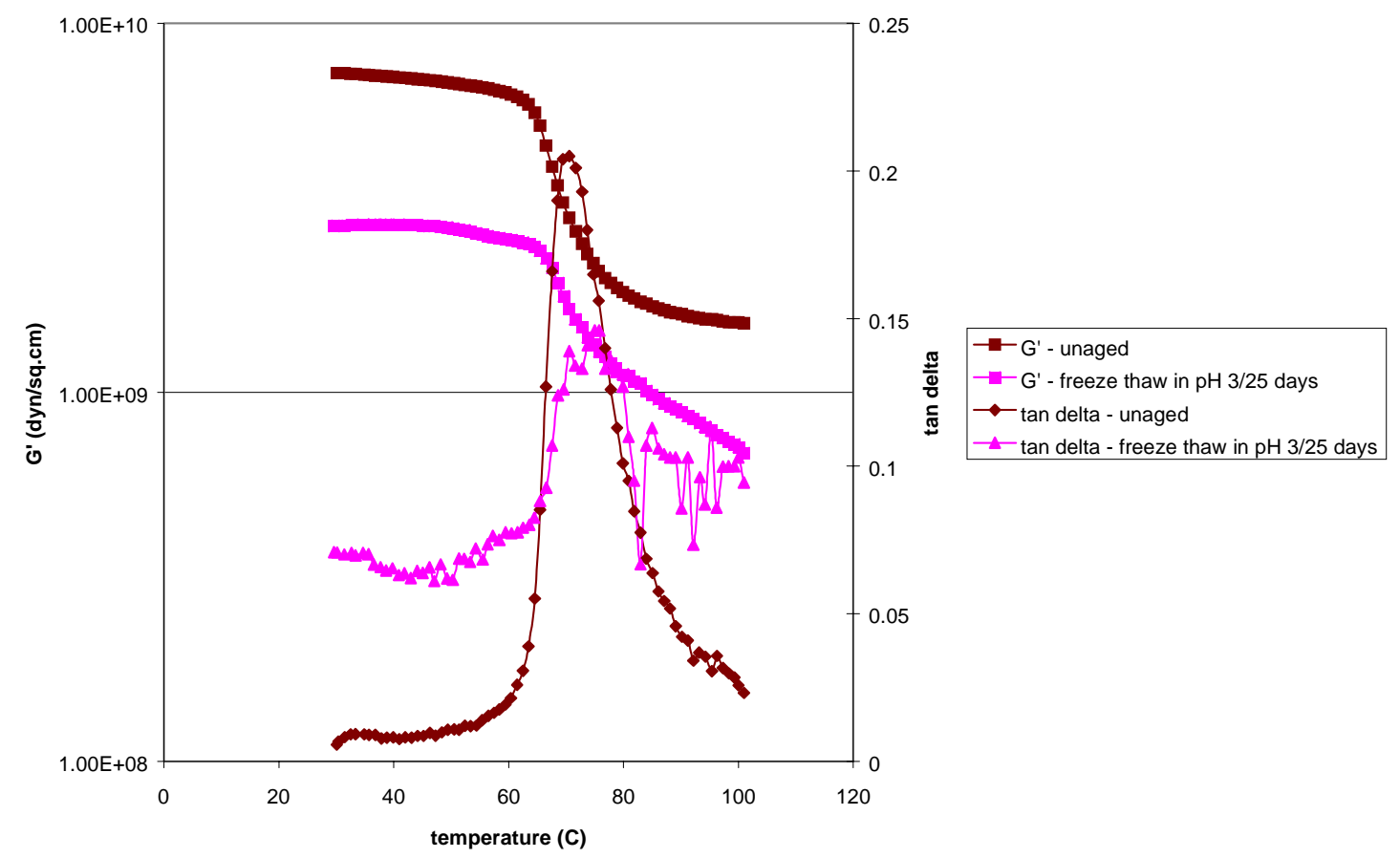

Figure 7.4: Dynamic properties of wood/HMR/epoxy/glass hybrid under unaged and acidic conditions

Figure 7.4 shows that $\mathrm{Tg}$ of unaged hybrid increased from $70.6^{0}$ to $75.8^{0} \mathrm{C}$ due to freeze-thaw in acidic solution of $\mathrm{pH} 3$ for 25 days. This is assumed to be due to enhanced 
curing of the epoxy resin. The width of $\tan \delta$ peak increased due to widening of the glass transition, which means the molecular weight distribution is broad in the aged hybrid. The storage modulus reduced i.e the stiffness of the hybrid reduced. An increase in $\mathrm{Tg}$ and reduction in modulus suggests that aging in acid medium produces some kind of irreversible damage in the hybrid. Since $\mathrm{G}^{\prime}$ and $\mathrm{G}^{\prime \prime}$ differ by an order of magnitude (as seen from Figure $\mathrm{C} 4$ of Appendix C) there could be delamination at the wood/FRP interface or lack of contact between the components of the hybrid specimen.

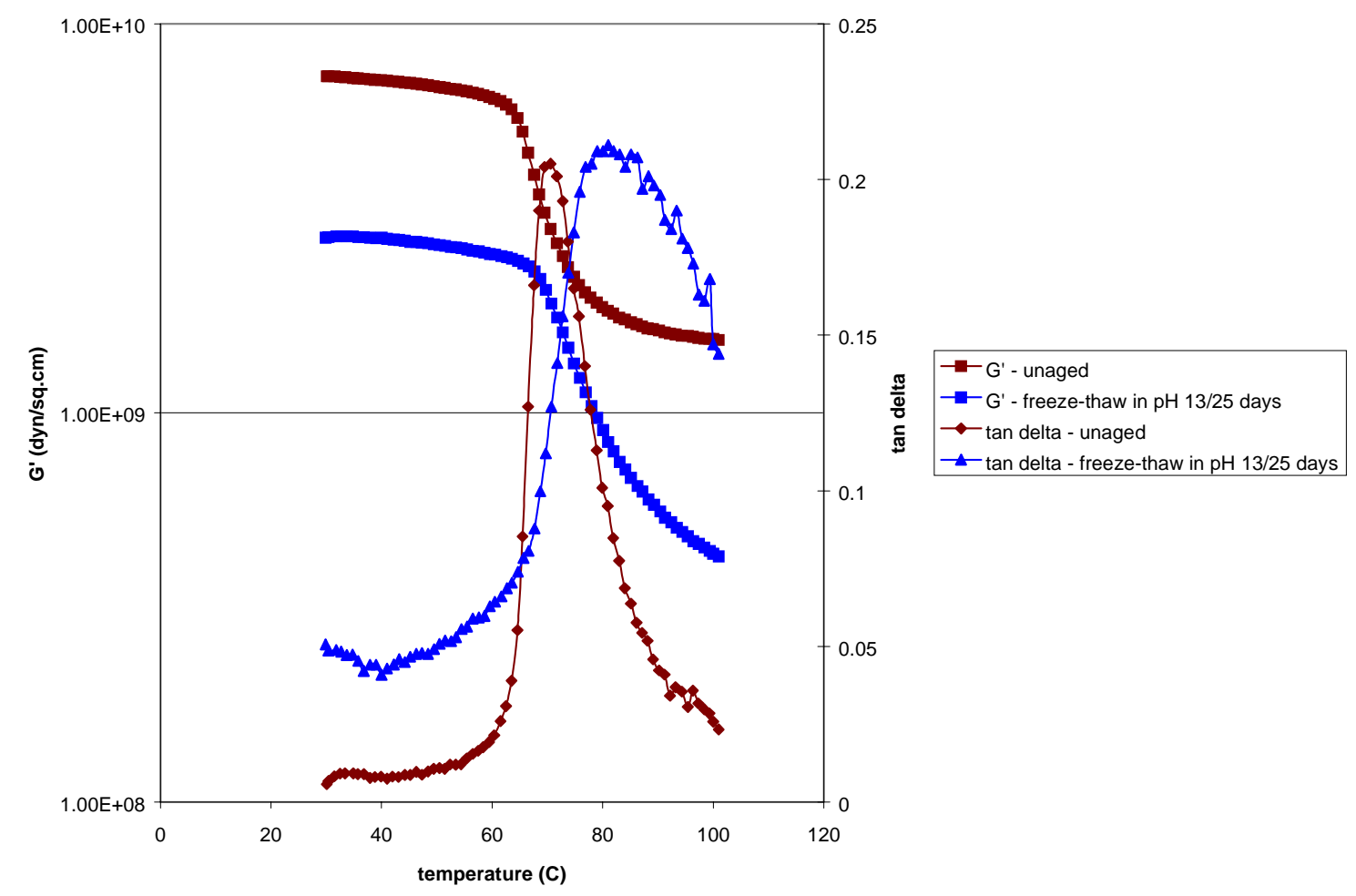

Figure 7.5: Dynamic properties of wood/HMR/epoxy/glass hybrid under unaged and alkaline conditions

From Figure 7.5 it can be observed that freeze-thaw in alkaline medium of pH 13 increased the Tg from $70.6^{0} \mathrm{C}$ to $81^{0} \mathrm{C}$. This could be due to better curing of the 
epoxy matrix. The storage modulus reduced, which means the stiffness of the hybrid reduced. The slight increase in the height of $\tan \delta$ peak can be attributed to the reduced stiffness. An increase in Tg and reduction in modulus suggest that aging in alkaline medium produces irreversible damage in the hybrid.

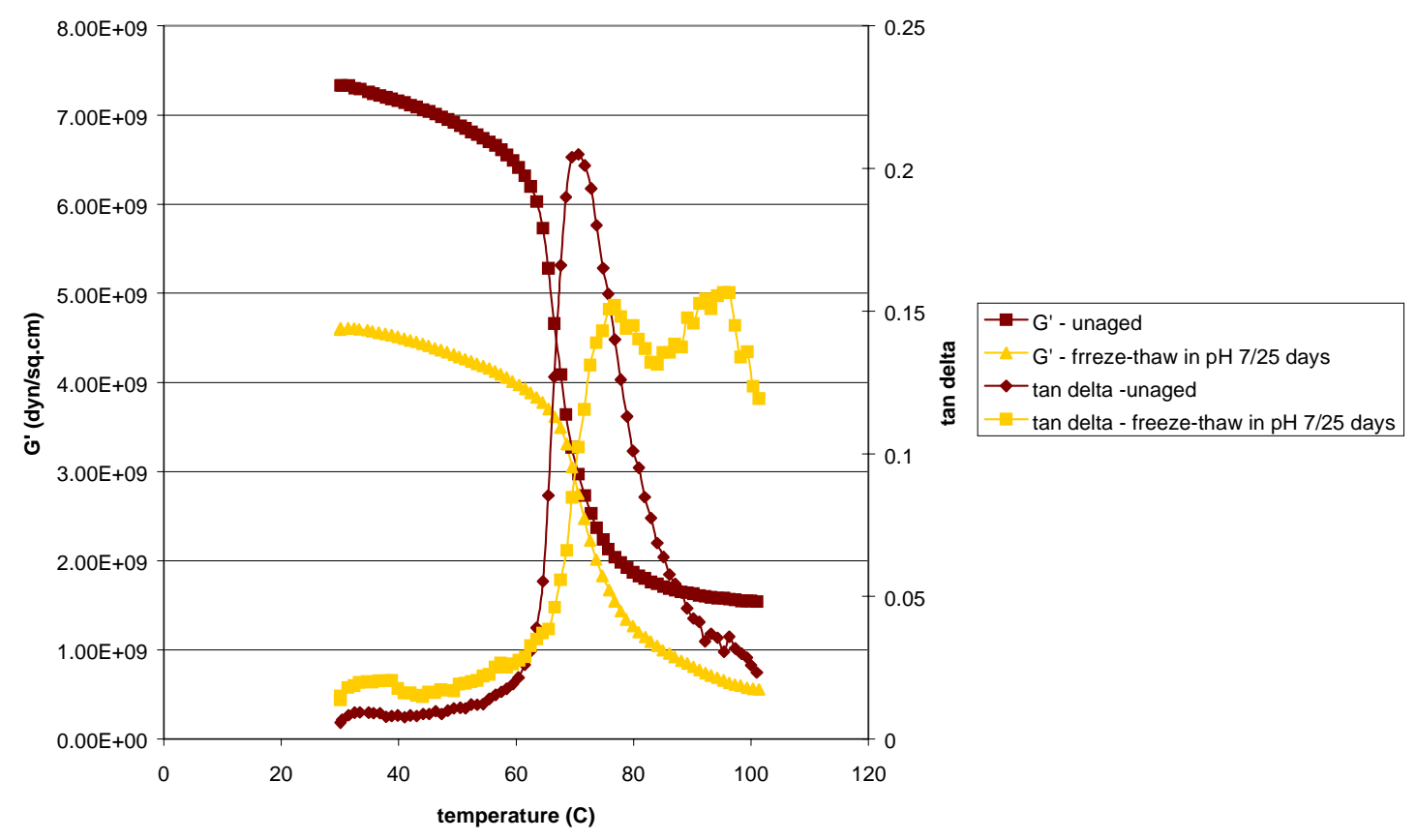

Figure 7.6: Dynamic properties of wood/HMR/epoxy/glass hybrid under unaged and neutral conditions

From Figure 7.6 it can be seen that freeze-thaw in water produced secondary glass transition peaks. The hybrid shows a wide range of glass transition $\left(76^{\circ} \mathrm{C}\right.$ to $\left.96^{0} \mathrm{C}\right)$. This suggests the progress of cross-linking of epoxy resin and appearance of secondary phases in the matrix. The decrease in modulus or stiffness despite the increase in Tg suggests that water also damages the hybrid. 


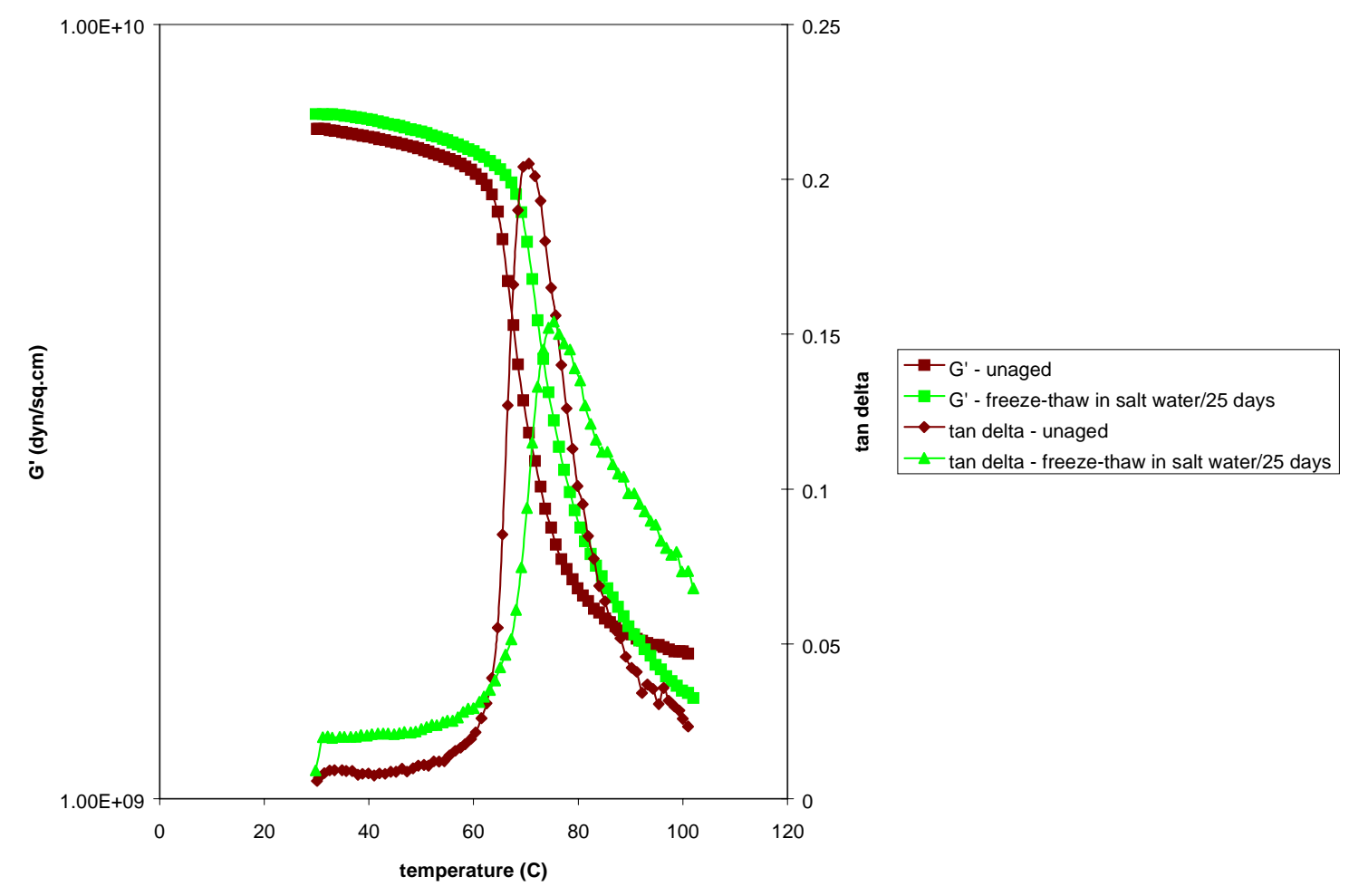

Figure 7.7: Dynamic properties of wood/HMR/epoxy/glass hybrid under unaged and salt water conditions

Figure 7.7 shows that freeze-thaw in salt water increased the $\mathrm{Tg}$ from $70.6^{0} \mathrm{C}$ to $75.3^{\circ} \mathrm{C}$ and slightly increased the modulus. This is attributed to the progress of the crosslinking reaction of the epoxy matrix. The decrease in the height of $\tan \delta$ peak may also be due to the increase in modulus. A comparison of Figures 7.4 through 7.7 shows that freeze-thaw cycling in salt water does not produce irreversible changes in the hybrid sample unlike freeze-thaw cycling in water, acidic medium and alkaline medium. 
Table 7.1: Variation of $T_{g}$ and storage modulus of wood/HMR/epoxy/glass hybrid under different aging conditions

\begin{tabular}{|l|l|l|}
\hline Condition & $\begin{array}{l}\text { Glass transition } \\
\text { temperature }\left({ }^{\circ} \mathrm{C}\right)\end{array}$ & $\begin{array}{l}\text { Percent change in storage } \\
\left.\text { modulus (measured at } 40^{\circ} \mathrm{C}\right)\end{array}$ \\
\hline Unaged & 70.6 & ----- \\
\hline Freeze-thaw in acidic medium & 75.8 & -60 \\
\hline Freeze-thaw in alkaline medium & 81 & -61 \\
\hline Freeze-thaw in water & 96.3 & -37 \\
\hline Freeze-thaw in salt water & 75.3 & +5 \\
\hline 6-cycle aging & 82.2 & -32 \\
\hline
\end{tabular}

The storage modulus of unaged wood/HMR/epoxy/glass hybrid was $7.16 \times 10^{9}$ dyn/sq.cm. The negative sign of percent change in modulus indicates a decrease and positive sign indicates an increase. The following is the summary of observation of Figures 7.4 through 7.7:

Freeze-thaw cycling in all the solutions widened the glass transition region and increased the Tg. It is assumed that liquid diffusion into the wrapped specimen plasticizes the epoxy matrix and facilitates molecular mobility. As a result, the cross-linking of partially cured epoxy resin occurs increasing the Tg. The maximum increase in $\mathrm{Tg}$ (from $70.6^{0} \mathrm{C}$ in dry/unaged condition to $96.3^{0} \mathrm{C}$ ) occurred in water. This suggests that the cross-linking of the epoxy matrix progresses faster in water. The decrease in storage modulus was found to be maximum due to freeze-thaw cycling in acidic and alkaline media. Freeze-thaw cycling in water for 25 days caused as much damage as 6-cycle accelerated aging (in terms of stiffness reduction). Salt water did not seem to cause damage to the hybrid. 


\subsubsection{Time-Temperature Superposition}

To compare the long-term behavior of wood and wood/HMR/epoxy/glass hybrid, a frequency/temperature sweep was conducted on the samples and master curves were generated. The process of generating a master curve from G' versus $\omega$ data at different isothermal temperatures is called time-temperature superposition. It is based on the assumption that the effects of changing temperature on the visco-elastic behavior of a material are equivalent to a shift in the actual time scale of measurement. A temperature range of $40^{\circ} \mathrm{C}$ to $100^{\circ} \mathrm{C}$ was used in the data collection. The frequency range was 0.1 to $100 \mathrm{rad} / \mathrm{sec}$. The reference temperature used in the generation of master curves was $40^{\circ} \mathrm{C}$.

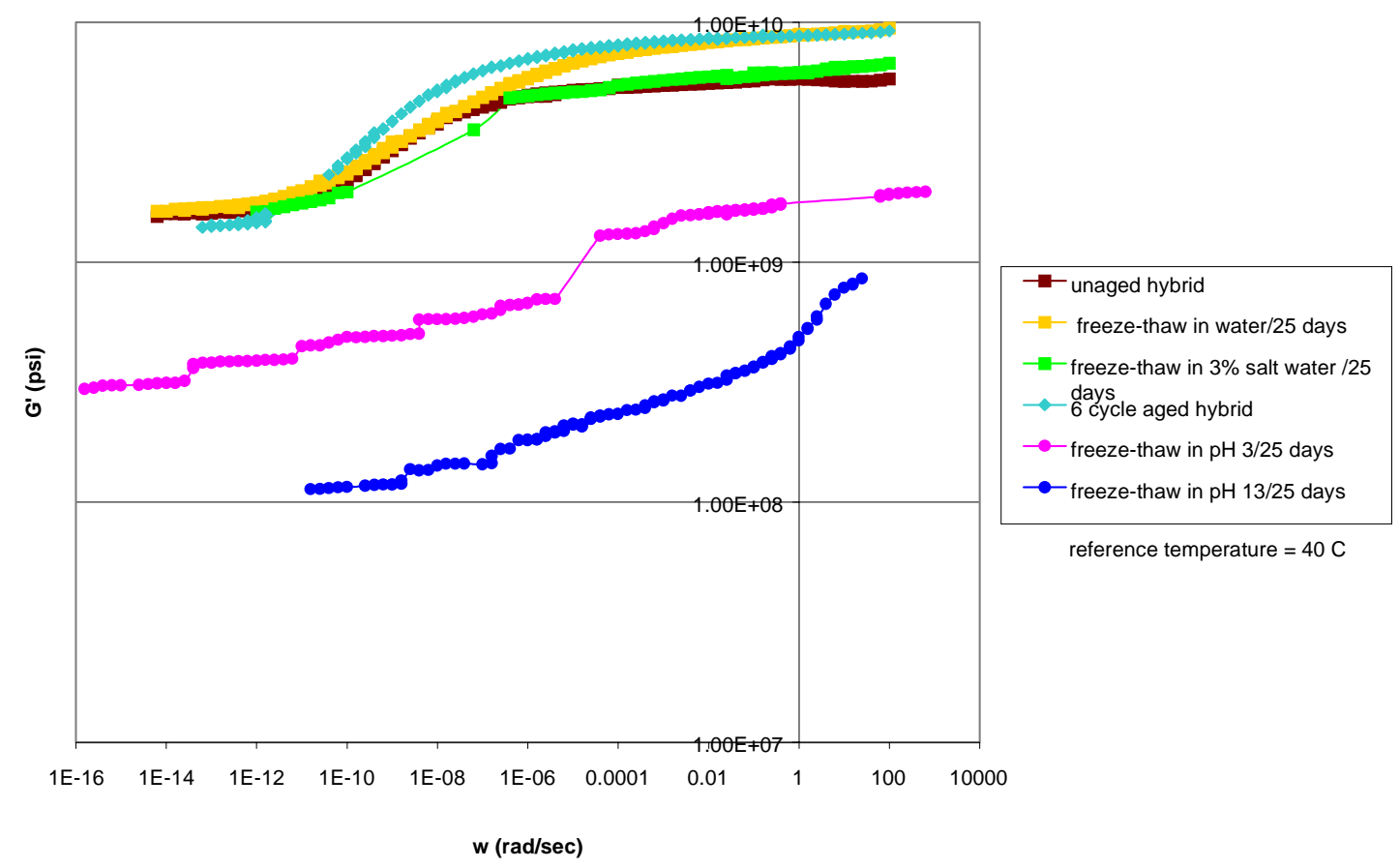

Figure 7.8: Comparison of master curves of wood/HMR/epoxy/glass hybrid aged in different media 
Figure 7.8 shows the variation of storage modulus of the wood/HMR/epoxy/glass hybrid conditioned in different environments with increasing frequency or decreasing time. The degradation trend of storage modulus of the hybrid aged in water, salt water and 6-cycle aging was similar to that of the unaged hybrid. This shows that the composite wrap is able to retain its stiffness after aging in water and salt water. The modulus of the wrapped specimen was reduced the most by the alkaline medium followed by the acidic medium.

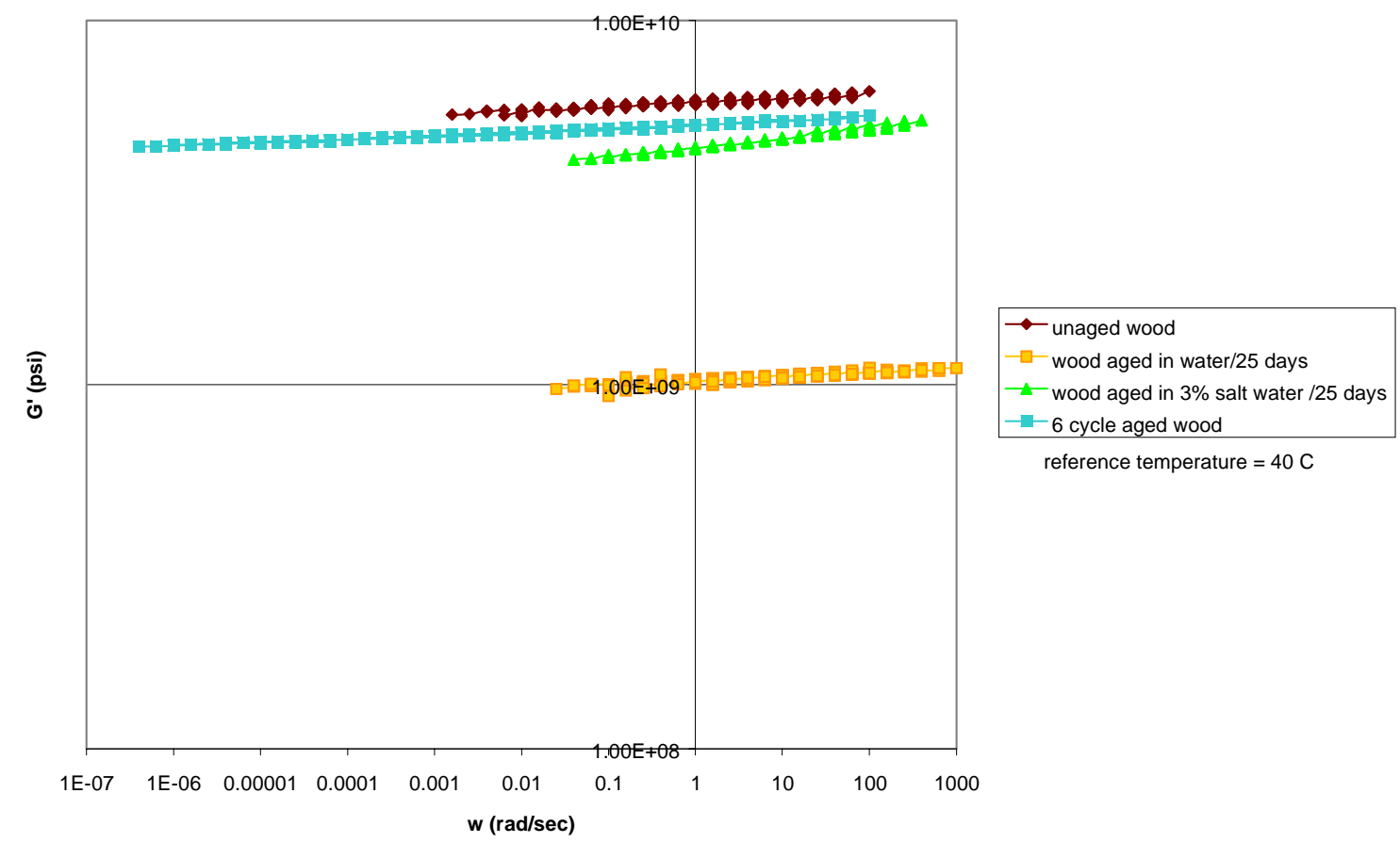

Figure 7.9: Comparison of master curves of CCA treated wood aged in different media

Figure 7.9 shows a comparison of storage modulus of unaged wood and wood exposed to freeze-thaw cycling in water and salt water. The figure shows that the stiffness of wood reduces in water and salt water and the reduction in water is higher than that in salt water. According to the research at the Forest Products Laboratory [26], 
exposure to water at elevated temperatures reduces the strength of wood. This damage is irreversible at temperatures above $100^{\circ} \mathrm{C}$. Wood is fairly resistant to many chemicals but is degraded by strong acids $(\mathrm{pH}<2)$ and strong alkalies $(\mathrm{pH}>10)$. Under the conditions used in this research, it was found that wood is damaged the most in an alkaline medium of $\mathrm{pH} 13$ and the least by 6-cycle aging.

The master curves shown in Figures 7.8 and 7.9 were extrapolated and the moduli of wood and the hybrid were compared at a service life of 20 years. A sample calculation of the storage modulus of a hybrid specimen at a desired service life is shown in Appendix B.3. Table 7.2 shows the stiffness of wood and hybrid under different aging conditions.

Table 7.2: Storage modulus $\left(G^{\prime}\right)$ of wood and wood/HMR/epoxy/glass hybrid at a service life of 20 years

\begin{tabular}{|l|l|l|}
\hline Aging condition & $\begin{array}{l}\mathrm{G}^{\prime} \text { of wood } \\
\left(\mathrm{dyn} / \mathrm{cm}^{2}\right)\end{array}$ & $\begin{array}{l}\mathrm{G}^{\prime} \text { of wood/HMR/epoxy/glass } \\
\text { hybrid }\left(\mathrm{dyn} / \mathrm{cm}^{2}\right)\end{array}$ \\
\hline Unaged & $4.55 \times 10^{9}$ & $2.94 \times 10^{9}$ \\
\hline Freeze-thaw cycling in water & $0.79 \times 10^{9}$ & $3.03 \times 10^{9}$ \\
\hline $\begin{array}{l}\text { Freeze-thaw cycling in 3\% salt } \\
\text { water }\end{array}$ & $1.93 \times 10^{9}$ & $2.34 \times 10^{9}$ \\
\hline 6-cycle aging & $3.96 \times 10^{9}$ & $3.88 \times 10^{9}$ \\
\hline
\end{tabular}

From Table 7.2, it can be seen that, under unaged conditions, the modulus of wood is reduced by wrapping. This contradicts the expectations as well as the results of chapter VI which show a $4 \%$ increase in modulus due to wrapping under unaged conditions. Since the modulus of the hybrid is greater than the modulus of wood under water and salt water conditions, it is assumed that the modulus of the hybrid is greater 
than the modulus of wood under unaged conditions also. In water, the hybrid specimen maintained a 3.8 fold increase in the modulus in comparison with unwrapped wood specimen. In salt water, the hybrid specimen maintained a 1.2 fold increase in the storage modulus in comparison with unwrapped wood specimen. Under 6-cycle aging, the wrap does not increase the stiffness. The results of unaged specimens and 6-cycle aged specimens contradict the results of chapter V. Chapter V shows that the wood/HMR/epoxy/glass bond is atleast as strong as wood under 6-cycle aging conditions. For better judgement, the DMTA hybrid samples were sectioned and the wood/wrap interface was observed. As mentioned in section 7.6.1, there was partial delamination at the wood/wrap interface. From the observations, it appears that the delamination occurred due to improper fiber wetting by the epoxy resin during sample preparation. Rectangular

cross-section of the thin wood core prevented good confinement of the wrap. Poor confinement of the wrap was primarily responsible for the low values of modulus under 6-cycle aging conditions.

\subsection{Summary}

From the master curves of wood/HMR/epoxy/glass hybrid, it was concluded that the performance of wrapped hybrid samples in water, salt water and under 6-cycle aging conditions is similar to the unaged hybrid samples (figure 7.8, section 7.6.3). This shows that the wrapped hybrid samples are durable under atmospheric conditions. However, wrapped hybrid samples are damaged the most in alkaline medium followed by acidic medium (figure 7.8 , section 7.6.3). In both the acidic and alkaline media, a possible delamination of the wood/FRP interface might have occurred (table 7.1). Based on the 
variation of $\mathrm{T}_{\mathrm{g}}$ and the percent reduction in storage modulus (table 7.1), it is assumed that the damage caused by freeze-thaw cycling is greater than the damage caused by vacuum and pressure cycles.

The storage modulus of wood and hybrid specimens, aged in different media, were compared at a service life of 20 years. It was found that, even under saturated conditions, wood samples wrapped with HMR/epoxy/glass fibers (using $31 \%$ fiber volume fraction in GFRP wrap and a $0.75 \mathrm{~mm}$ thick wrap around the $10 \mathrm{~mm} \mathrm{X} 2 \mathrm{~mm}$ wood core), maintained a 4 fold increase in the storage modulus in comparison with unwrapped, but aged wood. Under salt water conditions, the modulus of hybrid samples was found to be 1.2 times that of unwrapped wood. Under 6-cycle aging (table 7.2), the contribution of wrap in increasing the storage modulus of composite samples had diminished to an extent where no significant difference in the storage moduli of unwrapped wood and wrapped hybrid was observed. This is attributed to improper fiber wet out and poor confinement of the wrap to wood.

Results of Chapter VII are summarized in relation to the results of Chapters V and VI:

Results of chapter $\mathrm{V}$ show that under 6-cycle accelerated aging conditions, the failure of wood/epoxy/glass/epoxy/wood and wood/epoxy/wood samples is $100 \%$ in wood (tables 5.16 and 5.17). This means that the wood/HMR/epoxy interface(s) is durable under long-term aging conditions.

Results of chapter VI show that composite wrapping increases the flexural rigidity (EI) of wood under unaged condition as well as 6-cycle aging conditions (table 6.1). There was no delamination at the wood/FRP interface in the hybrid specimens. However, 
no improvement in the flexural strength or modulus under 6-cycle aging conditions was observed due to the effect of moisture fluctuation in the unwrapped wood and hybrid samples (section 6.6.1).

The results of chapter VII show that the storage modulus of wood improved by composite wrapping, but a significant reduction in the storage modulus of wrapped hybrid specimens occurred under 6-cycle aging conditions. However, the reductions in storage modulus of wrapped wood could be attributed to possible sample preparation defects such as improper fiber wet out and poor confinement between the wrap and wood due to the rectangular geometry of the test samples.

From all these results given in Chapters V, VI and VII, it is concluded that the mechanical properties of wood have definitely improved by composite wrapping under unaged conditions. Under 6-cycle aging conditions, the wood/FRP bond is not the weakest link as indicated by the results presented in Chapters V and VI. Therefore the technique of composite wrapping is found to be promising in improving the mechanical properties under 6-cycle aging conditions. A higher fiber volume fraction in the FRP wrap would enhance the mechanical properties and thus reveal the significant strength and stiffness increases between unwrapped wood and wrapped hybrid specimens. In addition, further improvements in mechanical properties of wrapped hybrid specimens can be attained through better wrapping techniques. Testing of large-scale posts is required as being done by Chamarthy [23]. The increase in strength, modulus and stiffness of the full-size wood posts would be higher than the increase found in the present case. This is because the wood core in the full-size posts would be less perfect than the small size $\left(0.5^{\prime \prime}\right.$ dia) posts that were used in this work. 


\section{Chapter VIII}

\section{CONCLUSIONS AND RECOMMENDATIONS}

The primary objective of this research was to determine the effectiveness of composite wrapping in improving the durability and mechanical properties of CCA treated wooden guard-rail posts. The system under investigation was CCA treated wood that is externally reinforced with glass fibers. The conclusions drawn from the experimental results are listed below.

\subsection{Conclusions}

\subsubsection{Testing of Wood/Adhesive and Wood/FRP Interface by Shear Tests}

(1) Among the six resins screened, the combination of epoxy resin and HMR primer provides the best possible adhesion to CCA treated wood and glass fibers. The failure of wood/HMR/epoxy/glass bond (wood/FRP bond) under 6-cycle accelerated aging conditions is completely in the wood, i.e., wood is damaged before the wood/FRP bond under long-term aging conditions.

(2) The loss of shear strength of wood/FRP bond under accelerated aging conditions is less than or equal to the decrease in shear strength of wood, suggesting that the wood/FRP bond is atleast as durable as wood.

(3) The wood/FRP bond is damaged the most by freeze-thaw cycling in an alkaline medium. The wood/HMR/epoxy bond is damaged the most by freeze-thaw cycling in an alkaline medium followed by freeze-thaw cycling in salt water.

(4) The acidic medium does not damage the wood/HMR/epoxy bond. 


\subsubsection{Testing of Wood/HMR/Epoxy/Glass Hybrids by Flexure Tests}

(1) GFRP wrapping of wood increases the mechanical properties of wood (flexural strength, modulus and rigidity) under unaged conditions.

(2) GFRP wrapping of wood improves the flexural rigidity of a CCA treated wood post under 6-cycle aging conditions.

(3) The strength and stiffness of a wood/HMR/epoxy/glass wrapped post is reduced the most by freeze-thaw cycling in an acidic medium. In all the aging media (water, salt water, acid, alkali), the strength is reduced more than the stiffness.

(4) The cost of a full-size glass fabric wrapped wood post is lower than the cost of a conventional steel guard-rail post.

\subsubsection{Testing of Wood/HMR/Epoxy/Glass Hybrids by DMTA}

(1) Composite wrapping of wood with HMR/epoxy/glass fibers increases the stiffness in water and salt water media.

(2) The strength and stiffness of wood/HMR/epoxy/glass hybrid is reduced the most under alkaline and acidic conditions.

\subsubsection{Effect of Aging Media}

(1) Freeze-thaw cycling helps the curing of uncured epoxy resin and increases the $\mathrm{Tg}$ in all aging media. The glass transition of the composite is widened due to aging. Maximum curing of the epoxy matrix occurs in water.

(2) Freeze-thaw cycling is more damaging to wood than vacuum and pressure cycling. Wood is damaged the most by freeze-thaw cycling in water. Damage caused by 
saltwater to wood is less compared to the damage caused by water.

(3) Protons in acid attack the glass fiber surface and primarily damage the glass fibers and the epoxy/glass interface. Acidic medium also damages the wood. Alkaline medium damages the epoxy matrix, the wood/HMR/epoxy interface and the epoxy/glass interface the most. Salt water damages the wood/HMR/epoxy bond the most. Water damages the glass fibers, the epoxy/glass interface and the wood. No significant damage is caused by water to the wood/HMR/epoxy interface. Of all the aging media, alkaline medium and acidic medium are the most damaging to the wood/HMR/epoxy/glass hybrid.

\subsection{Recommendations}

(1) Testing of large-scale posts is required for better understanding of the magnitude of difference in strength and modulus of wood produced by composite wrapping.

(2) Since the epoxy/glass interface is damaged in all aging media except in salt water, the morphological and chemical changes that take place at the interface need to be investigated.

(3) Monitoring the curing of the epoxy matrix during aging can help understand the specific reasons for damage at the interface(s). This can be done by using less damaging techniques such as ultrasonics.

(4) Coating the wrapped post with epoxy resin itself or any moisture resistant materials can be experimented if the process is not expensive.

(5) Standard methods of prediction of long-term performance should be developed. 


\section{BIBLIOGRAPHY}

1. A. K. Kaw, Mechanics of Composite Materials, CRC Press, Boca Raton, Florida, 1997, p 6-25.

2. P. K. Mallick, Fiber Reinforced Composites, Marcel Dekker, New York, Second edition, 1993, p 15-184.

3. A. A. Marra, Technology of Wood Bonding, Van Nostrand Reinhold, New York, 1993, Chapters 3-6 and 8-10.

4. C. A. Harper, Handbook of Plastics, Elastomers and Composites, Mc Graw-Hill, New York, Third edition, 1996, p C.1- C.62.

5. R. F. Blomquist, A. W. Christiansen, R. H. Gillespie and G. E. Myers, Adhesive Bonding of Wood and Structural Materials, Educational Modules for Materials Science and Engineering, University Park, Pennsylvania, Volume 3, 1985, Chapters 1-3.

6. K. Liao, C. R. Schultheisz, D. L. Hunston and L. C. Brinson, "Long-term Durability of Fiber-Reinforced Polymer-Matrix Composite Materials for Infrastructure Applications: A Review,” NIST, Gaithersburg, Maryland, p 23-27.

7. C. L. Schutte, "Environmental Durability of Glass-Fiber Composites," Materials Science and Engineering, November 15, 1994, p 256-323.

8. C. B. Vick and T. A. Kuster, “Mechanical Interlocking of Adhesive Bonds to CCA- Treated Southern Pine - A Scanning Electron Microscopic Study,” Wood and Fiber Science, Vol24, January 1992, p 36-46. 
9. C. B. Vick, "More Durable Epoxy Bonds to Wood with Hydroxymethylated Resorcinol,” Adhesives Age, Vol 40, July 1997, p 24-29.

10. C. B. Vick, K. H. Ritcher and B. H. River "Hydroxymethylated Resorcinol Coupling Agent and Method for Bonding Wood," United States Patent Number 5,543,487, Aug 1996 .

11. C. T. Lynch, Practical Handbook of Materials Science, CRC Press, Boca Raton, Florida, 1989, p 22-37 and 50-64.

12. S. Ghasemzadeh, S. Kajorncheappunngam, R. K. Gupta and H. V. S. GangaRao, "Durability of Glass-Epoxy-Wood Hybrid Composites for Rehabilitation of Railroad Crossties,” Durability of Fiber-Reinforced Polymer (FRP) Composites for Construction: Proceedings of the First International Conference (CDCC '98), Sherbrooke, Canada, Aug 1998, p 81-93,1998.

13. C. B.Vick, " Coupling Agent Improves Durability of PRF Bonds to CCA-Treated Southern Pine" Forest Products Journal, Vol45, March 1995, p 78- 84.

14. C.Lhyman and J.M.Schultz, " Environmental Testing of Glass-Fiber Reinforced Thermoplastics" Polym. Engg. and Sci., September 1984, Vol24, p 1064-1070.

15. S. Kshirsagar, R. Lopez-Anido and R. K. Gupta, "Durability of Fiber Reinforced Composite Wrapping for the Rehabilitation of Concrete Piers," Durability of Fiber Reinforced Polymer (FRP) Composites for Construction: Proceedings of the First International Conference (CDCC '98), Sherbrooke, Canada, Aug 1998, p $117-126$.

16. R. K. Devalpura, M. E. Greenwood, J. V. Ganchel and T. J. Humphry, “Evaluation of GFRP Performance Using Accelerated Test Methods,” Durability 
of Fiber Reinforced Polymer (FRP) Composites for Construction: Proceedings of the First International Conference (CDCC '98), Sherbrooke, Canada, Aug 1998, p $107-116$.

17. P. Chow, S. L. Lewis, A. J. Reinschmidt and E. J. Barenberg, " Effects of Natural and Accelerated Aging on Oak Crossties," Proceedings of the American Wood Preservers Association, Toronto, Canada, May 1987, p 308-329.

18. C. B.Vick, "Hydroxy Methylated Resorcinol Coupling Agent for Enhanced Adhesion of Epoxy and Other Thermosetting Adhesives to Wood," Proceedings of the 1996 Symposium Sponsored by USDA, Portland, Oregon, June 1995, p 47 55.

19. ASTM D 905-94, "Test Method for Strength Properties of Adhesive Bonds in Shear by Compression Loading," The 1995 Annual Book of ASTM Standards, Vol 15.06, p 21-24.

20. S. Kajorncheappunngam, "The Effects of Environmental Aging on the Durability of Glass/Epoxy Composites,” PhD. Dissertation, Dept. of Chemical Engg, West Virginia University, 1999, p 71-196.

21. ASTM D 790-92, "Test Method for Flexural Properties of Unreinforced and Reinforced Plastics and Electrical Insulating Materials," The 1995 Annual Book of ASTM Standards, Vol 8.01, p 155-164.

22. D. R. Talakanti, "Testing and Evaluation of Wood-GFRC Adhesive Interface Integrity Under Accelerated Aging and Mechanical Fatigue,” M.S. Thesis, Dept. of Mechanical Engg, West Virginia University, 1997, p 57-59. 
23. U. Chamarthy, Manufacture and Rehabilitation of Guard-rail Posts Using Composites for Superior Performance, M.S. Thesis, Dept. of Mechanical Engg, West Virginia University, in progress.

24. K. Laosiriphong, Development and Evaluation of Glass Fiber Reinforced Composite/Wood Railroad Cross-ties, M.S. Thesis, Dept. of Civil Engg, West Virginia University, in progress.

25. E. J. Barbero, Introduction to Composite Materials Design, Taylor and Francis, Philadelphia, Pennsylvania, 1998, Chapters 2-4.

26. http://www.fpl.fs.fed.us 
APPENDIX A

A.1 Calculation of Fiber Volume Fraction of Flexure Test Samples

A.2 Calculation of Fiber Volume Fraction of DMTA Samples 


\section{Appendix A.1}

\section{Calculation of Fiber Volume Fraction of Wrapped Samples Tested by 3 Point Bending}

The samples consisted of a wood core of diameter 0.5" with an FRP wrap of 0.048" thickness around the wood core.

Weight of the fabric used $=12 \mathrm{oz} / \mathrm{yd}^{2}$

$$
=12 / 9 \mathrm{oz} / \mathrm{ft}^{2}
$$

Weight of $1 \mathrm{sq} \mathrm{ft}$. of a $1.3 \mathrm{oz} / \mathrm{ft}^{2}$ fabric $=1.3 \mathrm{oz}$

$$
\begin{aligned}
& =1.3 / 16 \mathrm{lbs} \\
& =0.0813 \mathrm{lbs}
\end{aligned}
$$

for $50 \%$ over lap, weight of fabric $=0.0813 \times 2$

$$
=0.1626 \mathrm{lbs}
$$

Density of glass fibers

$$
=0.094 \mathrm{lb} / \mathrm{in}^{3}
$$

Volume of fibers

$$
\text { = weight } / \text { density }
$$$$
=0.1626 / 0.094 \mathrm{in}^{3}
$$$$
=1.73 \mathrm{in}^{3}
$$

Volume of the wrap

$$
\begin{aligned}
& =1 \text { sq.ft } X \text { thickness of wrap } \\
& =12^{\prime \prime} \times 12^{\prime \prime} \times 0.0475^{\prime \prime} \\
& =6.84 \mathrm{in}^{3}
\end{aligned}
$$

Fiber volume fraction

$$
\begin{aligned}
& =\text { volume of fibers /volume of wrap } \\
& =1.73 / 6.84 \\
& =25.3 \%
\end{aligned}
$$




\section{Appendix A.2}

\section{Calculation of Fiber Volume Fraction of Wrapped Samples Tested by Mechanical}

\section{Spectrometer}

Average weight of resin in a wood/HMR/epoxy $/$ glass hybrid $=0.553 \mathrm{~g}$

Average weight of glass fibers in a wood/HMR/epoxy/glass hybrid $=0.572 \mathrm{~g}$

Density of epoxy $=1.16 \times 10^{3} \mathrm{~kg} / \mathrm{m}^{3}$

Density of glass fibers $=2627 \mathrm{~kg} / \mathrm{m}^{3}$

Average volume of epoxy in a sample $=0.476 \times 10^{-6} \mathrm{~m}^{3}$

Average volume of glass fibers in a sample $=0.218 \times 10^{-6} \mathrm{~m}^{3}$

Fiber volume fraction $=$ volume of fibers $/$ volume of fibers + volume of resin

$$
=31.4 \%
$$




\section{APPENDIX B}

B.1 Sample Calculation of Shear Strength from Shear Test Data

B.2 Sample Calculations of Mechanical Properties from Flexure Test Data

B.3 Sample Calculations for the Generation of a Master Curve from Mechanical Spectroscopy Data 


\section{Appendix B.1}

\section{Sample Calculation of Shear Strength from Shear Test Data}

The following is the typical data obtained by testing 15 shear samples (of wood/epoxy/wood):

\begin{tabular}{|l|l|}
\hline max. load in lbs & \% wood failure \\
\hline 780 & 10 \\
\hline 420 & 8 \\
\hline 190 & 50 \\
\hline 300 & 25 \\
\hline 345 & 30 \\
\hline 342 & 20 \\
\hline 260 & 30 \\
\hline 280 & 10 \\
\hline 261 & 8 \\
\hline 776 & 40 \\
\hline 480 & 15 \\
\hline 277 & 30 \\
\hline 40 & 50 \\
\hline 133 & 25 \\
\hline 412 & 5 \\
\hline
\end{tabular}


The maximum load value is read from the machine and the percent failure is obtained by visual examination.

The average load taken by wood/epoxy/wood specimen $=316.25 \mathrm{lbs}$.

The shear area or the area on which the load was applied $=0.5^{\prime \prime} \times 0.5^{\prime \prime}$

$$
=0.25 \text { sq.in. }
$$

The average shear strength of wood/epoxy/wood bond = average load/area

$$
\begin{aligned}
& =316.25 / 0.25 \\
& =1265 \mathrm{psi}
\end{aligned}
$$

Average wood failure $=20 \%$ 


\section{Appendix B.2}

\section{$\underline{\text { Sample Calculations of Mechanical Properties from Flexure Test Data }}$}

For a 3 point bending test and cylindrical geometry of the sample,

$\mathrm{L}=$ loading span

$\mathrm{P}=$ maximum load taken by the sample before failure

$\mathrm{M}=$ maximum applied bending moment $=\mathrm{PL} / 4$

$\mathrm{I}=$ moment of inertia

for the present case of wood core of radius (r) and wrap of thickness ' $t$ ' around the core,

$$
\begin{aligned}
& I_{\text {hybrid }}=I_{\text {wood }}+E_{\text {wrap }} / E_{\text {wood }}\left(I_{\text {wrap }}\right) \\
& I_{\text {wood }}=\pi r^{4} / 4 \text { where 'r' is the radius of the wood core } \\
& E_{\text {wrap }} / E_{\text {wood }}=\text { approximately } 1.25 \text { for a fiber volume fraction of } 25 \% \\
& I_{\text {wrap }}=\pi\left[(r+t)^{4}-r^{4}\right] / 4
\end{aligned}
$$

$\mathrm{c}=$ distance between the axis of the specimen and point of application of load $=(\mathrm{r}+\mathrm{t})$

$\sigma=$ ultimate flexural strength $=\mathrm{Mc} / \mathrm{I}$

$$
=\mathrm{PL}(\mathrm{r}+\mathrm{t}) / 4 \mathrm{I}_{\text {hybrid }}
$$

$\delta=$ deflection at the mid span $=\mathrm{PL}^{3} / 48 \mathrm{EI}_{\text {hybrid }}$

$\mathrm{E}=$ Modulus of Elasticity $=(\mathrm{P} / \delta) \mathrm{L}^{3} / 48 \mathrm{I}_{\text {hybrid }}$

$\mathrm{EI}=$ flexural rigidity or bending stiffness $=(\mathrm{P} / \delta) \mathrm{L}^{3} / 48$

The load versus deflection data of a wood/HMR/epoxy/glass hybrid sample obtained during a 3 point bending test is given below: 
point \# deflection (in) load (lbs)

\begin{tabular}{|c|c|c|}
\hline 1 & 0 & 0.02685 \\
\hline 2 & 0.00007 & 0.02685 \\
\hline 3 & 0.00034 & 0.02685 \\
\hline 4 & 0.00061 & 0.08054 \\
\hline & 0.00087 & 0.16108 \\
\hline & 0.00114 & 0.16108 \\
\hline & 0.00141 & 0.16108 \\
\hline 8 & 0.00168 & 0.18792 \\
\hline & 0.00194 & 0.16108 \\
\hline & 0.00221 & 0.16108 \\
\hline & 0.00247 & 0.16108 \\
\hline & 0.00274 & 0.16108 \\
\hline & 0.00301 & 0.18792 \\
\hline & 0.00327 & 0.16108 \\
\hline & 0.00354 & 0.16108 \\
\hline & 0.00381 & 0.16108 \\
\hline & 0.00407 & 0.16108 \\
\hline & 0.00434 & 0.16108 \\
\hline & 0.00461 & 0.16108 \\
\hline & 0.00487 & 0.16108 \\
\hline & 0.00514 & 0.16108 \\
\hline & 0.00541 & 0.16108 \\
\hline & 0.00568 & 0.18792 \\
\hline & 0.00594 & 0.18792 \\
\hline & 0.00621 & 0.16108 \\
\hline & 0.00647 & 0.18792 \\
\hline & 0.00674 & 0.18792 \\
\hline & 0.00701 & 0.18792 \\
\hline I & 0.00727 & 0.18792 \\
\hline 30 & 0.00754 & 0.18792 \\
\hline & 0.00781 & 0.18792 \\
\hline & 0.00807 & 0.16108 \\
\hline & 0.00834 & 0.18792 \\
\hline 3 & 0.00861 & 0.18792 \\
\hline & 0.00887 & 0.16108 \\
\hline 6 & 0.00914 & 0.18792 \\
\hline 37 & 0.00941 & 0.16108 \\
\hline & 0.00968 & 0.16108 \\
\hline & 0.00994 & 0.16108 \\
\hline & 0.01021 & 0.16108 \\
\hline & 0.01047 & 0.16108 \\
\hline & 0.01074 & 0.16108 \\
\hline & 0.01101 & 0.16108 \\
\hline 14 & 0.01127 & 0.16108 \\
\hline & 0.01154 & 0.16108 \\
\hline & 0.01181 & 0.16108 \\
\hline 1 & 0.01208 & 0.16108 \\
\hline & 0.01234 & 0.16108 \\
\hline & 0.01261 & 0.16108 \\
\hline & 0.01287 & 0.18792 \\
\hline
\end{tabular}

point \# deflection (in) load (lbs)

\begin{tabular}{rrr}
51 & 0.01314 & 0.16108 \\
52 & 0.01341 & 0.16108 \\
53 & 0.01367 & 0.16108 \\
54 & 0.01394 & 0.16108 \\
55 & 0.01421 & 0.16108 \\
56 & 0.01447 & 0.16108 \\
57 & 0.01474 & 0.16108 \\
58 & 0.01501 & 0.16108 \\
59 & 0.01527 & 0.16108 \\
60 & 0.01554 & 0.18792 \\
61 & 0.01581 & 0.18792 \\
62 & 0.01608 & 0.48323 \\
63 & 0.01634 & 0.72484 \\
64 & 0.01661 & 0.91275 \\
65 & 0.01687 & 0.99329 \\
66 & 0.01714 & 1.0201 \\
67 & 0.01741 & 1.1544 \\
68 & 0.01767 & 1.3691 \\
69 & 0.01794 & 1.4228 \\
70 & 0.01821 & 1.5034 \\
71 & 0.01848 & 1.4228 \\
72 & 0.01874 & 1.1275 \\
73 & 0.01901 & 0.91275 \\
74 & 0.01927 & 0.67114 \\
75 & 0.01954 & 0.77853 \\
76 & 0.01981 & 1.047 \\
77 & 0.02008 & 1.3423 \\
78 & 0.02034 & 1.6644 \\
79 & 0.02061 & 2.0403 \\
80 & 0.02087 & 2.3893 \\
81 & 0.02114 & 2.7651 \\
82 & 0.02141 & 3.1678 \\
83 & 0.02167 & 3.5436 \\
84 & 0.02194 & 3.9463 \\
85 & 0.02221 & 4.349 \\
86 & 0.02248 & 4.7785 \\
87 & 0.02274 & 5.1812 \\
88 & 0.02301 & 5.5839 \\
89 & 0.02327 & 6.0134 \\
90 & 0.02354 & 6.3892 \\
91 & 0.02381 & 6.7919 \\
92 & 0.02408 & 7.1678 \\
93 & 0.02434 & 7.5973 \\
94 & 0.02461 & 7.9731 \\
95 & 0.02487 & 8.4027 \\
96 & 0.02514 & 8.7785 \\
97 & 0.02541 & 9.208 \\
98 & 0.02567 & 9.5302 \\
99 & 0.02594 & 9.9329 \\
100 & 0.02621 & 10.282 \\
\hline & & \\
\hline 5 & &
\end{tabular}




\begin{tabular}{|c|c|c|c|c|c|}
\hline point \# & deflection (in) & ad (lbs) & point \# & deflection (in) & ad (lbs) \\
\hline 101 & 0.02648 & 10.685 & 151 & 0.03981 & 17.476 \\
\hline 102 & 0.02674 & 11.06 & 152 & 0.04007 & 17.557 \\
\hline 103 & 0.02701 & 11.49 & 153 & 0.04034 & 17.745 \\
\hline 104 & 0.02727 & 11.866 & 154 & 0.04061 & 17.825 \\
\hline 105 & 0.02754 & 12.295 & 155 & 0.04088 & 18.04 \\
\hline 106 & 0.02781 & 12.671 & 156 & 0.04114 & 18.174 \\
\hline 107 & 0.02807 & 13.127 & 157 & 0.04141 & 18.443 \\
\hline 108 & 0.02834 & 13.53 & 158 & 0.04167 & 18.685 \\
\hline 109 & 0.02861 & 13.933 & 159 & 0.04194 & 19.034 \\
\hline 110 & 0.02888 & 14.174 & 160 & 0.04221 & 19.383 \\
\hline 111 & 0.02914 & 14.416 & 161 & 0.04247 & 19.731 \\
\hline 112 & 0.02941 & 14.738 & 162 & 0.04274 & 20.08 \\
\hline 113 & 0.02967 & 14.846 & 163 & 0.04301 & 20.403 \\
\hline 114 & 0.02994 & 14.899 & 164 & 0.04328 & 20.805 \\
\hline 115 & 0.03021 & 14.98 & 165 & 0.04354 & 21.235 \\
\hline 116 & 0.03048 & 14.98 & 166 & 0.04381 & 21.664 \\
\hline 117 & 0.03074 & 15.034 & 167 & 0.04407 & 22.094 \\
\hline 118 & 0.03101 & 15.114 & 168 & 0.04434 & 22.523 \\
\hline 119 & 0.03127 & 15.168 & 169 & 0.04461 & 22.98 \\
\hline 120 & 0.03154 & 15.221 & 170 & 0.04488 & 23.436 \\
\hline 121 & 0.03181 & 15.302 & 171 & 0.04514 & 23.893 \\
\hline 122 & 0.03207 & 15.383 & 172 & 0.04541 & 24.295 \\
\hline 123 & 0.03234 & 15.463 & 173 & 0.04568 & 24.778 \\
\hline 124 & 0.03261 & 15.517 & 174 & 0.04594 & 25.154 \\
\hline 125 & 0.03288 & 15.517 & 175 & 0.04621 & 25.611 \\
\hline 126 & 0.03314 & 15.597 & 176 & 0.04647 & 26.013 \\
\hline 127 & 0.03341 & 15.624 & 177 & 0.04674 & 26.443 \\
\hline 128 & 0.03367 & 15.624 & 178 & 0.04701 & 26.846 \\
\hline 129 & 0.03394 & 15.651 & 179 & 0.04728 & 27.275 \\
\hline 130 & 0.03421 & 15.678 & 180 & 0.04754 & 27.678 \\
\hline 131 & 0.03448 & 15.732 & 181 & 0.04781 & 28.107 \\
\hline 132 & 0.03474 & 15.758 & 182 & 0.04807 & 28.51 \\
\hline 133 & 0.03501 & 15.785 & 183 & 0.04834 & 28.966 \\
\hline 134 & 0.03528 & 15.812 & 184 & 0.04861 & 29.342 \\
\hline 135 & 0.03554 & 15.893 & 185 & 0.04888 & 29.799 \\
\hline 136 & 0.03581 & 15.946 & 186 & 0.04914 & 30.201 \\
\hline 137 & 0.03607 & 15.973 & 187 & 0.04941 & 30.658 \\
\hline 138 & 0.03634 & 16.054 & 188 & 0.04968 & 31.033 \\
\hline 139 & 0.03661 & 16.107 & 189 & 0.04994 & 31.49 \\
\hline 140 & 0.03688 & 16.134 & 190 & 0.05021 & 31.866 \\
\hline 141 & 0.03714 & 16.215 & 191 & 0.05047 & 32.295 \\
\hline 142 & 0.03741 & 16.268 & 192 & 0.05074 & 32.671 \\
\hline 143 & 0.03767 & 16.322 & 193 & 0.05101 & 33.101 \\
\hline 144 & 0.03794 & 16.483 & 194 & 0.05128 & 33.45 \\
\hline 145 & 0.03821 & 16.51 & 195 & 0.05154 & 33.879 \\
\hline 146 & 0.03848 & 16.591 & 196 & 0.05181 & 34.255 \\
\hline 147 & 0.03874 & 16.698 & 197 & 0.05208 & 34.658 \\
\hline 148 & 0.03901 & 17.02 & 198 & 0.05234 & 35.06 \\
\hline 149 & 0.03928 & 17.235 & 199 & 0.05261 & 35.49 \\
\hline 150 & 0.03954 & 17.342 & 200 & 0.05288 & 35.866 \\
\hline
\end{tabular}


point \# deflection (in) load (lbs)

$\begin{array}{lrr}201 & 0.05314 & 36.268 \\ 202 & 0.05341 & 36.671 \\ 203 & 0.05368 & 37.047 \\ 204 & 0.05394 & 37.423 \\ 205 & 0.05421 & 37.799 \\ 206 & 0.05447 & 38.174 \\ 207 & 0.05474 & 38.577 \\ 208 & 0.05501 & 38.953 \\ 209 & 0.05528 & 39.302 \\ 210 & 0.05554 & 39.731 \\ 211 & 0.05581 & 40.107 \\ 212 & 0.05608 & 40.483 \\ 213 & 0.05634 & 40.859 \\ 214 & 0.05661 & 41.235 \\ 215 & 0.05687 & 41.584 \\ 216 & 0.05714 & 41.96 \\ 217 & 0.05741 & 42.309 \\ 218 & 0.05768 & 42.711 \\ 219 & 0.05794 & 43.06 \\ 220 & 0.05821 & 43.463 \\ 221 & 0.05847 & 43.812 \\ 222 & 0.05874 & 44.215 \\ 223 & 0.05901 & 44.564 \\ 224 & 0.05928 & 44.966 \\ 225 & 0.05954 & 45.315 \\ 226 & 0.05981 & 45.718 \\ 227 & 0.06008 & 46.121 \\ 228 & 0.06034 & 46.55 \\ 229 & 0.06061 & 46.926 \\ 230 & 0.06087 & 47.382 \\ 231 & 0.06114 & 47.758 \\ 232 & 0.06141 & 48.215 \\ 233 & 0.06168 & 48.59 \\ 234 & 0.06194 & 49.047 \\ 235 & 0.06221 & 49.423 \\ 236 & 0.06248 & 49.852 \\ 237 & 0.06274 & 50.228 \\ 238 & 0.06301 & 50.684 \\ 239 & 0.06328 & 51.114 \\ 240 & 0.06354 & 51.57 \\ 241 & 0.06381 & 51.946 \\ 242 & 0.06408 & 52.403 \\ 243 & 0.06434 & 52.859 \\ 244 & 0.06461 & 53.288 \\ 245 & 0.06487 & 53.691 \\ 246 & 0.06514 & 54.094 \\ 247 & 0.06541 & 54.523 \\ 248 & 0.06568 & 54.98 \\ 249 & 0.06594 & 55.409 \\ 250 & 0.06621 & 55.866\end{array}$

point \# deflection (in) load (lbs)

$\begin{array}{rrr}251 & 0.06648 & 56.322 \\ 252 & 0.06674 & 56.752 \\ 253 & 0.06701 & 57.208 \\ 254 & 0.06728 & 57.637 \\ 255 & 0.06754 & 58.067 \\ 256 & 0.06781 & 58.47 \\ 257 & 0.06808 & 58.926 \\ 258 & 0.06834 & 59.329 \\ 259 & 0.06861 & 59.812 \\ 260 & 0.06888 & 60.215 \\ 261 & 0.06914 & 60.698 \\ 262 & 0.06941 & 61.101 \\ 263 & 0.06968 & 61.584 \\ 264 & 0.06994 & 61.986 \\ 265 & 0.07021 & 62.416 \\ 266 & 0.07048 & 62.819 \\ 267 & 0.07074 & 63.275 \\ 268 & 0.07101 & 63.678 \\ 269 & 0.07127 & 64.134 \\ 270 & 0.07154 & 64.537 \\ 271 & 0.07181 & 65.02 \\ 272 & 0.07208 & 65.44901 \\ 273 & 0.07234 & 65.90601 \\ 274 & 0.07261 & 66.30901 \\ 275 & 0.07288 & 66.792 \\ 276 & 0.07314 & 67.194 \\ 277 & 0.07341 & 67.678 \\ 278 & 0.07368 & 68.08 \\ 279 & 0.07394 & 68.59 \\ 280 & 0.07421 & 69.02 \\ 281 & 0.07448 & 69.50301 \\ 282 & 0.07474 & 69.93301 \\ 283 & 0.07501 & 70.416 \\ 284 & 0.07527 & 70.872 \\ 285 & 0.07554 & 71.356 \\ 286 & 0.07581 & 71.785 \\ 287 & 0.07608 & 72.215 \\ 288 & 0.07634 & 72.67101 \\ 289 & 0.07661 & 73.12701 \\ 290 & 0.07688 & 73.58401 \\ 291 & 0.07714 & 74.067 \\ 292 & 0.07741 & 74.523 \\ 293 & 0.07768 & 75.007 \\ 294 & 0.07794 & 75.46301 \\ 295 & 0.07821 & 75.89201 \\ 296 & 0.07848 & 76.34901 \\ 297 & 0.07874 & 76.778 \\ 298 & 0.07901 & 77.262 \\ 299 & 0.07928 & 77.691 \\ 300 & 0.07954 & 78.147\end{array}$


point \# deflection (in) load (lbs)

$\begin{array}{rrr}301 & 0.07981 & 78.577 \\ 302 & 0.08008 & 79.06001 \\ 303 & 0.08034 & 79.49001 \\ 304 & 0.08061 & 79.97301 \\ 305 & 0.08088 & 80.402 \\ 306 & 0.08114 & 80.859 \\ 307 & 0.08141 & 81.262 \\ 308 & 0.08168 & 81.718 \\ 309 & 0.08194 & 82.121 \\ 310 & 0.08221 & 82.604 \\ 311 & 0.08248 & 83.006 \\ 312 & 0.08274 & 83.49001 \\ 313 & 0.08301 & 83.89201 \\ 314 & 0.08328 & 84.37601 \\ 315 & 0.08354 & 84.75101 \\ 316 & 0.08488 & 86.899 \\ 317 & 0.08621 & 89.02 \\ 318 & 0.08754 & 91.11401 \\ 319 & 0.08888 & 93.20801 \\ 320 & 0.09021 & 95.16801 \\ 321 & 0.09154 & 97.23501 \\ 322 & 0.09288 & 99.11401 \\ 323 & 0.09421 & 101.15 \\ 324 & 0.09554 & 102.98 \\ 325 & 0.09688 & 105.02 \\ 326 & 0.09821 & 106.95 \\ 327 & 0.09954 & 108.99 \\ 328 & 0.10088 & 110.87 \\ 329 & 0.10221 & 112.86 \\ 330 & 0.10354 & 114.79 \\ 331 & 0.10488 & 116.72 \\ 332 & 0.10621 & 118.66 \\ 333 & 0.10754 & 120.59 \\ 334 & 0.10888 & 122.58 \\ 335 & 0.11021 & 124.46 \\ 336 & 0.11154 & 126.39 \\ 337 & 0.11288 & 128.27 \\ 338 & 0.11421 & 130.15 \\ 339 & 0.11554 & 132.08 \\ 340 & 0.11688 & 133.96 \\ 341 & 0.11821 & 135.84 \\ 342 & 0.11954 & 137.72 \\ 343 & 0.12088 & 139.54 \\ 344 & 0.12221 & 141.37 \\ 345 & 0.12354 & 143.14 \\ 346 & 0.12488 & 144.97 \\ 347 & 0.12621 & 146.68 \\ 348 & 0.12754 & 148.51 \\ 350 & 0.12888 & 150.23 \\ & 0.13021 & 152\end{array}$

point \# deflection (in) load (lbs)

$\begin{array}{lrr}351 & 0.13154 & 153.66 \\ 352 & 0.13288 & 155.44 \\ 353 & 0.13421 & 157.1 \\ 354 & 0.13554 & 158.82 \\ 355 & 0.13688 & 160.43 \\ 356 & 0.13821 & 162.09 \\ 357 & 0.13954 & 163.76 \\ 358 & 0.14088 & 165.42 \\ 359 & 0.14221 & 167.09 \\ 360 & 0.14355 & 168.75 \\ 361 & 0.14488 & 170.31 \\ 362 & 0.14621 & 171.92 \\ 363 & 0.14755 & 173.42 \\ 364 & 0.14888 & 175.03 \\ 365 & 0.15021 & 176.48 \\ 366 & 0.15155 & 178.04 \\ 367 & 0.15288 & 179.54 \\ 368 & 0.15421 & 181.05 \\ 369 & 0.15554 & 182.44 \\ 370 & 0.15688 & 183.89 \\ 371 & 0.15821 & 185.23 \\ 372 & 0.15954 & 186.63 \\ 373 & 0.16088 & 188.08 \\ 374 & 0.16221 & 189.42 \\ 375 & 0.16354 & 190.87 \\ 376 & 0.16488 & 192.21 \\ 377 & 0.16621 & 193.56 \\ 378 & 0.16754 & 194.9 \\ 379 & 0.16888 & 196.11 \\ 380 & 0.17021 & 197.31 \\ 381 & 0.17154 & 198.52 \\ 382 & 0.17288 & 199.6 \\ 383 & 0.17421 & 200.67 \\ 384 & 0.17554 & 201.88 \\ 385 & 0.17688 & 202.95 \\ 386 & 0.17821 & 204.03 \\ 387 & 0.17954 & 204.97 \\ 388 & 0.18088 & 206.17 \\ 389 & 0.18221 & 207.38 \\ 390 & 0.18354 & 208.46 \\ 391 & 0.18488 & 209.66 \\ 392 & 0.18621 & 210.87 \\ 393 & 0.18755 & 212.08 \\ 394 & 0.18888 & 213.15 \\ 395 & 0.19021 & 214.36 \\ 396 & 0.19154 & 215.57 \\ 397 & 0.19288 & 216.64 \\ 398 & 0.19421 & 217.72 \\ 399 & 0.19555 & 218.66 \\ 400 & 0.19687 & 219.19\end{array}$


point \# deflection (in) load (lbs)

$\begin{array}{rrr}401 & 0.19821 & 219.73 \\ 402 & 0.19954 & 220.27 \\ 403 & 0.20088 & 220.94 \\ 404 & 0.20221 & 221.74 \\ 405 & 0.20355 & 222.55 \\ 406 & 0.20488 & 223.36 \\ 407 & 0.20621 & 224.16 \\ 408 & 0.20754 & 223.76 \\ 409 & 0.20888 & 224.16 \\ 410 & 0.21021 & 224.56 \\ 411 & 0.21155 & 225.23 \\ 412 & 0.21288 & 225.91 \\ 413 & 0.21421 & 226.58 \\ 414 & 0.21554 & 227.25 \\ 415 & 0.21688 & 228.05 \\ 416 & 0.21821 & 228.72 \\ 417 & 0.21955 & 229.4 \\ 418 & 0.22088 & 230.2 \\ 419 & 0.22221 & 230.74 \\ 420 & 0.22354 & 231.54 \\ 421 & 0.22488 & 232.21 \\ 422 & 0.22621 & 233.02 \\ 423 & 0.22754 & 233.69 \\ 424 & 0.22888 & 234.36 \\ 425 & 0.23021 & 235.03 \\ 426 & 0.23155 & 235.7 \\ 427 & 0.23288 & 236.24 \\ 428 & 0.23421 & 236.91 \\ 429 & 0.23554 & 237.58 \\ 430 & 0.23688 & 238.39 \\ 431 & 0.23821 & 238.93 \\ 432 & 0.23955 & 239.73 \\ 433 & 0.24088 & 240.4 \\ 434 & 0.24221 & 241.21 \\ 435 & 0.24354 & 241.74 \\ 436 & 0.24488 & 242.55 \\ 437 & 0.24621 & 243.22 \\ 438 & 0.24755 & 243.89 \\ 439 & 0.24888 & 244.43 \\ 440 & 0.25021 & 245.1 \\ 441 & 0.25154 & 245.64 \\ 442 & 0.25288 & 246.17 \\ 443 & 0.25421 & 246.58 \\ 444 & 0.25555 & 246.98 \\ 445 & 0.25688 & 247.38 \\ 446 & 0.25821 & 247.78 \\ 447 & 0.25954 & 248.19 \\ 448 & 0.26088 & 248.72 \\ 449 & 0.26221 & 249.13 \\ 450 & 0.26355 & 249.53\end{array}$

point \# deflection (in) load (lbs)

$\begin{array}{rrr}451 & 0.26488 & 249.93 \\ 452 & 0.26621 & 250.2 \\ 453 & 0.26754 & 250.6 \\ 454 & 0.26888 & 251.01 \\ 455 & 0.27021 & 251.27 \\ 456 & 0.27155 & 251.68 \\ 457 & 0.27288 & 251.95 \\ 458 & 0.27421 & 252.21 \\ 459 & 0.27555 & 252.35 \\ 460 & 0.27688 & 252.62 \\ 461 & 0.27821 & 252.89 \\ 462 & 0.27955 & 253.02 \\ 463 & 0.28088 & 253.42 \\ 464 & 0.28221 & 253.69 \\ 465 & 0.28355 & 253.82 \\ 466 & 0.28488 & 254.09 \\ 467 & 0.28621 & 254.5 \\ 468 & 0.28755 & 254.76 \\ 469 & 0.28888 & 255.03 \\ 470 & 0.29021 & 255.44 \\ 471 & 0.29155 & 255.7 \\ 472 & 0.29288 & 255.97 \\ 473 & 0.29421 & 256.38 \\ 474 & 0.29554 & 256.64 \\ 475 & 0.29688 & 256.78 \\ 476 & 0.29821 & 256.91 \\ 477 & 0.29955 & 257.05 \\ 478 & 0.30088 & 257.05 \\ 479 & 0.30222 & 257.31 \\ 480 & 0.30354 & 257.45 \\ 481 & 0.30488 & 257.85 \\ 482 & 0.30621 & 258.12 \\ 483 & 0.30755 & 258.39 \\ 484 & 0.30888 & 258.79 \\ 485 & 0.31022 & 259.19 \\ 486 & 0.31154 & 259.6 \\ 487 & 0.31288 & 260 \\ 488 & 0.31421 & 260.4 \\ 489 & 0.31555 & 260.94 \\ 490 & 0.31688 & 261.34 \\ 491 & 0.31822 & 261.88 \\ 492 & 0.31955 & 262.28 \\ 493 & 0.32088 & 262.82 \\ 494 & 0.32221 & 263.22 \\ 495 & 0.32355 & 263.62 \\ 496 & 0.32488 & 263.89 \\ 497 & 0.32621 & 264.16 \\ 498 & 0.32755 & 264.56 \\ 499 & 0.32888 & 264.97 \\ 500 & 0.33021 & 265.23\end{array}$


point \# deflection (in) load (lbs)

\begin{tabular}{rrr}
501 & 0.33155 & \multicolumn{1}{r}{265.5} \\
502 & 0.33288 & 265.77 \\
503 & 0.33421 & 265.91 \\
504 & 0.33555 & 266.17 \\
505 & 0.33688 & 266.44 \\
506 & 0.33821 & 266.58 \\
507 & 0.33955 & 266.84 \\
508 & 0.34088 & 267.11 \\
509 & 0.34221 & 267.38 \\
510 & 0.34355 & 267.78 \\
511 & 0.34488 & 268.19 \\
512 & 0.34622 & 268.59 \\
513 & 0.34755 & 268.99 \\
514 & 0.34888 & 269.53 \\
515 & 0.35021 & 269.93 \\
516 & 0.35155 & 270.2 \\
517 & 0.35288 & 270.33 \\
518 & 0.35422 & 270.6 \\
519 & 0.35555 & 270.87 \\
520 & 0.35688 & 271.27 \\
521 & 0.35821 & 271.54 \\
522 & 0.35955 & 270.6 \\
523 & 0.36088 & 270.87 \\
524 & 0.36222 & 271.14 \\
525 & 0.36328 & 257.45 \\
526 & 0.36461 & 257.58 \\
527 & 0.36595 & 257.99 \\
528 & 0.36728 & 258.66 \\
529 & 0.36861 & 259.33 \\
530 & 0.36995 & 260 \\
531 & 0.37128 & 260.67 \\
532 & 0.37262 & 261.34 \\
533 & 0.37395 & 262.01 \\
534 & 0.37527 & 262.68 \\
535 & 0.37661 & 263.36 \\
536 & 0.37794 & 263.89 \\
537 & 0.37928 & 264.43 \\
538 & 0.38061 & 264.97 \\
539 & 0.38194 & 265.5 \\
540 & 0.38328 & 266.04 \\
541 & 0.38461 & 266.58 \\
542 & 0.38595 & 266.98 \\
543 & 0.38728 & 267.38 \\
544 & 0.38862 & 267.78 \\
545 & 0.38995 & 268.05 \\
546 & 0.39128 & 268.32 \\
547 & 0.39261 & 268.72 \\
548 & 0.39394 & 268.99 \\
550 & 0.39528 & 269.4 \\
& 0.39661 & 269.66
\end{tabular}

point \# deflection (in) load (lbs)

$\begin{array}{llr}551 & 0.39794 & 269.93 \\ 552 & 0.39928 & 270.07 \\ 553 & 0.40061 & 270.47 \\ 554 & 0.40195 & 270.6 \\ 555 & 0.40328 & 270.74 \\ 556 & 0.40462 & 270.87 \\ 557 & 0.40595 & 271.14 \\ 558 & 0.40728 & 271.27 \\ 559 & 0.40862 & 271.41 \\ 560 & 0.40995 & 271.54 \\ 561 & 0.41128 & 271.54 \\ 562 & 0.41155 & 271.68 \\ 563 & 0.41288 & 271.68 \\ 564 & 0.41422 & 271.54 \\ 565 & 0.41555 & 271.27 \\ 566 & 0.41661 & 170.74\end{array}$


In order to evaluate the mechanical properties, a graph of the load versus deflection data is plotted. The straight-line portion of the curve is plotted again with zeroed intercept. This is done by subtracting the initial values of load and deflection from all the subsequent values. The slope of the straight-line portion of the curve gives the value of $(\mathrm{P} / \delta)$.

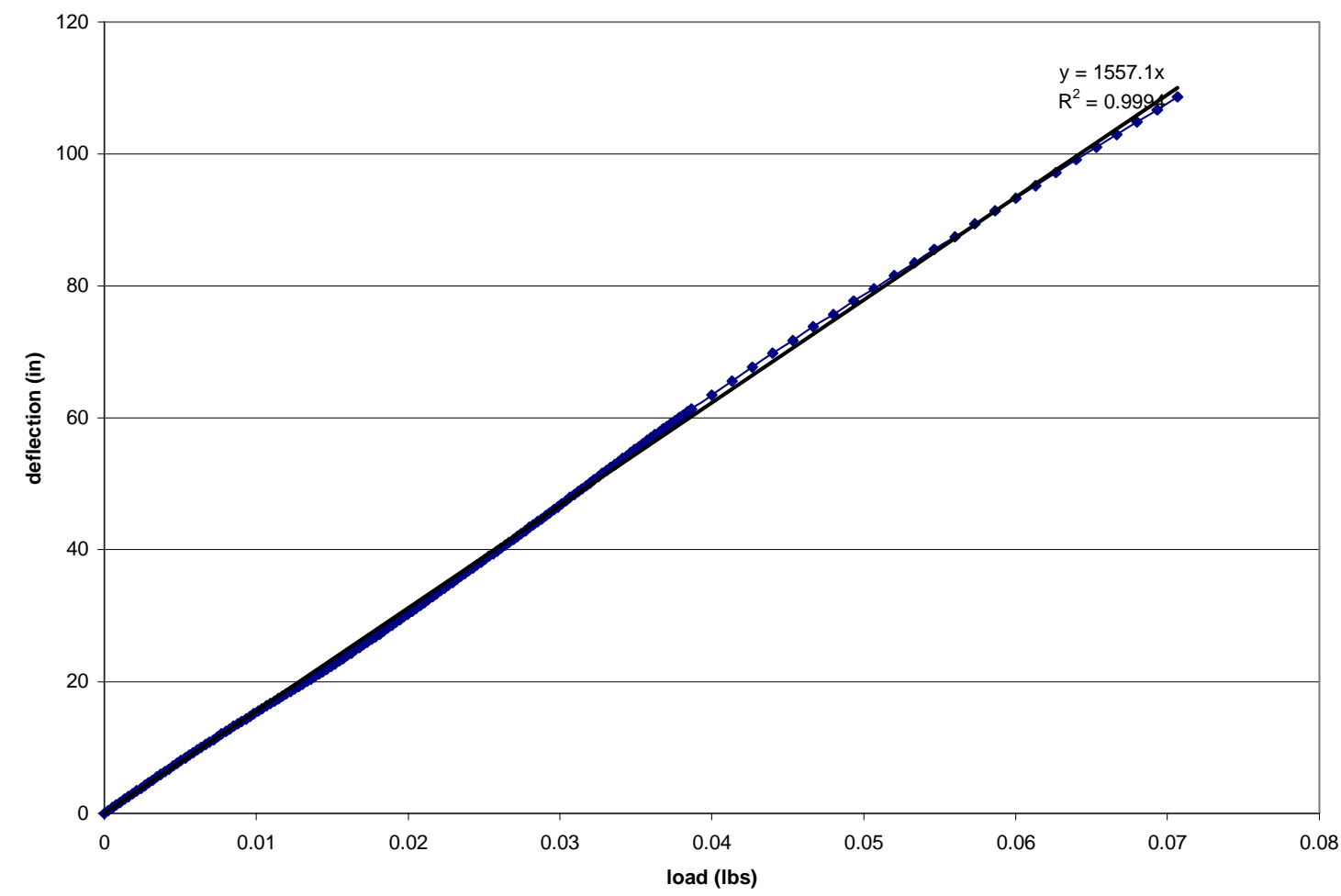

Figure B1: load versus deflection data of wood/HMR/epoxy/glass hybrid with zeroed intercept

Using the graph and the formulae listed, the following data is calculated:

\begin{tabular}{|l|l|l|}
\hline property & Value & Units \\
\hline $\mathrm{r}+\mathrm{t}$ & 0.301 & inches \\
\hline $\mathrm{L}$ & 6 & inches \\
\hline $\mathrm{P}$ & 271.7 & lbs \\
\hline $\mathrm{P} / \delta$ & 1557.1 & lbs/in \\
\hline $\mathrm{I}_{\text {wood }}$ & 0.0031 & in $^{4}$ \\
\hline $\mathrm{I}_{\text {hybrid }}$ & $8.38 \mathrm{E}-03$ & in $^{4}$ \\
\hline$\sigma$ & $1.46 \mathrm{E}+04$ & psi \\
\hline $\mathrm{E}$ & $8.36 \mathrm{E}+05$ & psi \\
\hline EI & $7.01 \mathrm{E}+03$ & lb-in \\
\hline
\end{tabular}


Table B1: 6-cycle aging data of wood/HMR/epoxy/glass hybrid samples:

\begin{tabular}{|l|l|l|l|l|l|l|l|}
\hline Condition & $\begin{array}{l}\mathrm{P} \\
(\mathrm{lb})\end{array}$ & $\begin{array}{l}\mathrm{R} \\
\text { (in) }\end{array}$ & $\begin{array}{l}\mathrm{I} \\
\left(\mathrm{in}^{4}\right)\end{array}$ & $\begin{array}{l}\sigma \\
(\mathrm{psi})\end{array}$ & $\begin{array}{l}\mathrm{E} / \delta \\
(\mathrm{psi})\end{array}$ & $\begin{array}{l}\mathrm{EI} \\
(\mathrm{psi})\end{array}$ \\
\hline Unaged & 287.24 & 0.305 & $7.76 \mathrm{E}-03$ & $1.69 \mathrm{E}+04$ & 1953.9 & $1.13 \mathrm{E}+06$ & $8.8 \mathrm{E}+03$ \\
\hline Cycle 1 & 221.9 & 0.305 & $7.76 \mathrm{E}-03$ & $1.31 \mathrm{E}+04$ & 1556.3 & $0.90 \mathrm{E}+06$ & $7.0 \mathrm{E}+03$ \\
\hline Cycle 2 & 340.54 & 0.32 & $9.55 \mathrm{E}-03$ & $1.71 \mathrm{E}+04$ & 2386 & $1.12 \mathrm{E}+06$ & $10.7 \mathrm{E}+03$ \\
\hline Cycle 3 & 254.9 & 0.295 & $6.70 \mathrm{E}-03$ & $1.68 \mathrm{E}+04$ & 1615.4 & $1.08 \mathrm{E}+06$ & $7.24 \mathrm{E}+03$ \\
\hline Cycle 4 & 251.4 & 0.315 & $8.93 \mathrm{E}-03$ & $1.33 \mathrm{E}+04$ & 1911.3 & $0.96 \mathrm{E}+06$ & $8.59 \mathrm{E}+03$ \\
\hline Cycle 6 & 178.1 & 0.298 & $7.01 \mathrm{E}-03$ & $1.14 \mathrm{E}+04$ & 1517.8 & $0.97 \mathrm{E}+06$ & $6.86 \mathrm{E}+03$ \\
\hline
\end{tabular}

Table B2: 6-cycle aging data of wood/epoxy/glass hybrid samples:

\begin{tabular}{|l|l|l|l|l|l|l|l|}
\hline Condition & $\begin{array}{l}\mathrm{P} \\
(\mathrm{lb})\end{array}$ & $\begin{array}{l}\mathrm{R} \\
(\mathrm{in})\end{array}$ & $\begin{array}{l}\mathrm{I} \\
\left(\mathrm{in}^{4}\right)\end{array}$ & $\begin{array}{l}\mathrm{P} / \delta \\
(\mathrm{psi})\end{array}$ & $\mathrm{E}$ & $\begin{array}{l}\mathrm{EI} \\
(\mathrm{psi})\end{array}$ & \\
\hline Unaged & 299.5 & 0.292 & $6.40 \mathrm{E}-03$ & $2.05 \mathrm{E}+04$ & 2552.3 & $1.79 \mathrm{E}+06$ & $11.47 \mathrm{E}+03$ \\
\hline Cycle 1 & 155 & 0.31 & $8.33 \mathrm{E}-03$ & $8.65 \mathrm{E}+03$ & 1328.8 & $0.72 \mathrm{E}+06$ & $5.98 \mathrm{E}+03$ \\
\hline Cycle 2 & 123.87 & 0.289 & $6.11 \mathrm{E}-03$ & $8.78 \mathrm{E}+03$ & 1213.4 & $0.89 \mathrm{E}+06$ & $5.46 \mathrm{E}+03$ \\
\hline Cycle 3 & 120.38 & 0.283 & $5.56 \mathrm{E}-03$ & $9.18 \mathrm{E}+03$ & 891.79 & $0.72 \mathrm{E}+06$ & $4.01 \mathrm{E}+03$ \\
\hline Cycle 4 & 108.9 & 0.292 & $6.40 \mathrm{E}-03$ & $7.45 \mathrm{E}+03$ & 744.96 & $0.52 \mathrm{E}+06$ & $3.35 \mathrm{E}+03$ \\
\hline Cycle 6 & 166.5 & 0.305 & $7.76 \mathrm{E}-03$ & $9.82 \mathrm{E}+03$ & 1196.6 & $0.69 \mathrm{E}+06$ & $5.38 \mathrm{E}+03$ \\
\hline
\end{tabular}


Table B3: 6-cycle aging data of unwrapped wood samples:

\begin{tabular}{|l|l|l|l|l|l|l|l|}
\hline Condition & $\begin{array}{l}\mathrm{P} \\
(\mathrm{lb})\end{array}$ & $\begin{array}{l}\mathrm{R} \\
(\mathrm{in})\end{array}$ & $\begin{array}{l}\mathrm{I} \\
\left(\mathrm{in}^{4}\right)\end{array}$ & $\begin{array}{l}\mathrm{P} / \delta \\
(\mathrm{psi})\end{array}$ & $\begin{array}{l}\mathrm{E} \\
(\mathrm{psi})\end{array}$ & $\begin{array}{l}\mathrm{EI} \\
(\mathrm{psi})\end{array}$ \\
\hline Unaged & 133.25 & 0.25 & $3.07 \mathrm{E}-03$ & $1.63 \mathrm{E}+04$ & 743.83 & $1.09 \mathrm{E}+06$ & $3.35 \mathrm{E}+03$ \\
\hline Cycle 1 & 147 & 0.25 & $3.07 \mathrm{E}-03$ & $1.80 \mathrm{E}+04$ & 772.75 & $1.13 \mathrm{E}+06$ & $3.48 \mathrm{E}+03$ \\
\hline Cycle 2 & 164.1 & 0.25 & $3.07 \mathrm{E}-03$ & $2.01 \mathrm{E}+04$ & 940.88 & $1.38 \mathrm{E}+06$ & $4.23 \mathrm{E}+03$ \\
\hline Cycle 3 & 154.4 & 0.25 & $3.07 \mathrm{E}-03$ & $1.89 \mathrm{E}+04$ & 917.68 & $1.35 \mathrm{E}+06$ & $4.13 \mathrm{E}+03$ \\
\hline Cycle 4 & 171.8 & 0.25 & $3.07 \mathrm{E}-03$ & $2.10 \mathrm{E}+04$ & 948.88 & $1.39 \mathrm{E}+06$ & $4.27 \mathrm{E}+03$ \\
\hline Cycle 6 & 160.1 & 0.25 & $3.07 \mathrm{E}-03$ & $1.96 \mathrm{E}+04$ & 859.63 & $1.26 \mathrm{E}+06$ & $3.87 \mathrm{E}+03$ \\
\hline
\end{tabular}

Table B4: Data of wood/HMR/epoxy/glass samples exposed to freeze-thaw cycling in acidic solution of pH 3:

\begin{tabular}{|c|c|c|c|c|c|c|c|}
\hline $\begin{array}{l}\text { Number } \\
\text { of days }\end{array}$ & $\begin{array}{l}\mathrm{P} \\
\text { (lb) }\end{array}$ & $\begin{array}{l}\mathrm{r} \\
\text { (in) }\end{array}$ & $\begin{array}{l}\text { I } \\
\left(\mathrm{in}^{4}\right)\end{array}$ & $\begin{array}{l}\sigma \\
\text { (psi) }\end{array}$ & $\mathrm{P} / \delta$ & $\begin{array}{l}\text { E } \\
\text { (psi) }\end{array}$ & $\begin{array}{l}\text { EI } \\
\text { (psi) }\end{array}$ \\
\hline 5 & 271.7 & 0.301 & 7.33E-03 & $1.67 \mathrm{E}+04$ & 1557.1 & $0.96 \mathrm{E}+06$ & $0.70 \mathrm{E}+04$ \\
\hline 5 & 221.2 & 0.297 & $6.91 \mathrm{E}-03$ & $1.43 \mathrm{E}+04$ & 1847.2 & $1.21 \mathrm{E}+06$ & $0.83 \mathrm{E}+04$ \\
\hline \multicolumn{6}{|c|}{$1.55 \mathrm{E}+04$} & $1.08 \mathrm{E}+06$ & $0.76 \mathrm{E}+04$ \\
\hline 15 & 148.89 & 0.295 & $6.70 \mathrm{E}-03$ & $9.83 \mathrm{E}+03$ & 1248.3 & $0.84 \mathrm{E}+06$ & $5.62 \mathrm{E}+03$ \\
\hline 15 & 164.4 & 0.295 & $6.70 \mathrm{E}-03$ & $1.09 \mathrm{E}+04$ & 1407.2 & $0.94 \mathrm{E}+06$ & $6.33 \mathrm{E}+03$ \\
\hline \multicolumn{6}{|c|}{$1.03 \mathrm{E}+04$} & $0.89 \mathrm{E}+06$ & $5.97 \mathrm{E}+03$ \\
\hline 25 & 145 & 0.303 & $7.49 \mathrm{E}-03$ & $8.79 \mathrm{E}+03$ & 1212.7 & $0.73 \mathrm{E}+06$ & $5.46 \mathrm{E}+03$ \\
\hline 25 & 156.9 & 0.295 & $6.70 \mathrm{E}-03$ & $1.04 \mathrm{E}+04$ & 1225.5 & $0.82 \mathrm{E}+06$ & $5.51 \mathrm{E}+03$ \\
\hline \multicolumn{6}{|c|}{$9.57 \mathrm{E}+03$} & $0.78 \mathrm{E}+06$ & $5.49 \mathrm{E}+03$ \\
\hline
\end{tabular}


Table B5: Data of wood/HMR/epoxy/glass samples exposed to freeze-thaw cycling in alkaline solution of $\mathrm{pH} 13$ :

\begin{tabular}{|l|l|l|l|l|l|l|l|}
\hline $\begin{array}{l}\text { Number } \\
\text { of days }\end{array}$ & $\begin{array}{l}\mathrm{P} \\
(\mathrm{lb})\end{array}$ & $\begin{array}{l}\mathrm{r} \\
\text { (in) }\end{array}$ & $\begin{array}{l}\mathrm{I} \\
\left(\mathrm{in}^{4}\right)\end{array}$ & $\begin{array}{l}\sigma \\
(\mathrm{psi})\end{array}$ & $\begin{array}{l}\mathrm{E} / \delta \\
(\mathrm{psi})\end{array}$ & $\begin{array}{l}\mathrm{EI} \\
(\mathrm{psi})\end{array}$ \\
\hline 5 & 274.2 & 0.297 & $6.91 \mathrm{E}-03$ & $1.77 \mathrm{E}+04$ & 1729.6 & $1.13 \mathrm{E}+06$ & $7.8 \mathrm{E}+03$ \\
\hline 5 & 257.9 & 0.297 & $6.91 \mathrm{E}-03$ & $1.66 \mathrm{E}+04$ & 1895.3 & $1.24 \mathrm{E}+06$ & $8.5 \mathrm{E}+03$ \\
\hline \multicolumn{7}{|c|}{$1.72 \mathrm{E}+04$} \\
\hline 15 & 215.97 & 0.295 & $6.70 \mathrm{E}-03$ & $1.43 \mathrm{E}+04$ & 1330 & $0.89 \mathrm{E}+06$ & $5.99 \mathrm{E}+03$ \\
\hline & 170.5 & 0.298 & $6.96 \mathrm{E}-03$ & $1.09 \mathrm{E}+04$ & 1530 & $0.99 \mathrm{E}+06$ & $6.86 \mathrm{E}+03$ \\
\hline 25 & 193.69 & 0.299 & $7.06 \mathrm{E}-03$ & $1.23 \mathrm{E}+04$ & 1241.9 & $0.79 \mathrm{E}+06$ & $5.59 \mathrm{E}+03$ \\
\hline 25 & & & & & & \\
\hline
\end{tabular}

Table B6: Data of wood/HMR/epoxy/glass samples exposed to freeze-thaw cycling in neutral solution of $\mathrm{pH} 7$ :

\begin{tabular}{|l|l|l|l|l|l|l|l|}
\hline $\begin{array}{l}\text { Number } \\
\text { of days }\end{array}$ & $\begin{array}{l}\mathrm{P} \\
(\mathrm{lb})\end{array}$ & $\begin{array}{l}\mathrm{r} \\
\text { (in) }\end{array}$ & $\begin{array}{l}\mathrm{I} \\
\left(\mathrm{in}^{4}\right)\end{array}$ & $\begin{array}{l}\sigma \\
(\mathrm{psi})\end{array}$ & & $\mathrm{E} / \delta$ & $\mathrm{E}$ \\
$(\mathrm{psi})$ & $(\mathrm{psi})$ \\
\hline 5 & 206 & 0.297 & $6.91 \mathrm{E}-03$ & $1.33 \mathrm{E}+04$ & 1060.8 & $0.69 \mathrm{E}+06$ & $4.78 \mathrm{E}+03$ \\
\hline 15 & 136.59 & 0.297 & $6.91 \mathrm{E}-03$ & $8.81 \mathrm{E}+03$ & 794.5 & $0.52 \mathrm{E}+06$ & $3.58 \mathrm{E}+03$ \\
\hline 25 & 174.12 & 0.295 & $6.70 \mathrm{E}-03$ & $1.15 \mathrm{E}+04$ & 1310.6 & $0.88 \mathrm{E}+06$ & $5.90 \mathrm{E}+03$ \\
\hline
\end{tabular}


Table B7: Data of wood/HMR/epoxy/glass samples exposed to freeze-thaw cycling in $3 \%$ salt water solution:

\begin{tabular}{|l|l|l|l|l|l|l|l|}
\hline $\begin{array}{l}\text { Number } \\
\text { of days }\end{array}$ & $\begin{array}{l}\mathrm{P} \\
(\mathrm{lb})\end{array}$ & $\mathrm{r}$ & $\mathrm{I}$ & $\sigma$ & $\mathrm{P} / \delta$ & $\mathrm{E}$ & $\mathrm{EI}$ \\
$(\mathrm{in})$ & $\left(\mathrm{in}^{4}\right)$ & $(\mathrm{psi})$ & & $(\mathrm{psi})$ & $(\mathrm{psi})$ \\
\hline 5 & 266.6 & 0.301 & $7.33 \mathrm{E}-03$ & $1.64 \mathrm{E}+04$ & 1752.1 & $1.08 \mathrm{E}+06$ & $7.88 \mathrm{E}+03$ \\
\hline 15 & 228.7 & 0.3 & $7.22 \mathrm{E}-03$ & $1.43 \mathrm{E}+04$ & 1653.7 & $1.03 \mathrm{E}+06$ & $7.44 \mathrm{E}+03$ \\
\hline 25 & 194.23 & 0.295 & $6.70 \mathrm{E}-03$ & $1.28 \mathrm{E}+04$ & 1375.5 & $0.92 \mathrm{E}+06$ & $6.19 \mathrm{E}+03$ \\
\hline
\end{tabular}

Table B8: Data of wood/epoxy/glass samples exposed to freeze-thaw cycling in neutral solution of $\mathrm{pH} 7$ :

\begin{tabular}{|l|l|l|l|l|l|l|l|}
\hline $\begin{array}{l}\text { Number } \\
\text { of days }\end{array}$ & $\begin{array}{l}\mathrm{P} \\
(\mathrm{lb})\end{array}$ & $\mathrm{r}$ & $\mathrm{I}$ & $\sigma$ & $\mathrm{P} / \delta$ & $\mathrm{E}$ & $\mathrm{EI}$ \\
$(\mathrm{in})$ & $\left(\mathrm{in}^{4}\right)$ & $(\mathrm{psi})$ & & $(\mathrm{psi})$ & $(\mathrm{psi})$ \\
\hline 5 & 225.52 & 0.288 & $5.98 \mathrm{E}-03$ & $1.63 \mathrm{E}+04$ & 1444.4 & $1.09 \mathrm{E}+06$ & $6.47 \mathrm{E}+03$ \\
\hline 15 & 139.76 & 0.295 & $6.70 \mathrm{E}-03$ & $9.22 \mathrm{E}+03$ & 1007.5 & $0.67 \mathrm{E}+06$ & $4.53 \mathrm{E}+03$ \\
\hline 25 & 155.28 & 0.298 & $6.96 \mathrm{E}-03$ & $9.96 \mathrm{E}+03$ & 1275 & $0.83 \mathrm{E}+06$ & $5.74 \mathrm{E}+03$ \\
\hline
\end{tabular}

Table B9: Data of wood/epoxy/glass samples exposed to freeze-thaw cycling in 3\% salt water solution:

\begin{tabular}{|l|l|l|l|l|l|l|l|}
\hline $\begin{array}{l}\text { Number } \\
\text { of days }\end{array}$ & $\begin{array}{l}\mathrm{P} \\
(\mathrm{lb})\end{array}$ & $\begin{array}{l}\mathrm{r} \\
\text { (in) }\end{array}$ & $\begin{array}{l}\mathrm{I} \\
\left(\mathrm{in}^{4}\right)\end{array}$ & $\begin{array}{l}\sigma \\
(\mathrm{psi})\end{array}$ & $\begin{array}{l}\mathrm{P} / \delta \\
(\mathrm{psi})\end{array}$ & $\begin{array}{l}\mathrm{EI} \\
(\mathrm{psi})\end{array}$ \\
\hline 5 & 222.1 & 0.297 & $6.91 \mathrm{E}-03$ & $1.43 \mathrm{E}+04$ & 1489.3 & $0.97 \mathrm{E}+06$ & $6.73 \mathrm{E}+03$ \\
\hline 15 & 179.17 & 0.284 & $5.70 \mathrm{E}-03$ & $1.34 \mathrm{E}+04$ & 1443 & $1.14 \mathrm{E}+06$ & $6.47 \mathrm{E}+03$ \\
\hline 25 & 175.57 & 0.285 & $5.75 \mathrm{E}-03$ & $1.31 \mathrm{E}+04$ & 1217.7 & $0.96 \mathrm{E}+06$ & $5.48 \mathrm{E}+03$ \\
\hline
\end{tabular}




\section{Appendix B.3}

\section{Sample Calculations for the Generation of a Master Curve from Mechanical}

\section{Spectroscopy Data}

During the frequency/temperature sweep of a hybrid specimen, the storage modulus data over a range of frequency and at different isothermal temperatures is obtained. The following is the data of a wood/HMR/epoxy/glass hybrid subjected to freeze-thaw cycling in water for 25 days.

\section{Data Set A:}

\begin{tabular}{|c|c|}
\hline \multicolumn{2}{|c|}{ Temp = 40C } \\
\hline $\mathbf{w}$ & G' \\
\hline $\mathrm{rad} / \mathrm{s}$ & dyn/cm.sq. \\
\hline 0.1 & $9.02 E+09$ \\
\hline 0.158489 & $8.59 \mathrm{E}+09$ \\
\hline 0.25119 & $8.67 \mathrm{E}+09$ * \\
\hline 0.398109 & $8.73 \mathrm{E}+09$ \\
\hline 0.630966 & $8.79 E+09$ \\
\hline 1.00003 & $8.84 \mathrm{E}+09$ \\
\hline 1.58496 & $8.9 E+09$ \\
\hline 2.51202 & $8.94 \mathrm{E}+09$ \\
\hline 3.98132 & $9 \mathrm{E}+09$ \\
\hline 6.31006 & $9.04 \mathrm{E}+09$ \\
\hline 10.0007 & $9.09 E+09$ \\
\hline 15.8501 & $9.13 E+09$ \\
\hline 25.1206 & $9.18 \mathrm{E}+09$ \\
\hline 39.8135 & $9.24 \mathrm{E}+09$ \\
\hline 63.1006 & $9.31 \mathrm{E}+09$ \\
\hline 100 & $9.46 \mathrm{E}+09$ \\
\hline
\end{tabular}

\begin{tabular}{|c|c|}
\hline \multicolumn{2}{|c|}{ Temp = 45C } \\
\hline w & $\mathbf{G}^{\prime}$ \\
\hline$d / s$ & \\
\hline 0.1 & $8.48 \mathrm{E}+09$ \\
\hline 0.158489 & $8.28 \mathrm{E}+09$ \\
\hline 0.25119 & $8.36 E+09$ \\
\hline 0.398109 & $8.43 \mathrm{E}+09$ \\
\hline 0.630966 & $8.5 E+09$ \\
\hline 1.00003 & $8.56 E+09$ \\
\hline 1.58496 & $8.61 E+09$ \\
\hline 2.51202 & $8.67 E+09$ \\
\hline 3.98132 & $8.72 E+09$ \\
\hline 6.31006 & 8.77E+09 \\
\hline 10.0007 & $8.82 \mathrm{E}+09$ \\
\hline 15.8501 & 8.87E+09 \\
\hline 25.1206 & $8.91 E+09$ \\
\hline 39.8135 & $8.96 \mathrm{E}+09$ \\
\hline 63.100 & $9.04 \mathrm{E}+09$ \\
\hline & $9.18 \mathrm{E}+09$ \\
\hline
\end{tabular}

\begin{tabular}{|c|c|}
\hline \multicolumn{2}{|c|}{ Temp = 50C } \\
\hline & $\mathbf{G}^{\prime}$ \\
\hline $\mathrm{rad} / \mathrm{s}$ & $\mathrm{in} / \mathrm{sm}$ \\
\hline 0.1 & $8.08 E+09$ \\
\hline 0.158489 & $7.91 E+09$ \\
\hline 0.25119 & $8 E+09$ \\
\hline 0.398109 & $8.08 \mathrm{E}+09$ \\
\hline 0.630966 & $8.17 \mathrm{E}+09$ \\
\hline 1.00003 & $8.24 \mathrm{E}+09$ \\
\hline 1.58496 & $8.3 E+09$ \\
\hline 2.51202 & 8.37E+09 \\
\hline 3.98132 & $8.43 E+09$ \\
\hline 6.31006 & $8.48 E+09$ \\
\hline 10.0007 & $8.54 \mathrm{E}+09$ \\
\hline 15.8501 & $8.58 E+09$ \\
\hline 25.1206 & $8.63 E+09$ \\
\hline 39.8135 & $8.69 E+09$ \\
\hline 63.1006 & 8.77E+09 \\
\hline 100 & $8.9 E+09$ \\
\hline
\end{tabular}




\begin{tabular}{|c|c|}
\hline \multicolumn{2}{|c|}{ Temp = 50C } \\
\hline $\mathbf{w}$ & $\mathbf{G}^{\prime}$ \\
\hline $\mathrm{rad} / \mathrm{s}$ & dyn/cm.sq. \\
\hline 0.1 & $8.08 \mathrm{E}+09$ \\
\hline 0.158489 & $7.91 \mathrm{E}+09$ \\
\hline 0.25119 & $8 E+09$ \\
\hline 0.398109 & $8.08 E+09$ \\
\hline 0.630966 & $8.17 \mathrm{E}+09$ \\
\hline 1.00003 & $8.24 \mathrm{E}+09$ \\
\hline 1.58496 & 8.3E+09 \\
\hline 2.51202 & $8.37 E+09$ \\
\hline 3.98132 & $8.43 E+09$ \\
\hline 6.31006 & $8.48 E+09$ \\
\hline 10.0007 & $8.54 \mathrm{E}+09$ \\
\hline 15.8501 & $8.58 \mathrm{E}+09$ \\
\hline 25.1206 & $8.63 E+09$ \\
\hline 39.8135 & $8.69 E+09$ \\
\hline 63.1006 & $8.77 E+09$ \\
\hline 100 & $8.9 E+09$ \\
\hline
\end{tabular}

Temp $=65 \mathrm{C}$

w

$\mathrm{rad} / \mathrm{s} \quad \mathrm{dyn} / \mathrm{cm} . \mathrm{sq}$.

$0.1 \quad 5.02 \mathrm{E}+09$

$0.158489 \quad 5.1 \mathrm{E}+09$

$0.25119 \quad 5.3 \mathrm{E}+09$

$0.398109 \quad 5.5 \mathrm{E}+09$

$0.630966 \quad 5.71 \mathrm{E}+09$

$1.00003 \quad 5.9 \mathrm{E}+09$

$1.58496 \quad 6.09 \mathrm{E}+09$

$2.51202 \quad 6.26 \mathrm{E}+09$

$3.98132 \quad 6.43 \mathrm{E}+09$

$6.31006 \quad 6.59 \mathrm{E}+09$

$10.0007 \quad 6.74 \mathrm{E}+09$

$15.8501 \quad 6.89 \mathrm{E}+09$

$25.1206 \quad 7.03 \mathrm{E}+09$

$39.8135 \quad 7.17 \mathrm{E}+09$

63.1006 7.31E+09

$100 \quad 7.5 \mathrm{E}+09$
Temp $=55 \mathrm{C}$

w G'

$\mathbf{r a d} / \mathrm{s} \quad$ dyn/cm.sq.

0.1 7.47E+09

$0.158489 \quad 7.4 \mathrm{E}+09$

$0.25119 \quad 7.5 \mathrm{E}+09$

$0.398109 \quad 7.62 \mathrm{E}+09$

$0.630966 \quad 7.7 \mathrm{E}+09$

$1.00003 \quad 7.81 \mathrm{E}+09$

$1.58496 \quad 7.89 \mathrm{E}+09$

$2.51202 \quad 7.97 \mathrm{E}+09$

3.98132 8.04E+09

$6.31006 \quad 8.11 \mathrm{E}+09$

10.0007 8.17E+09

$15.8501 \quad 8.23 \mathrm{E}+09$

$25.1206 \quad 8.3 \mathrm{E}+09$

$39.8135 \quad 8.36 \mathrm{E}+09$

$63.1006 \quad 8.44 \mathrm{E}+09$

$100 \quad 8.58 \mathrm{E}+09$

Temp $=70 \mathrm{C}$

w $\quad G^{\prime}$

$\mathrm{rad} / \mathrm{s} \quad \mathrm{dyn} / \mathrm{cm} . \mathrm{sq}$.

$0.1 \quad 3.62 \mathrm{E}+09$

$0.158489 \quad 3.84 \mathrm{E}+09$

$0.25119 \quad 4.05 \mathrm{E}+09$

$0.398109 \quad 4.24 \mathrm{E}+09$

$0.630966 \quad 4.45 \mathrm{E}+09$

$1.00003 \quad 4.65 \mathrm{E}+09$

$1.58496 \quad 4.84 \mathrm{E}+09$

$2.51202 \quad 5.03 \mathrm{E}+09$

$3.98132 \quad 5.25 \mathrm{E}+09$

$6.31006 \quad 5.44 \mathrm{E}+09$

$10.0007 \quad 5.63 \mathrm{E}+09$

$15.8501 \quad 5.81 \mathrm{E}+09$

$25.1206 \quad 5.99 \mathrm{E}+09$

$39.8135 \quad 6.17 \mathrm{E}+09$

$63.1006 \quad 6.36 \mathrm{E}+09$

$100 \quad 6.59 \mathrm{E}+09$
Temp $=60 \mathrm{C}$

$\mathrm{rad} / \mathrm{s} \quad \mathrm{dyn} / \mathrm{cm} . \mathrm{sq}$.

$0.1 \quad 6.43 \mathrm{E}+09$

$0.158489 \quad 6.42 \mathrm{E}+09$

$0.25119 \quad 6.6 \mathrm{E}+09$

$0.3981096 .76 \mathrm{E}+09$

$0.630966 \quad 6.92 \mathrm{E}+09$

$1.00003 \quad 7.06 \mathrm{E}+09$

$1.58496 \quad 7.2 \mathrm{E}+09$

$2.51202 \quad 7.31 \mathrm{E}+09$

$3.98132 \quad 7.41 \mathrm{E}+09$

$6.310067 .52 \mathrm{E}+09$

$10.0007 \quad 7.62 \mathrm{E}+09$

$15.8501 \quad 7.71 \mathrm{E}+09$

$25.1206 \quad 7.8 \mathrm{E}+09$

$39.8135 \quad 7.88 \mathrm{E}+09$

63.1006 7.99E+09

$100 \quad 8.14 \mathrm{E}+09$

Temp $=75 \mathrm{C}$

w G'

$\mathrm{rad} / \mathrm{s}$ dyn/cm.sq.

$0.12 .73 \mathrm{E}+09$

$0.1584892 .91 \mathrm{E}+09$

0.25119 3.03E +09

$0.398109 \quad 3.19 \mathrm{E}+09$

$0.630966 \quad 3.35 \mathrm{E}+09$

$1.00003 \quad 3.54 \mathrm{E}+09$

$1.58496 \quad 3.71 \mathrm{E}+09$

$2.512023 .89 \mathrm{E}+09$

$3.98132 \quad 4.07 \mathrm{E}+09$

$6.31006 \quad 4.26 \mathrm{E}+09$

$10.0007 \quad 4.46 \mathrm{E}+09$

$15.8501 \quad 4.67 \mathrm{E}+09$

$25.1206 \quad 4.88 \mathrm{E}+09$

$39.8135 \quad 5.09 \mathrm{E}+09$

$63.1006 \quad 5.31 \mathrm{E}+09$

$100 \quad 5.56 \mathrm{E}+09$ 


\begin{tabular}{|c|c|}
\hline \multicolumn{2}{|c|}{ Temp = 80C } \\
\hline $\mathbf{w}$ & G' \\
\hline $\mathrm{rad} / \mathrm{s}$ & dyn/cm.sq. \\
\hline 0.1 & $2.09 \mathrm{E}+09$ \\
\hline 0.158489 & $2.14 \mathrm{E}+09$ \\
\hline 0.25119 & $2.25 E+09$ \\
\hline 0.398109 & 2.33E+09 \\
\hline 0.630966 & $2.45 \mathrm{E}+09$ \\
\hline 1.00003 & $2.58 \mathrm{E}+09$ \\
\hline 1.58496 & $2.71 \mathrm{E}+09$ \\
\hline 2.51202 & $2.85 E+09$ \\
\hline 3.98132 & $3.02 \mathrm{E}+09$ \\
\hline 6.31006 & $3.19 E+09$ \\
\hline 10.0007 & 3.38E+09 \\
\hline 15.8501 & $3.57 \mathrm{E}+09$ \\
\hline 25.1206 & $3.76 \mathrm{E}+09$ \\
\hline 39.8135 & $3.96 \mathrm{E}+09$ \\
\hline 63.1006 & $4.18 \mathrm{E}+09$ \\
\hline 100 & $4.44 \mathrm{E}+09$ \\
\hline
\end{tabular}

Temp $=95 \mathrm{C}$

w G'

$\mathbf{r a d} / \mathrm{s}$ dyn/cm.sq.

$0.1 \quad 1.67 \mathrm{E}+09$

$0.158489 \quad 1.68 \mathrm{E}+09$

$0.25119 \quad 1.67 \mathrm{E}+09$

$0.398109 \quad 1.69 \mathrm{E}+09$

$0.630966 \quad 1.71 \mathrm{E}+09$

$1.00003 \quad 1.71 \mathrm{E}+09$

$1.58496 \quad 1.73 \mathrm{E}+09$

$2.51202 \quad 1.74 \mathrm{E}+09$

$3.981321 .76 \mathrm{E}+09$

$6.31006 \quad 1.79 \mathrm{E}+09$

$10.0007 \quad 1.83 \mathrm{E}+09$

$15.8501 \quad 1.87 \mathrm{E}+09$

$25.1206 \quad 1.92 \mathrm{E}+09$

$39.8135 \quad 1.99 \mathrm{E}+09$

$63.1006 \quad 2.07 \mathrm{E}+09$

$100 \quad 2.18 \mathrm{E}+09$

\author{
Temp $=85 \mathrm{C}$ \\ w G' \\ $\mathrm{rad} / \mathrm{s} \quad \mathrm{dyn} / \mathrm{cm} . \mathrm{sq}$. \\ $0.1 \quad 1.92 \mathrm{E}+09$ \\ $0.158489 \quad 1.83 \mathrm{E}+09$ \\ $0.25119 \quad 1.84 \mathrm{E}+09$ \\ $0.398109 \quad 1.89 \mathrm{E}+09$ \\ $0.630966 \quad 1.95 \mathrm{E}+09$ \\ $1.00003 \quad 2.02 \mathrm{E}+09$ \\ $1.58496 \quad 2.09 \mathrm{E}+09$ \\ $2.51202 \quad 2.17 \mathrm{E}+09$ \\ 3.98132 2.27E+09 \\ $6.31006 \quad 2.39 \mathrm{E}+09$ \\ $10.0007 \quad 2.52 \mathrm{E}+09$ \\ $15.8501 \quad 2.66 \mathrm{E}+09$ \\ $25.1206 \quad 2.82 \mathrm{E}+09$ \\ $39.8135 \quad 2.99 \mathrm{E}+09$ \\ $63.1006 \quad 3.18 \mathrm{E}+09$ \\ $100 \quad 3.41 \mathrm{E}+09$
}

Temp $=100 \mathrm{C}$

w G'

$\mathrm{rad} / \mathrm{s} \quad \mathrm{dyn} / \mathrm{cm} . \mathrm{sq}$.

$0.1 \quad 1.63 \mathrm{E}+09$

$0.158489 \quad 1.63 \mathrm{E}+09$

$0.25119 \quad 1.67 \mathrm{E}+09$

$0.398109 \quad 1.65 \mathrm{E}+09$

$0.630966 \quad 1.67 \mathrm{E}+09$

$1.00003 \quad 1.69 \mathrm{E}+09$

$1.58496 \quad 1.69 \mathrm{E}+09$

$2.51202 \quad 1.71 \mathrm{E}+09$

$3.981321 .72 \mathrm{E}+09$

$6.31006 \quad 1.74 \mathrm{E}+09$

$10.0007 \quad 1.75 \mathrm{E}+09$

$15.8501 \quad 1.77 \mathrm{E}+09$

$25.1206 \quad 1.8 \mathrm{E}+09$

$39.8135 \quad 1.84 \mathrm{E}+09$

$63.1006 \quad 1.88 \mathrm{E}+09$

$100 \quad 1.95 \mathrm{E}+09$

\begin{tabular}{|c|c|}
\hline \multicolumn{2}{|c|}{ Temp = 90C } \\
\hline $\mathbf{w}$ & G' \\
\hline $\mathrm{rad} / \mathrm{s}$ & \\
\hline 0.1 & $1.82 E+09$ \\
\hline 0.158489 & $1.69 E+09$ \\
\hline 0.25119 & $1.69 E+09$ \\
\hline 0.398109 & $1.74 \mathrm{E}+09$ \\
\hline 0.630966 & $1.76 \mathrm{E}+09$ \\
\hline 1.00003 & $1.78 \mathrm{E}+09$ \\
\hline .58496 & $1.81 \mathrm{E}+09$ \\
\hline 2.51202 & $1.86 \mathrm{E}+09$ \\
\hline 3.98132 & 1.9E+09 \\
\hline 6.31006 & $1.96 \mathrm{E}+09$ \\
\hline 10.0007 & $2.03 E+09$ \\
\hline 15.8501 & $2.11 E+09$ \\
\hline 25.1206 & $2.2 E+09$ \\
\hline 39.8135 & $2.32 E+09$ \\
\hline 63.1006 & $2.45 E+09$ \\
\hline 100 & $2.62 \mathrm{E}+09$ \\
\hline
\end{tabular}

Temp $=90 \mathrm{C}$

rad/s dyn/cm.sq.

$0.158489 \quad 1.69 \mathrm{E}+09$

$0.25119 \quad 1.69 \mathrm{E}+09$

$0.398109 \quad 1.74 \mathrm{E}+09$

$0.630966 \quad 1.76 \mathrm{E}+09$

$1.00003 \quad 1.78 \mathrm{E}+09$

$1.58496 \quad 1.81 \mathrm{E}+09$

$2.51202 \quad 1.86 \mathrm{E}+09$

$3.98132 \quad 1.9 \mathrm{E}+09$

$6.31006 \quad 1.96 \mathrm{E}+09$

10.0007 2.03E+09

$15.8501 \quad 2.11 \mathrm{E}+09$

$25.1206 \quad 2.2 \mathrm{E}+09$

$39.8135 \quad 2.32 \mathrm{E}+09$

$100 \quad 2.62 \mathrm{E}+09$ 
For generation of the master curve, $40^{\circ} \mathrm{C}$ is used as the reference temperature. Therefore, all the G' versus $\omega$ curves at different temperatures are shifted with respect to $40{ }^{\circ} \mathrm{C}$. To do this, the value of $\mathrm{G}^{\prime}$ at $45^{0} \mathrm{C}$ (say $\mathrm{G}_{1}^{\prime}$ ) that is closest to the value of $\mathrm{G}^{\prime}$ at $40^{0} \mathrm{C}$ (say $\mathrm{G}_{2}^{\prime}$ ) is chosen. Let $\omega_{1}$ and $\omega_{2}$ be the frequency corresponding to $\mathrm{G}^{\prime}{ }_{1}$ and $\mathrm{G}^{\prime}{ }_{2}$ respectively. The frequency values at $45^{0} \mathrm{C}$ are then multiplied by a shift factor of $\left(\omega_{2} / \omega_{1}\right)$ without changing the $\mathrm{G}^{\prime}$ values. This means that the data at $45^{0} \mathrm{C}$ is shifted with respect to $40^{\circ} \mathrm{C}$. In the next step, the value of $\mathrm{G}^{\prime}$ at $50^{0} \mathrm{C}$ (say $\mathrm{G}_{3}^{\prime}$ ) that is closest to the value of $\mathrm{G}^{\prime}$ at $45^{\circ} \mathrm{C}$ (say $\mathrm{G}_{4}^{\prime}$ ) is chosen. Let $\omega_{3}$ and $\omega_{4}$ be the frequency corresponding to $\mathrm{G}_{3}^{\prime}$ and $\mathrm{G}_{4}^{\prime}$ respectively. The frequency values at $50^{\circ} \mathrm{C}$ are then multiplied by a shift factor of $\left(\omega_{4} / \omega_{3}\right)$ without changing the $\mathrm{G}^{\prime}$ values. This shifts the data at $50^{\circ} \mathrm{C}$ to $40^{\circ} \mathrm{C}$. This process is repeated until all the data up to $100^{\circ} \mathrm{C}$ is shifted. A plot of the generated $\mathrm{G}^{\prime}$ versus $\omega$ data gives the master curve.

For illustration, the data at $40^{\circ} \mathrm{C}$ and $45^{\circ} \mathrm{C}$ before and after shifting is shown below. 


\begin{tabular}{|c|c|}
\hline \multicolumn{2}{|c|}{ data at $40 \mathrm{C}\left(\right.$ ref $\left.\mathrm{T}^{\star}\right)$} \\
\hline$\grave{A}$ & $G^{\prime}$ \\
\hline $\mathrm{rad} / \mathrm{s}$ & dyn/cm.sc \\
\hline 0.1 & $9.02 E+09$ \\
\hline 0.158489 & $8.59 E+09$ \\
\hline 0.25119 & 8.67E+09 \\
\hline 0.398109 & $8.73 E+09$ \\
\hline 0.630 & 8.79 \\
\hline 1.0 & $E+09$ \\
\hline 1.5 & $8.9 E+09$ \\
\hline 2.51202 & $8.94 E+09$ \\
\hline 3.98 & $9 \mathrm{E}+09$ \\
\hline 6.31006 & $9.04 E+09$ \\
\hline 10.0007 & $9.09 E+09$ \\
\hline $15 . \varepsilon$ & $9.13 E+09$ \\
\hline 25.1206 & $9.18 \mathrm{E}+09$ \\
\hline 39.8135 & $9.24 \mathrm{E}+09$ \\
\hline 63.1006 & $9.31 E+09$ \\
\hline 100 & $9.46 \mathrm{E}+09$ \\
\hline
\end{tabular}

data at $45 \mathrm{C}$ before shift

$\begin{array}{ll}\text { w } & \text { G' } \\ \mathbf{r a d} / \mathrm{s} & \text { dyn/cm.sq. }\end{array}$

$0.1 \quad 8.48 \mathrm{E}+09$

$0.158489 \quad 8.28 \mathrm{E}+09$

$0.25119 \quad 8.36 \mathrm{E}+09$

$0.398109 \quad 8.43 \mathrm{E}+09$

$0.630966 \quad 8.5 \mathrm{E}+09$

$1.00003 \quad 8.56 \mathrm{E}+09$

$1.58496 \quad 8.61 \mathrm{E}+09$

$2.51202 \quad 8.67 \mathrm{E}+09$

$3.98132 \quad 8.72 \mathrm{E}+09$

$6.31006 \quad 8.77 \mathrm{E}+09$

$10.0007 \quad 8.82 \mathrm{E}+09$

$15.8501 \quad 8.87 \mathrm{E}+09$

$25.1206 \quad 8.91 \mathrm{E}+09$

$39.8135 \quad 8.96 \mathrm{E}+09$

$63.1006 \quad 9.04 \mathrm{E}+09$

$100 \quad 9.18 \mathrm{E}+09$ data at $45 \mathrm{C}$ after shift À G'

$\mathrm{rad} / \mathrm{s} \quad$ dyn/cm.sq.

$0.01 \quad 8.48 \mathrm{E}+09$

$0.015848 \quad 8.28 \mathrm{E}+09$

$0.025118 \quad 8.36 \mathrm{E}+09$

$0.039809 \quad 8.43 \mathrm{E}+09$

$0.063094 \quad 8.5 \mathrm{E}+09$

$0.099998 \quad 8.56 \mathrm{E}+09$

$0.158488 \quad 8.61 \mathrm{E}+09$

$0.25119 \quad 8.67 \mathrm{E}+09$

$0.398113 \quad 8.72 \mathrm{E}+09$

$0.630976 \quad 8.77 \mathrm{E}+09$

$1.000022 \quad 8.82 \mathrm{E}+09$

$1.584934 \quad 8.87 \mathrm{E}+09$

$2.51194 \quad 8.91 \mathrm{E}+09$

$3.98116 \quad 8.96 \mathrm{E}+09$

$6.309759 \quad 9.04 \mathrm{E}+09$

$9.999522 \quad 9.18 \mathrm{E}+09$

ref $\mathrm{T}^{*}=$ reference temperature

The entire data shifted with respect to $40^{\circ} \mathrm{C}$ is given in data set $\mathrm{B}$.

\section{Data Set B:}

\begin{tabular}{|c|c|}
\hline \multicolumn{2}{|c|}{ data at $40 \mathrm{C}\left(\right.$ ref $\left.\mathrm{T}^{\star}\right)$} \\
\hline À & \\
\hline $\mathrm{rad} / \mathrm{s}$ & dyn/cm.sq \\
\hline 0.1 & $9.02 E+09$ \\
\hline 0.158489 & $8.59 E+09$ \\
\hline & 8.6 \\
\hline 0.398109 & $E+09$ \\
\hline 0.630966 & $8.79 E+09$ \\
\hline 1.00 & 8.8 \\
\hline 1.58496 & $E+09$ \\
\hline 2.51202 & $8.94 \mathrm{E}+09$ \\
\hline 3.98132 & $9 \mathrm{E}+09$ \\
\hline .31006 & $9.04 \mathrm{E}+09$ \\
\hline 10.0007 & $9.09 E+09$ \\
\hline 15.8501 & $9.13 E+09$ \\
\hline 25.1 & $9.18 \mathrm{E}+09$ \\
\hline 39.8135 & $9.24 \mathrm{E}+09$ \\
\hline 63.1006 & $9.31 E+09$ \\
\hline 100 & $9.46 \mathrm{E}+09$ \\
\hline
\end{tabular}

\begin{tabular}{|c|c|}
\hline \multicolumn{2}{|c|}{ data at $45 \mathrm{C}$} \\
\hline$\grave{A}$ & $G^{\prime}$ \\
\hline$d / s$ & dyn/cm.sq. \\
\hline 0.01 & $8.48 \mathrm{E}+09$ \\
\hline 0.015848 & $8.28 \mathrm{E}+09$ \\
\hline 0.025118 & $8.36 \mathrm{E}+09$ \\
\hline 0.039809 & $8.43 E+09$ \\
\hline 0.063094 & 8.5E+09 \\
\hline 0.09 & $8.56 \mathrm{E}+09$ \\
\hline 0.158488 & $8.61 E+09$ \\
\hline 0.25119 & $8.67 E+09$ \\
\hline 0.398113 & $8.72 E+09$ \\
\hline 0.630976 & $8.77 E+09$ \\
\hline 1.000022 & $8.82 E+09$ \\
\hline 1.584934 & 8.87E+09 \\
\hline 2.51194 & $8.91 E+09$ \\
\hline 3.98116 & $8.96 E+09$ \\
\hline 6.309759 & $9.04 \mathrm{E}+09$ \\
\hline 0000 & $9.18 \mathrm{E}+09$ \\
\hline
\end{tabular}

\begin{tabular}{|c|c|}
\hline & \\
\hline$\grave{A}$ & $G^{\prime}$ \\
\hline $\mathrm{rad} / \mathrm{s}$ & dyn/cm.sq \\
\hline 0.001 & $8.08 E+09$ \\
\hline 0.001585 & $7.91 \mathrm{E}+09$ \\
\hline 0.002512 & $8 \mathrm{E}+09$ \\
\hline 0.0 & $8.08 E+09$ \\
\hline 0.00 & 8.17E+09 \\
\hline 0.010003 & $8.24 \mathrm{E}+09$ \\
\hline 0.01 & $8.3 \mathrm{E}+09$ \\
\hline 0.02 & 8.37E+09 \\
\hline 0.03 & $8.43 E+09$ \\
\hline 0.063115 & $8.48 E+09$ \\
\hline 10003 & $8.54 \mathrm{E}+09$ \\
\hline 0.158537 & $8.58 E+09$ \\
\hline 0.251263 & $8.63 E+09$ \\
\hline 0.398225 & $8.69 E+09$ \\
\hline & 8.77E+09 \\
\hline 1.000226 & $8.9 \mathrm{E}+09$ \\
\hline
\end{tabular}




\begin{tabular}{|c|c|}
\hline & \\
\hline À & $G^{\prime}$ \\
\hline $\mathrm{rad} / \mathrm{s}$ & \\
\hline 6.31E-05 & 7.47E+ \\
\hline & \\
\hline 0.0001 & $7.5 \mathrm{E}+09$ \\
\hline 0.000251 & $7.62 E+09$ \\
\hline 0.000 & 7.7E+09 \\
\hline 0.00 & $E+09$ \\
\hline 001 & $7.89 E+09$ \\
\hline 0.00 & $7.97 \mathrm{E}+09$ \\
\hline 0.00 & $8.04 \mathrm{E}+09$ \\
\hline 0.003982 & $8.11 E+09$ \\
\hline 0.006 & $8.17 E+09$ \\
\hline 0.01( & $8.23 E+09$ \\
\hline 0.015 & $8.3 E+09$ \\
\hline 0.025125 & $8.36 E+09$ \\
\hline 0.03982 & $8.44 E+09$ \\
\hline 0.063106 & $8.58 \mathrm{E}+09$ \\
\hline
\end{tabular}

\section{data at $70 \mathrm{C}$}

À

$\mathrm{rad} / \mathrm{s} \quad$ dyn/cm.sq.

6.3E-09 3.62E+09

9.99E-09 3.84E+09

$1.58 \mathrm{E}-08 \quad 4.05 \mathrm{E}+09$

2.51E-08 4.24E+09

3.98E-08 4.45E+09

$6.3 \mathrm{E}-08 \quad 4.65 \mathrm{E}+09$

9.99E-08 4.84E+09

1.58E-07 5.03E+09

2.51E-07 5.25E+09

3.98E-07 5.44E+09

6.31E-07 5.63E+09

9.99E-07 5.81E+09

1.58E-06 5.99E+09

2.51E-06 6.17E+09

3.98E-06 6.36E+09

6.3E-06 6.59E+09 data at $60 \mathrm{C}$

À $\quad G^{\prime}$

$\mathrm{rad} / \mathrm{s} \quad$ dyn/cm.sq.

2.51E-06 6.43E+09

$3.98 \mathrm{E}-06 \quad 6.42 \mathrm{E}+09$

6.3E-06 $\quad 6.6 \mathrm{E}+09$

9.99E-06 6.76E+09

$1.58 \mathrm{E}-05 \quad 6.92 \mathrm{E}+09$

2.51E-05 7.06E+09

3.98E-05 7.2E+09

6.3E-05 7.31E+09

9.99E-05 7.41E+09

$0.000158 \quad 7.52 \mathrm{E}+09$

$0.000251 \quad 7.62 \mathrm{E}+09$

$0.000398 \quad 7.71 \mathrm{E}+09$

$0.00063 \quad 7.8 \mathrm{E}+09$

$0.000999 \quad 7.88 \mathrm{E}+09$

$0.001584 \quad 7.99 \mathrm{E}+09$

$0.00251 \quad 8.14 \mathrm{E}+09$

data at $75 \mathrm{C}$

À

$\mathrm{rad} / \mathrm{s} \quad$ dyn/cm.sq

3.98E-10 2.73E+09

$6.3 \mathrm{E}-10 \quad 2.91 \mathrm{E}+09$

9.99E-10 3.03E+09

1.58E-09 3.19E+09

2.51E-09 3.35E+09

3.98E-09 3.54E+09

6.3E-09 3.71E+09

9.99E-09 3.89E+09

1.58E-08 4.07E+09

$2.51 \mathrm{E}-08 \quad 4.26 \mathrm{E}+09$

3.98E-08 4.46E+09

6.3E-08 4.67E+09

9.99E-08 $\quad 4.88 \mathrm{E}+09$

$1.58 \mathrm{E}-07 \quad 5.09 \mathrm{E}+09$

2.51E-07 5.31E+09

3.98E-07 5.56E+09 data at $65 \mathrm{C}$ R54

\begin{tabular}{|c|c|}
\hline $\begin{array}{l}\hat{A} \\
\mathrm{rad} / \mathrm{s}\end{array}$ & $\begin{array}{l}\mathrm{G}^{\prime} \\
\text { dyn/cm.so }\end{array}$ \\
\hline 9.99E-08 & $5.02 E+09$ \\
\hline $1.58 \mathrm{E}-07$ & $5.1 \mathrm{E}+09$ \\
\hline $2.51 \mathrm{E}-07$ & $5.3 E+09$ \\
\hline 3.98E-07 & $5.5 E+09$ \\
\hline 6.3E-07 & $5.71 E+09$ \\
\hline 9.99E-07 & $5.9 \mathrm{E}+09$ \\
\hline $1.58 \mathrm{E}-06$ & $6.09 E+09$ \\
\hline 2.51E-06 & $6.26 \mathrm{E}+09$ \\
\hline 3.98E-06 & $6.43 E+09$ \\
\hline 6.3E-06 & $6.59 E+09$ \\
\hline 9.99E-06 & $6.74 \mathrm{E}+09$ \\
\hline 1.58E-05 & $6.89 \mathrm{E}+09$ \\
\hline 2.51E-05 & $7.03 E+09$ \\
\hline 3.98E-05 & 7.17E+09 \\
\hline 6.3E-05 & $7.31 E+09$ \\
\hline 9.99E-05 & $7.5 \mathrm{E}+0$ \\
\hline
\end{tabular}

data at $80 \mathrm{C}$

À

$\mathrm{rad} / \mathrm{s}$ dyn/cm.sq

2.51E-11 2.09E+09

$3.98 \mathrm{E}-11 \quad 2.14 \mathrm{E}+09$

6.3E-11 2.25E+09

9.99E-11 2.33E+09

$1.58 \mathrm{E}-10 \quad 2.45 \mathrm{E}+09$

$2.51 \mathrm{E}-10 \quad 2.58 \mathrm{E}+09$

$3.98 \mathrm{E}-10 \quad 2.71 \mathrm{E}+09$

$6.3 \mathrm{E}-10 \quad 2.85 \mathrm{E}+09$

9.99E-10 3.02E+09

$1.58 \mathrm{E}-09 \quad 3.19 \mathrm{E}+09$

2.51E-09 3.38E+09

3.98E-09 3.57E+09

6.3E-09 3.76E+09

9.99E-09 3.96E+09

$1.58 \mathrm{E}-08 \quad 4.18 \mathrm{E}+09$

$2.51 \mathrm{E}-08 \quad 4.44 \mathrm{E}+09$ 


\begin{tabular}{|c|c|}
\hline \multicolumn{2}{|c|}{ data at $85 \mathrm{C}$} \\
\hline$\grave{A}$ & $G^{\prime}$ \\
\hline $\mathrm{rad} / \mathrm{s}$ & dyn/cm.sq. \\
\hline $1.58 \mathrm{E}-12$ & $1.92 \mathrm{E}+09$ \\
\hline $2.51 \mathrm{E}-12$ & $1.83 E+09$ \\
\hline $3.98 \mathrm{E}-12$ & $1.84 \mathrm{E}+09$ \\
\hline 6.3E-12 & $1.89 E+09$ \\
\hline $9.99 \mathrm{E}-12$ & $1.95 \mathrm{E}+09$ \\
\hline $1.58 \mathrm{E}-11$ & $2.02 E+09$ \\
\hline $2.51 \mathrm{E}-11$ & $2.09 E+09$ \\
\hline $3.98 \mathrm{E}-11$ & $2.17 E+09$ \\
\hline $6.3 \mathrm{E}-11$ & $2.27 E+09$ \\
\hline $9.99 \mathrm{E}-11$ & $2.39 E+09$ \\
\hline $1.58 \mathrm{E}-10$ & $2.52 E+09$ \\
\hline $2.51 \mathrm{E}-10$ & $2.66 \mathrm{E}+09$ \\
\hline $3.98 \mathrm{E}-10$ & $2.82 E+09$ \\
\hline 6.3E-10 & $2.99 E+09$ \\
\hline 9.99E-10 & $3.18 E+09$ \\
\hline 1.58E-09 & $3.41 E+09$ \\
\hline
\end{tabular}

data at $100 \mathrm{C}$

\begin{tabular}{|c|c|}
\hline$\dot{A}$ & G' \\
\hline $\mathrm{ad} / \mathrm{s}$ & dyn/cm.sq \\
\hline 6.3E-15 & $1.63 E+09$ \\
\hline $9.99 \mathrm{E}-15$ & $1.63 \mathrm{E}+09$ \\
\hline $1.58 \mathrm{E}-14$ & $1.67 E+09$ \\
\hline $2.51 \mathrm{E}-14$ & $1.65 E+09$ \\
\hline $3.98 \mathrm{E}-14$ & 1.67E+09 \\
\hline $6.3 \mathrm{E}-14$ & $1.69 \mathrm{E}+09$ \\
\hline 9.99E-14 & $1.69 \mathrm{E}+09$ \\
\hline $1.58 \mathrm{E}-13$ & $1.71 E+09$ \\
\hline $2.51 \mathrm{E}-13$ & $1.72 \mathrm{E}+09$ \\
\hline $3.98 \mathrm{E}-13$ & $1.74 \mathrm{E}+09$ \\
\hline 6.3E-13 & $1.75 E+09$ \\
\hline 9.99E-13 & 1.77E+09 \\
\hline $1.58 \mathrm{E}-12$ & $1.8 \mathrm{E}+09$ \\
\hline $2.51 \mathrm{E}-12$ & $1.84 \mathrm{E}+09$ \\
\hline $3.98 \mathrm{E}-12$ & $1.88 E+09$ \\
\hline 6.3E-12 & $1.95 \mathrm{E}+0$ \\
\hline
\end{tabular}

\begin{tabular}{ll}
\multicolumn{3}{l}{\begin{tabular}{l}
\multicolumn{3}{l}{ data at $90 \mathrm{C}$} \\
$\dot{\mathrm{A}}$
\end{tabular}} & \multicolumn{2}{l}{$\mathrm{G}^{\prime}$} \\
$\mathrm{rad} / \mathrm{s}$ & dyn/cm.sq. \\
$1.58 \mathrm{E}-13$ & $1.82 \mathrm{E}+09$ \\
$2.51 \mathrm{E}-13$ & $1.69 \mathrm{E}+09$ \\
$3.98 \mathrm{E}-13$ & $1.69 \mathrm{E}+09$ \\
$6.3 \mathrm{E}-13$ & $1.74 \mathrm{E}+09$ \\
$9.99 \mathrm{E}-13$ & $1.76 \mathrm{E}+09$ \\
$1.58 \mathrm{E}-12$ & $1.78 \mathrm{E}+09$ \\
$2.51 \mathrm{E}-12$ & $1.81 \mathrm{E}+09$ \\
$3.98 \mathrm{E}-12$ & $1.86 \mathrm{E}+09$ \\
$6.3 \mathrm{E}-12$ & $1.9 \mathrm{E}+09$ \\
$9.99 \mathrm{E}-12$ & $1.96 \mathrm{E}+09$ \\
$1.58 \mathrm{E}-11$ & $2.03 \mathrm{E}+09$ \\
$2.51 \mathrm{E}-11$ & $2.11 \mathrm{E}+09$ \\
$3.98 \mathrm{E}-11$ & $2.2 \mathrm{E}+09$ \\
$6.3 \mathrm{E}-11$ & $2.32 \mathrm{E}+09$ \\
$9.99 \mathrm{E}-11$ & $2.45 \mathrm{E}+09$ \\
$1.58 \mathrm{E}-10$ & $2.62 \mathrm{E}+09$
\end{tabular}

data at 95C

A $\quad G^{\prime}$

$\mathrm{rad} / \mathrm{s} \quad$ dyn/cm.sq

2.51E-14 1.67E+09

$3.98 \mathrm{E}-14 \quad 1.68 \mathrm{E}+09$

6.3E-14 1.67E+09

9.99E-14 1.69E+09

$1.58 \mathrm{E}-13 \quad 1.71 \mathrm{E}+09$

$2.51 \mathrm{E}-13 \quad 1.71 \mathrm{E}+09$

3.98E-13 1.73E+09

6.3E-13 1.74E+09

$9.99 \mathrm{E}-13 \quad 1.76 \mathrm{E}+09$

$1.58 \mathrm{E}-12 \quad 1.79 \mathrm{E}+09$

$2.51 \mathrm{E}-12 \quad 1.83 \mathrm{E}+09$

$3.98 \mathrm{E}-12 \quad 1.87 \mathrm{E}+09$

6.3E-12 1.92E+09

$9.99 \mathrm{E}-12 \quad 1.99 \mathrm{E}+09$

$1.58 \mathrm{E}-11 \quad 2.07 \mathrm{E}+09$

$2.51 \mathrm{E}-11 \quad 2.18 \mathrm{E}+09$ 
A graph of $\mathrm{G}^{\prime}$ versus $\mathrm{w}$ (or A) of data set $\mathrm{B}$ gives the master curve as shown in figure B2:

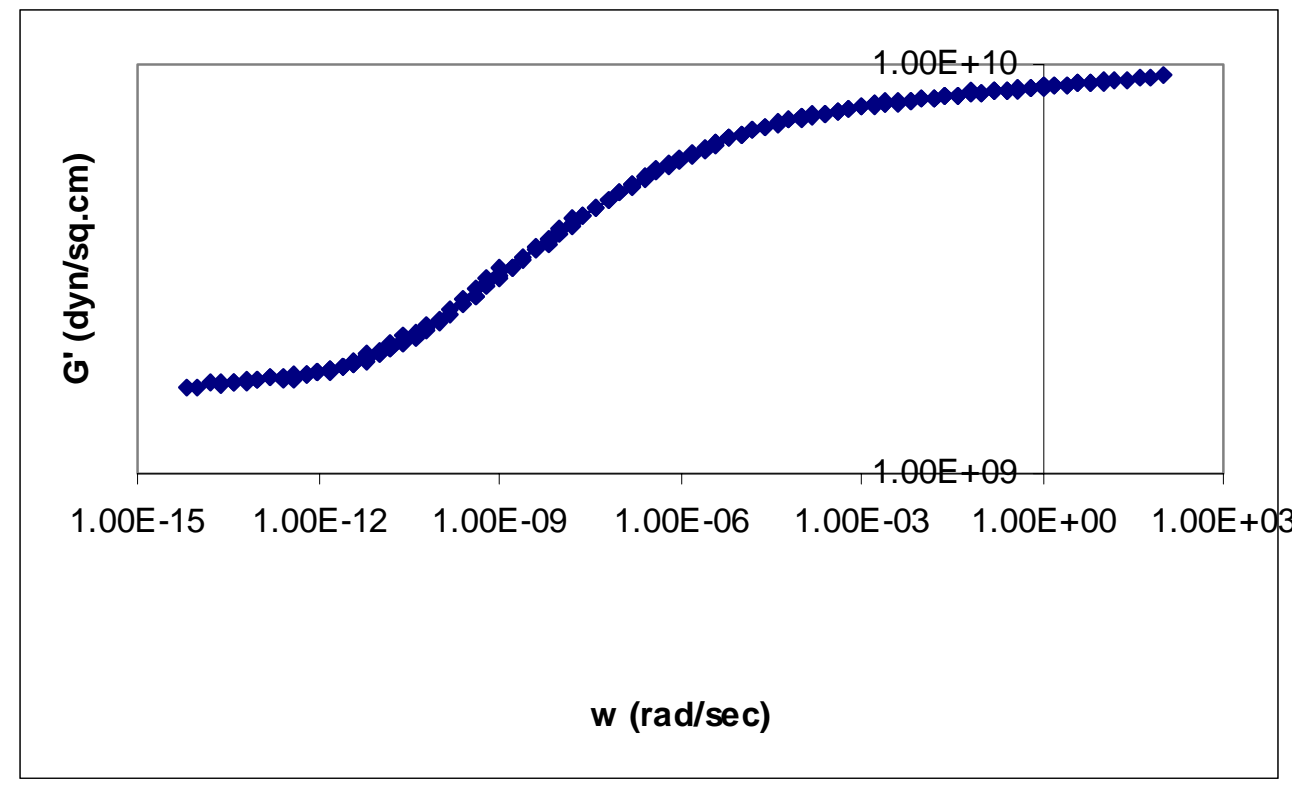

Figure B2: Master curve of wood/HMR/epoxy/glass hybrid subjected to freeze-thaw cycling in water for 25 days 


\section{APPENDIX C}

Dynamic Spectra of Wood and Wood/HMR/Epoxy/Glass Hybrid Samples Under Unaged and Aged Conditions 


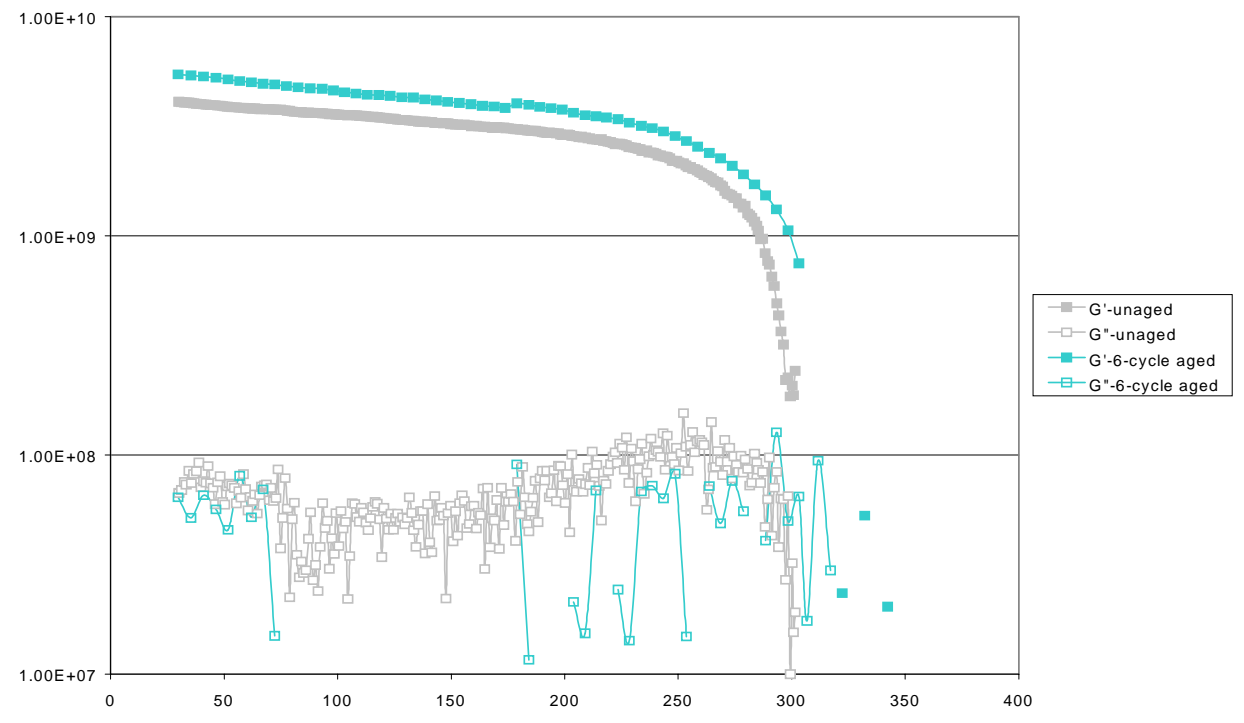

Figure C1: Dynamic properties of wood under unaged and 6-cycle aged conditions

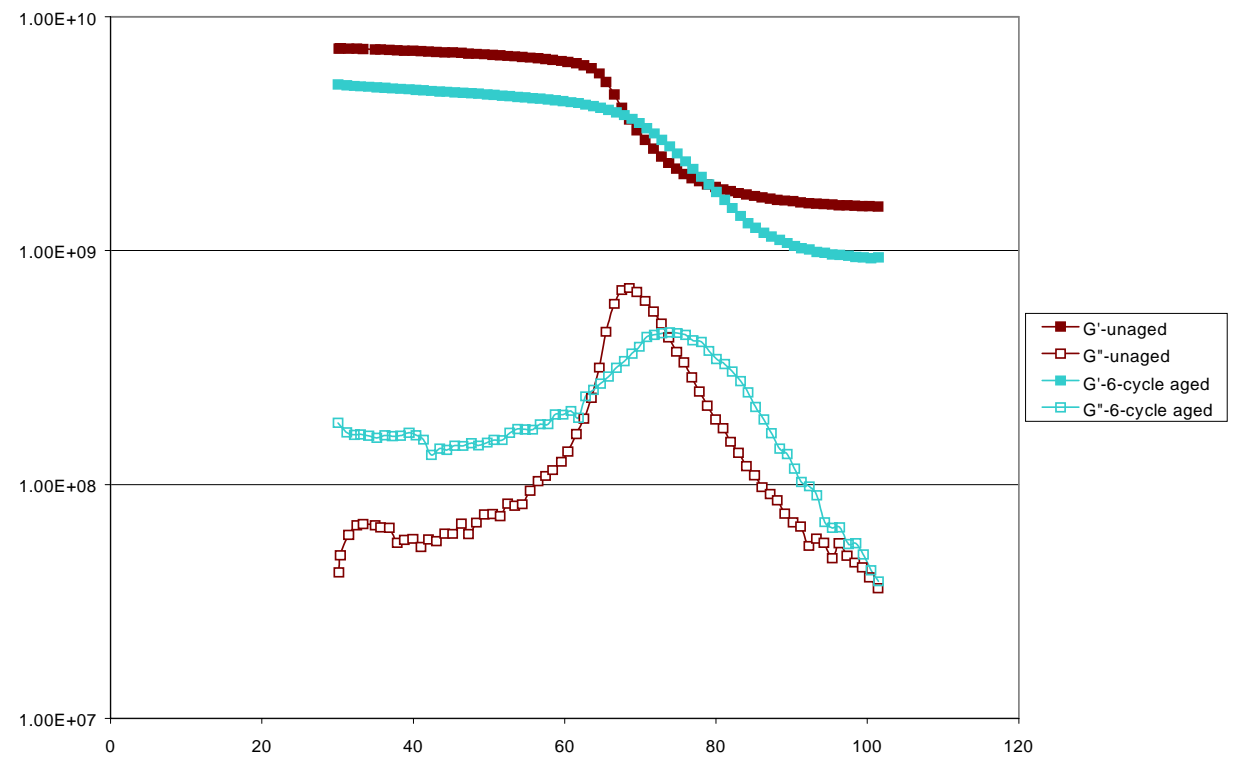

Figure C2: Dynamic properties of wood/HMR/epoxy/glass hybrid under unaged and 6-cycle aged conditions 


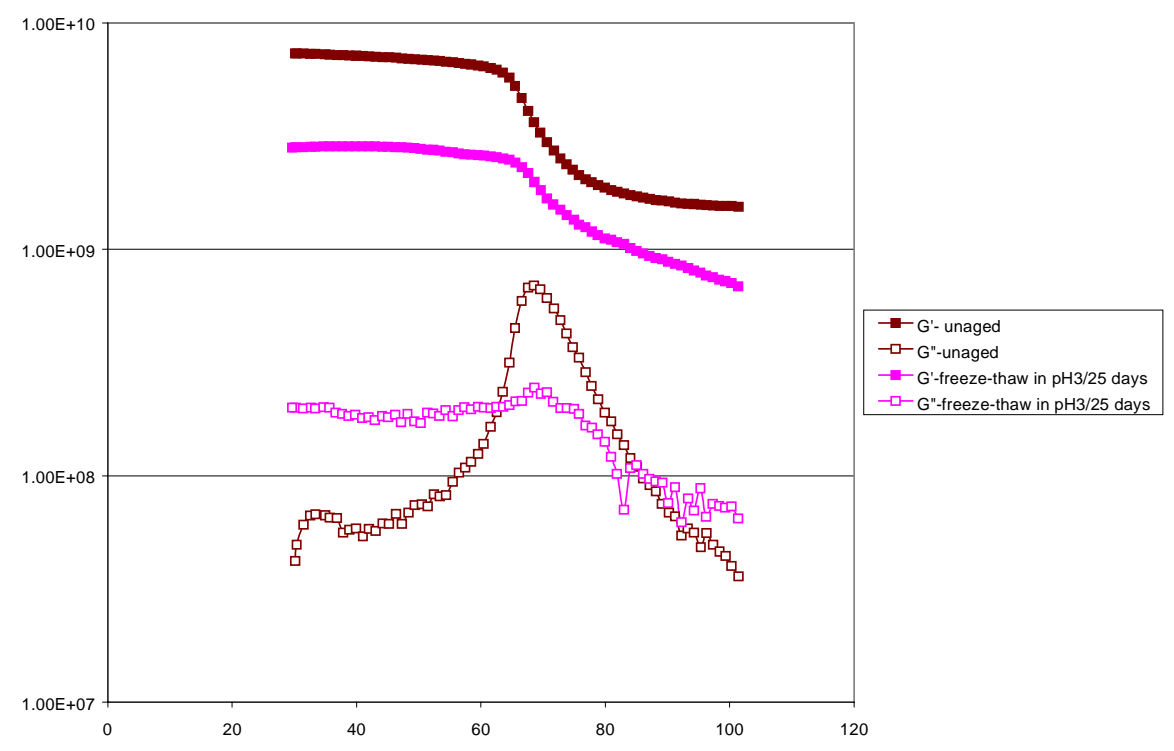

Figure C3: Dynamic properties of wood/HMR/epoxy/glass hybrid under unaged and acidic conditions

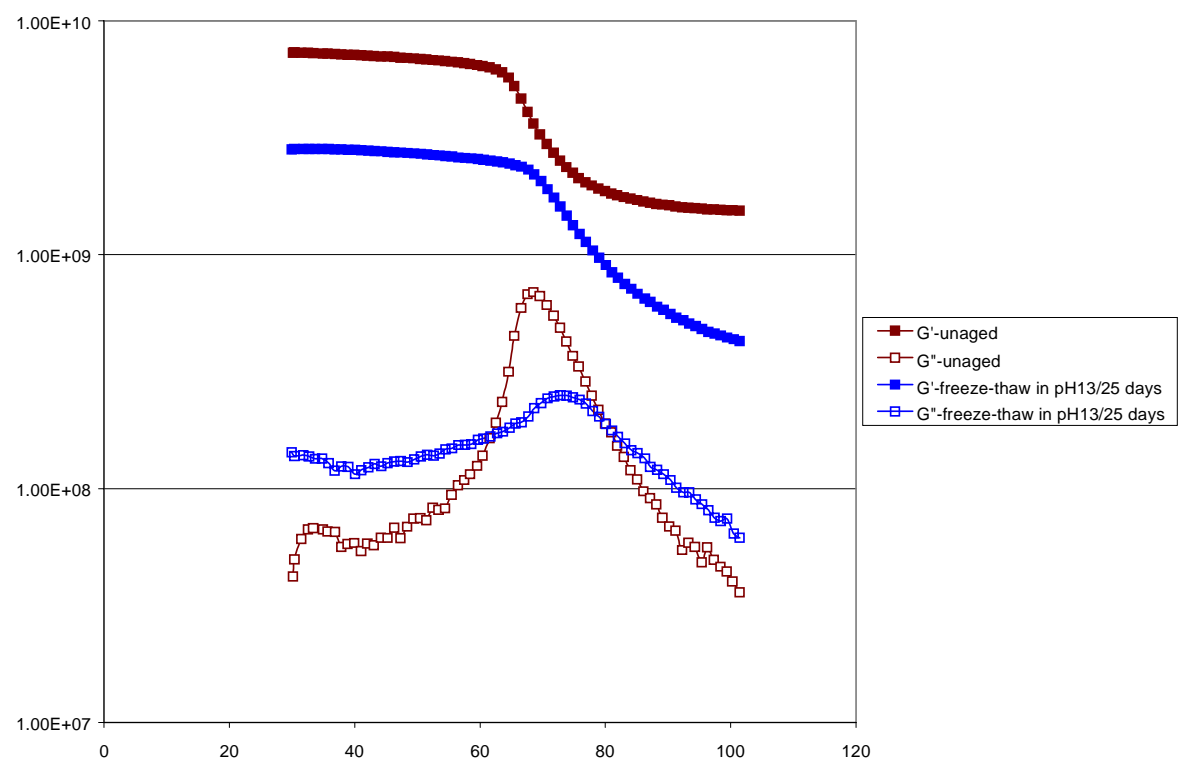

Figure C4: Dynamic properties of wood/HMR/epoxy/glass hybrid under unaged and alkaline conditions 


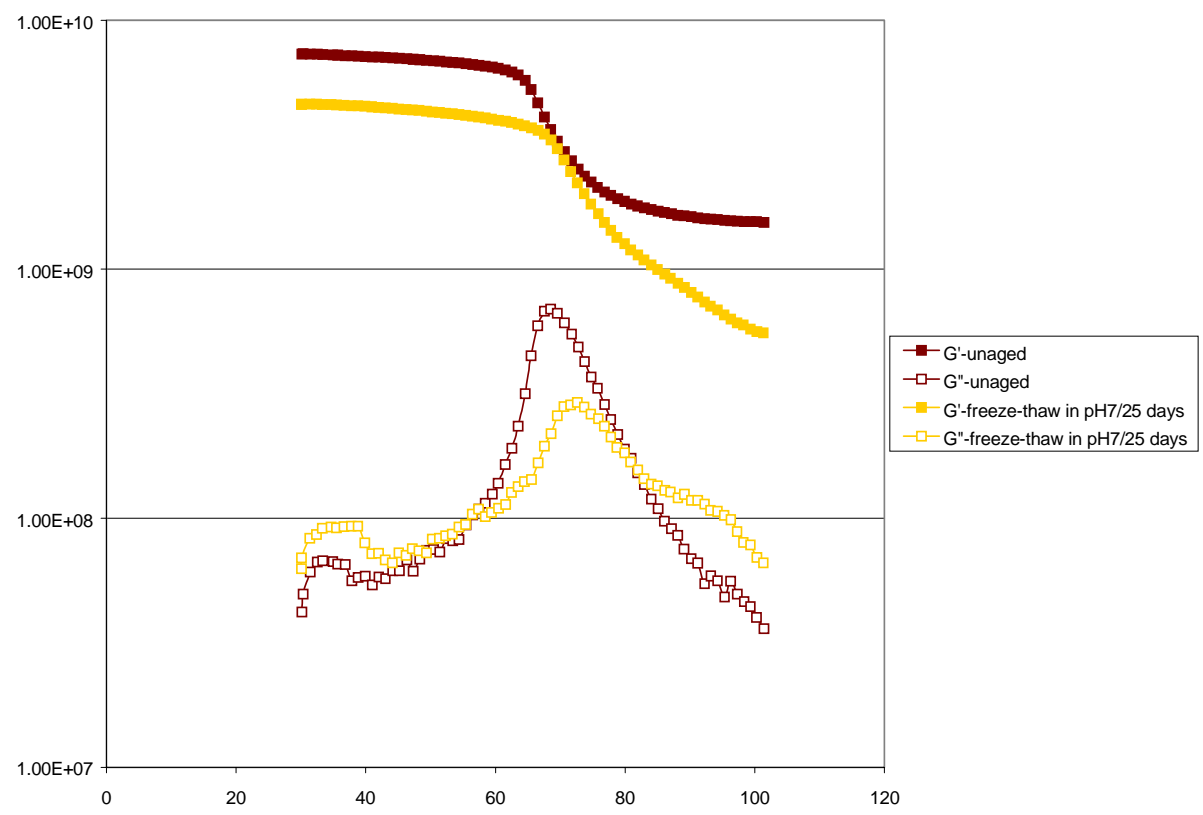

Figure C5: Dynamic properties of wood/HMR/epoxy/glass hybrid under unaged and neutral conditions

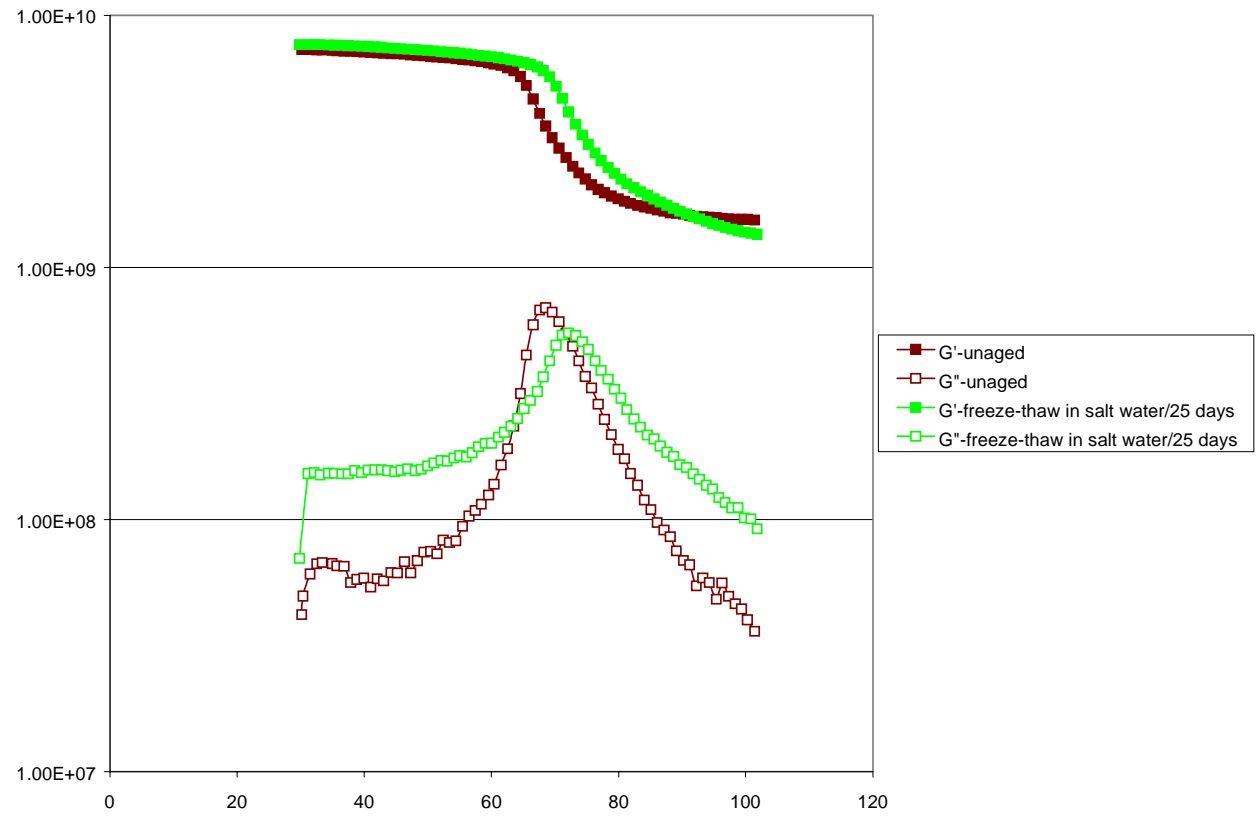

Figure C6: Dynamic properties of wood/HMR/epoxy/glass hybrid under unaged and salt water conditions 